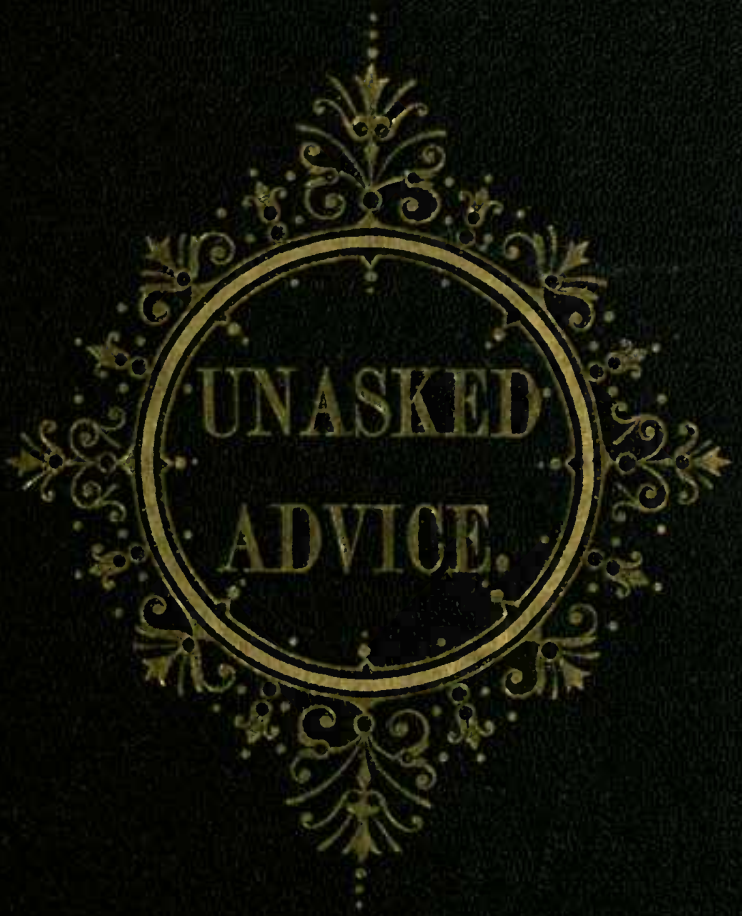




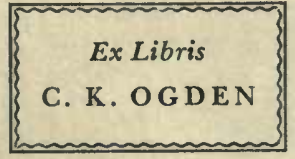



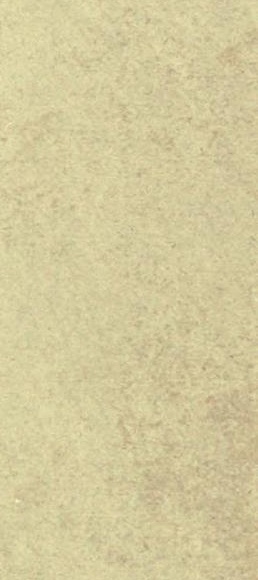



\title{
UNASKKED ADVICEx
}

\author{
A SERIES OF ARTICLES
}

HORSES AND HUNTING,

\author{
REPRINTED FROM "THE FIELD."
}

By "Jmpecuniosus."

LONDON :

HORACE COX, 346, STRAND.

1872. 


\section{LONDON :}

PRINTED BY HORACE COX, 346, STRAND, W.C. 


\section{PREFACE.}

THe following Essays have been written at different times, and are not supposed to contain any very new ideas. The only merit to which they pretend to lay claim is the fact that they recommend nothing which has not been personally tried, and found to answer, by

The Author. 



\section{CONTENTS.}

The Lady's Horse...

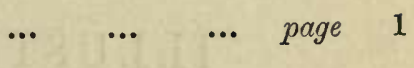

VARIETIES OF THE HORSE:

The Arab

The Barb

The Racehorse...

The Light Weight Hunter

The Weight-carrying Hunter...

The Park Hack

The Cob

The Charger ...

The Covert Hack

The Harness Horse

"HANDFULS"

The Season of the Year

The Stable in a Frost ...

New Brooms

How Sport Is SpoILed

The Charlier Shoe

Economical Sport ...

Restiveness and Vice

THE "SCREW"

The Honter at Home

Use AND SHow

Light HoRse

Stable Reforms 


\section{ILLUSTRATIONS.}

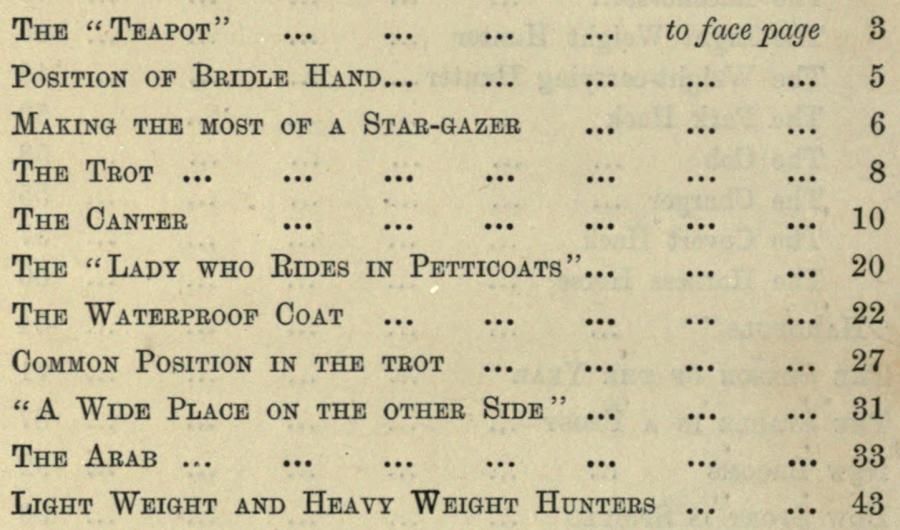




\section{UNASKED ADVICE.}

\section{THE LADY'S HORSE.}

THAт whatever is worth doing is worth doing well, is a truism which, in words at least, is never contradicted. In deeds there is the usual difference between theory and practice; and in no instance is this difference so noticeable as in the theory and practice of lady equestrianism.

I do not for a moment mean to withhold honour where honour is due, or to deny that there are hundreds of ladies whose riding is perfection; but at the same time a very short lounge in Rotten-row will convince the most casual observer that, while there is more to admire there in the way of female horsemanship than in any similar resort in the world, yet there are many ladies-or perhaps young ladies' fathers, guardians, \&c.- to whom a word of advice, which they need not take, may at least convey some new ideas on the subject of riding. The ladies themselves only need to be told what is right, for happily they are apt enough at learning what is becoming; and there are some things of which all need to be informed at the beginning of their equestrian career. The reason is obvious. A lady's seat on horseback is so purely an artificial and acquired position, that, unless by a fortunate "fluke," no lady can teach herself; and in riding, as in 
everything else, bad habits can be learned with fatal facility, getting rid of them being quite another thing.

What a number of advantages a lady who rides has over one who does not! In London, when the weather is not too hot, an hour's ride or so in the park before lunch is, I am told on good authority, one of the best restoratives after a ball-or, more probably in these days, two balls and a concert. When, as seldom happens before July, the weather really is too hot for midday rides, it is surely more profitable to have a canter with papa after five o'clock than to be at a crowded "kettledrum," where the proportion of gentlemen to ladies is probably about two per cent! Besides one can see one's friends - an incalculable advantage to people who might otherwise meet only once, or at most twice a day-and talk to them better when riding; hear where they are going in the evening, and about what time they are likely to be at any especial entertainment. I consider that more business may be done in the saddle than by sitting on a chair ; the draw back (?) being that, as a rule, mamma is not of the riding party, while she probably is of the pedestrian or sedentary one. And if papa's thoughts are far away, in "the House" or the hayfield, as the case may be, and he is for the time no great company, may not a little consolation be gleaned among the owners of those numerous well-bred and well-groomed hacks which are to be seen, between the hours of five and six p.m., being led up and down in front of most of the clubs? Be it borne in mind, however, that the spirited proprietors of these quadrupeds have mostly an eye, not for make and shape only, but also for action; and that an awkward position in the saddle may do away, in the morning, with the overnight effect of a new ball dress, combined with ever 


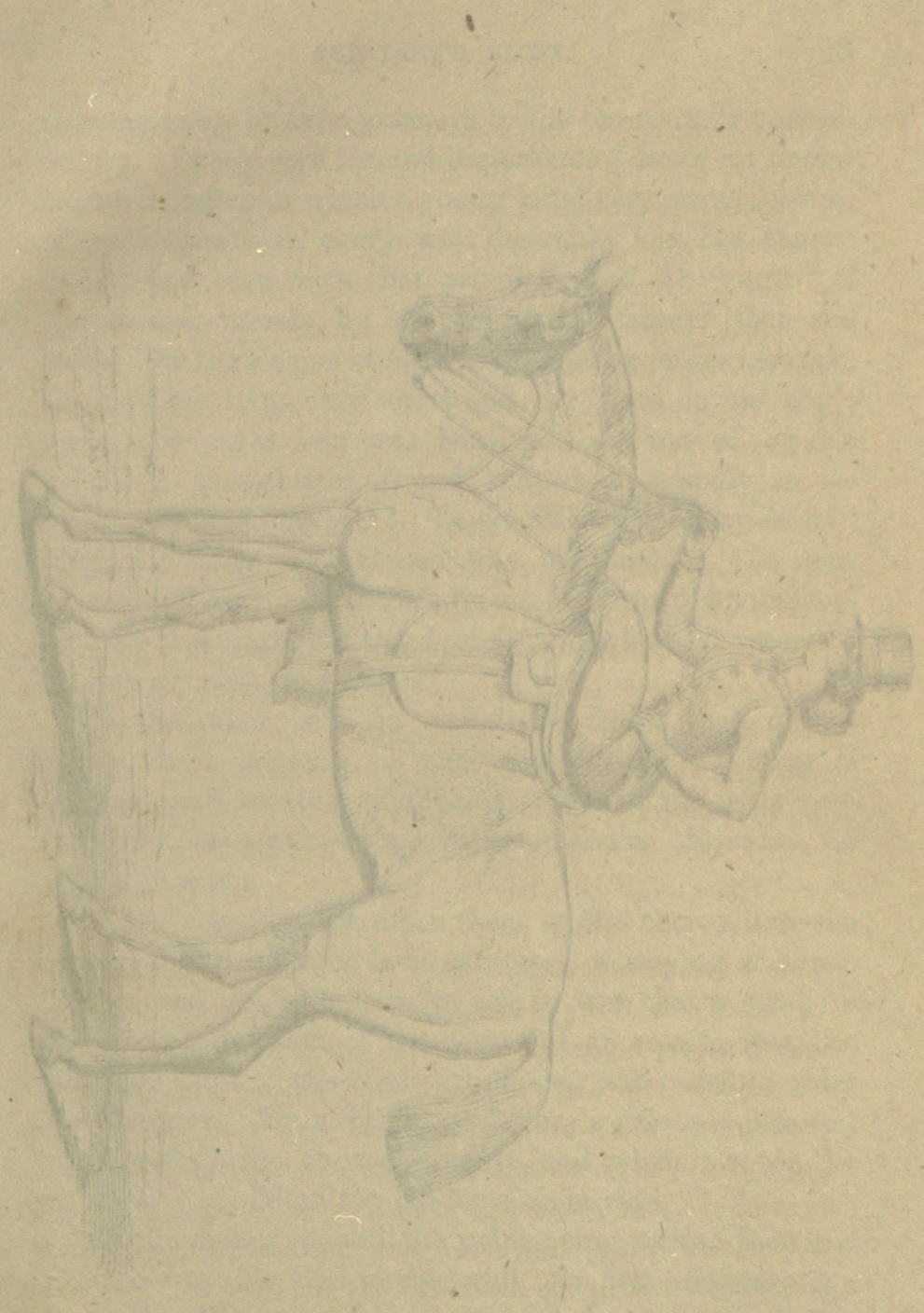




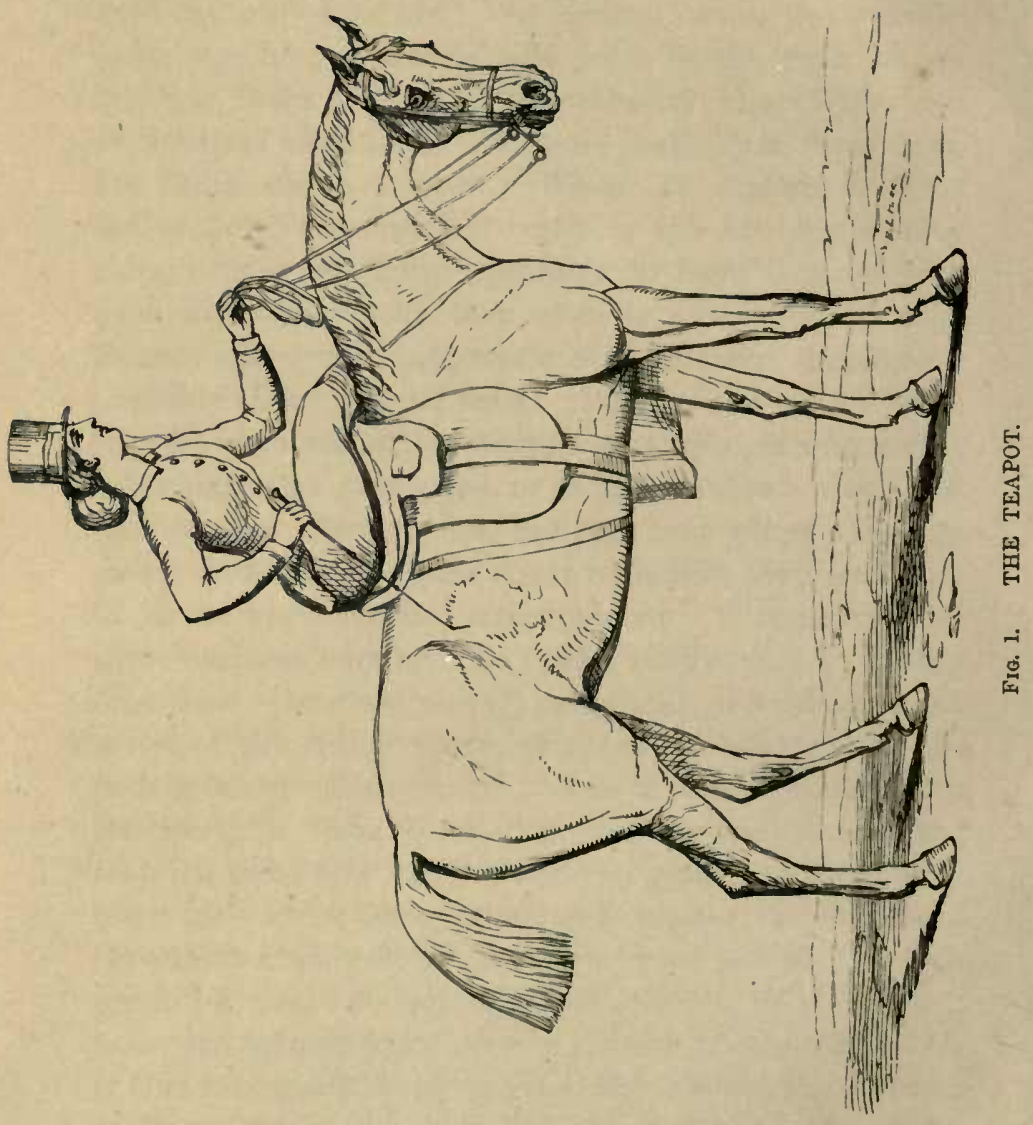


so many valses or even journeys to the tea-room or conservatory. In my own limited experience I knew an unfortunate instance in which a young lady, very pretty, clever, of good family, in every way desirable, lost her chance (which had been more than promising) of the "parti" of the season, merely by an unfortunate notion that she would like to ride one of $h i$ s horses. Being rather nervous, she held her reins very short and her hand on the nag's mane; her right arm was bent, and she was all on one side. A thoughtless friend remarked casually to the object, "Who's that girl ? Looks like a teapot, by Jove !" (Fig. 1.) The resemblance was undeniable; the convinced and horror-stricken admirer fled from town to Scotland by that night's limited mail, and when he returned he was a "père de famille."

On the other hand, a well-fitting habit on a decent figure, held properly, is one of the most becoming of dresses, and excites admiration in about the same proportion that a bad one provokes ridicule. So much for riding in town.

In the country how often there is the choice between riding, driving (which is no exercise), or staying at home. When even the gravel walks are so wet that a stroll in the garden partakes of the nature of an aquatic feat, the fields or sides of the roads are in the best possible order for a canter. Even in dry weather, a ride is a pleasant change from the eternal croquet, and when it is too hot to walk it is seldom too hot for a quiet ride.

All this being so, and the point being settled that it is desirable to ride, and to ride well, the first necessary is a horse; and I know of but one way of procuring a lady's horse-viz., paying for it what most likely would be considered a fancy price for any other hack. But it must be 
remembered that in this instance we want the perfection of a hack. Other horses may be "picked up" in odd corners cheaply by those who follow what I think must be the insupportably fatiguing plan of "always looking out" and "keeping their eyes open." Certainly I know a most respectable hunter which came out of a Hansom cab, but he has failed to convince me that the "rank" is, as a rule, the place to go to for fliers. Vivian, the steeplechaser, came out of an Irish car; and it was by dragging about a watercart that the Godolphin Arabian improved his shining hours in Paris, before he took up the position of Father of the British Turf. These, however, are exceptions to the general rule, for at present neither steeplechasers nor racehorses are found, or looked for, in carts. Salamander, Lord George, Alcibiade, and other horses who have made themselves a name across country, were bought -and paid for, too, no doubt-as first-class young horses.

A first-class hack, being a fancy article, will always command rather a fancy price, and for a lady, as before remarked, we want perfection. A gentleman's hack, if a good goer, may be pardoned one or two minor faults which would spoil him for a lady. For example there are many good hacks with rather straighter shoulders than are desirable, but yet posessing good action and plenty of liberty. Such horses would not do for a lady, as the side saddle, being at best rather a cumbrous affair, on a horse who is at all "short in front" puts the lady's hands in an inconvenient position, for she can then hardly get them down in a difficulty; and, worse still, throws an undue share of weight on the near fore leg. Another most important point is the way the horse carries his head. If he puts it up or pokes out his nose, he will not do. A lady's bridle hand is of necessity higher than that 



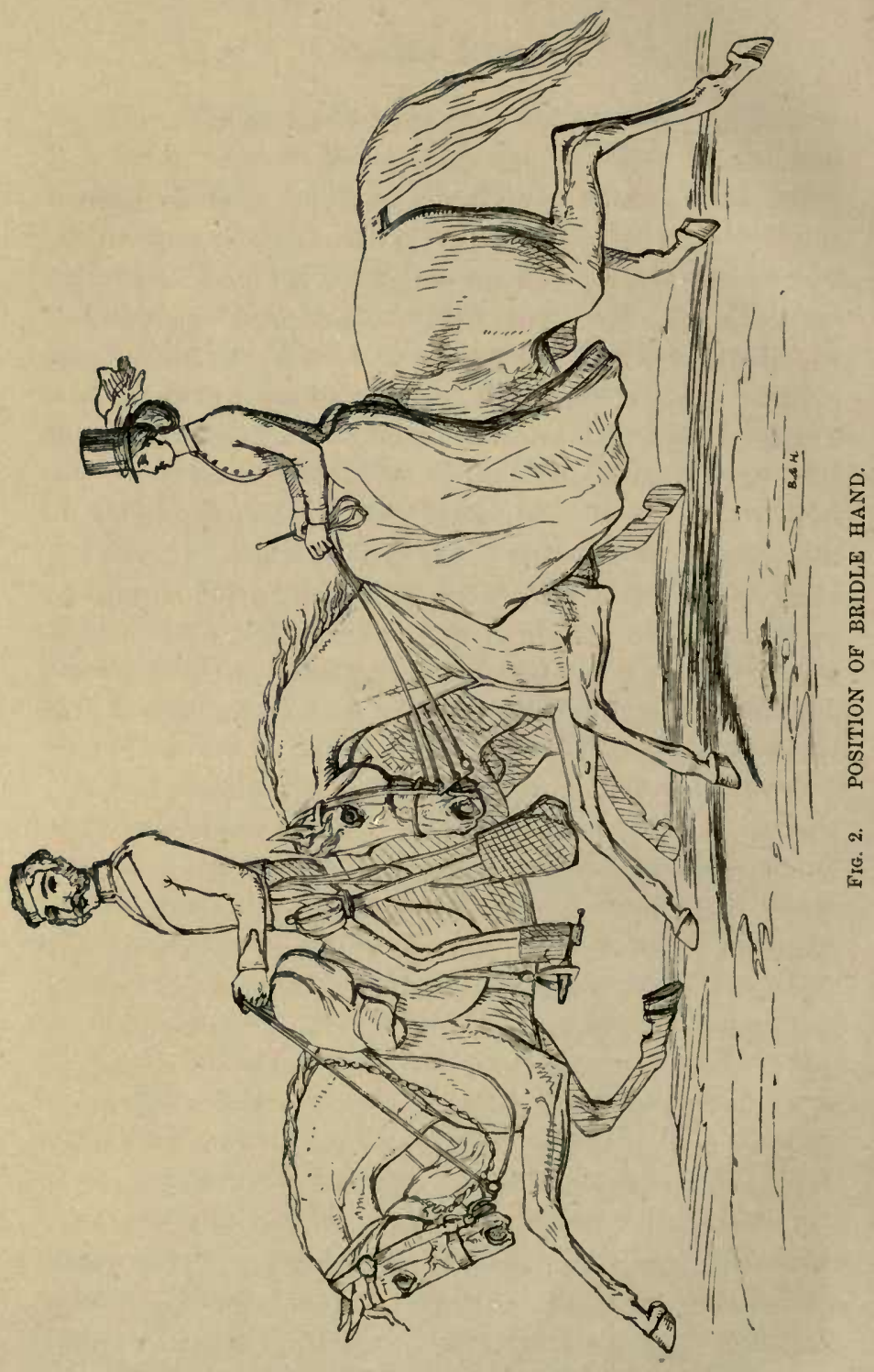


of any man but a dragoon, and therefore calculated to make either of these faults worse.

Troopers and chargers are the most carefully trained of all horses. Much trouble is taken in bitting them, and getting their heads properly placed; and this training is done by men mounted on "stripped" saddles, in which they have as much the use of their hands as on a hunting one. In marching or field-day order-in fact, whenever the cloak is on the saddle-a dragoon's hand is in much the same place as a lady's. (Fig. 2.)

The engraving (Fig. 3) represents a lady doing all that can be done with a stargazer, which, it will be observed, is not much. The same result being wished for with the trooper's and the lady's horse, a little training of the hack, similar to that undergone by his warlike brother, will not be amiss; but of training I will speak presently.

It being settled that lis fore hand must be good, his legs are the next consideration. They must be of the best, and he cannot be pardoned if he hits himself anywhere. His hocks must be under him, or he will seldom canter well. Action is a matter of taste. Some people like nothing short of the knee in the curb-chain; but as these gaudy steppers are often rough in their paces, a trial is advisable when possible. I presume the animal to be perfectly quiet and sound; and a very few minutes on his back will show the purchaser whether he is free from stumbling and shying.

A nervous horse will never be made fit to carry a lady. Of course horses can be bought which are used to side saddles, but their former owners seldom have parted with them for their good qualities; and I am at present supposing the case of a gentleman buying a clever young 
horse, to make into a lady's hack-her hunter is another affair altogether. Having bought him, the question of training him follows.

Having got your horse-whose height, for a hack, should not much exceed 15-1, and for a hunter 15-2 1 the making him handy and pleasant will not be very difficult, supposing his temper to be perfectly good. A horse much over the height mentioned will require more holding together than is pleasant for a lady. If a military riding-school be within reach, I know of no better plan than to send the horse there for a fortnight or so, mentioning that he is to canter to the right, and that he need not be troubled with an overdose of the "bending lesson." He will there be accustomed to firing, music, \&c., which is rather a difficult matter to manage in private life; but as the advantage of a school in one's neighbourhood is the fortunate exception, not the rule, people who don't enjoy it must do the best they can without. We want the horse rather more set on his haunches than anything short of a trooper usually is, and the best way of arriving at this desirable result is to work the horse on a circle, as in a school ; in fact, to improvise a manège.

Mark out for yourself a space of ground some fortyfive yards long by twenty; if it can be done in the corner of a field all the better, as then you have a wall to two sides. A large stone will be enough to mark each corner. The length of a cavalry manège is sixty yards; but, for one horse, you will have lots of room in fortyfive. Begin by riding round your manège to the right, at a walk, keeping the marking stones on your right hand: going outside them, in short. After a few times round the horse will understand that he is to keep in the 


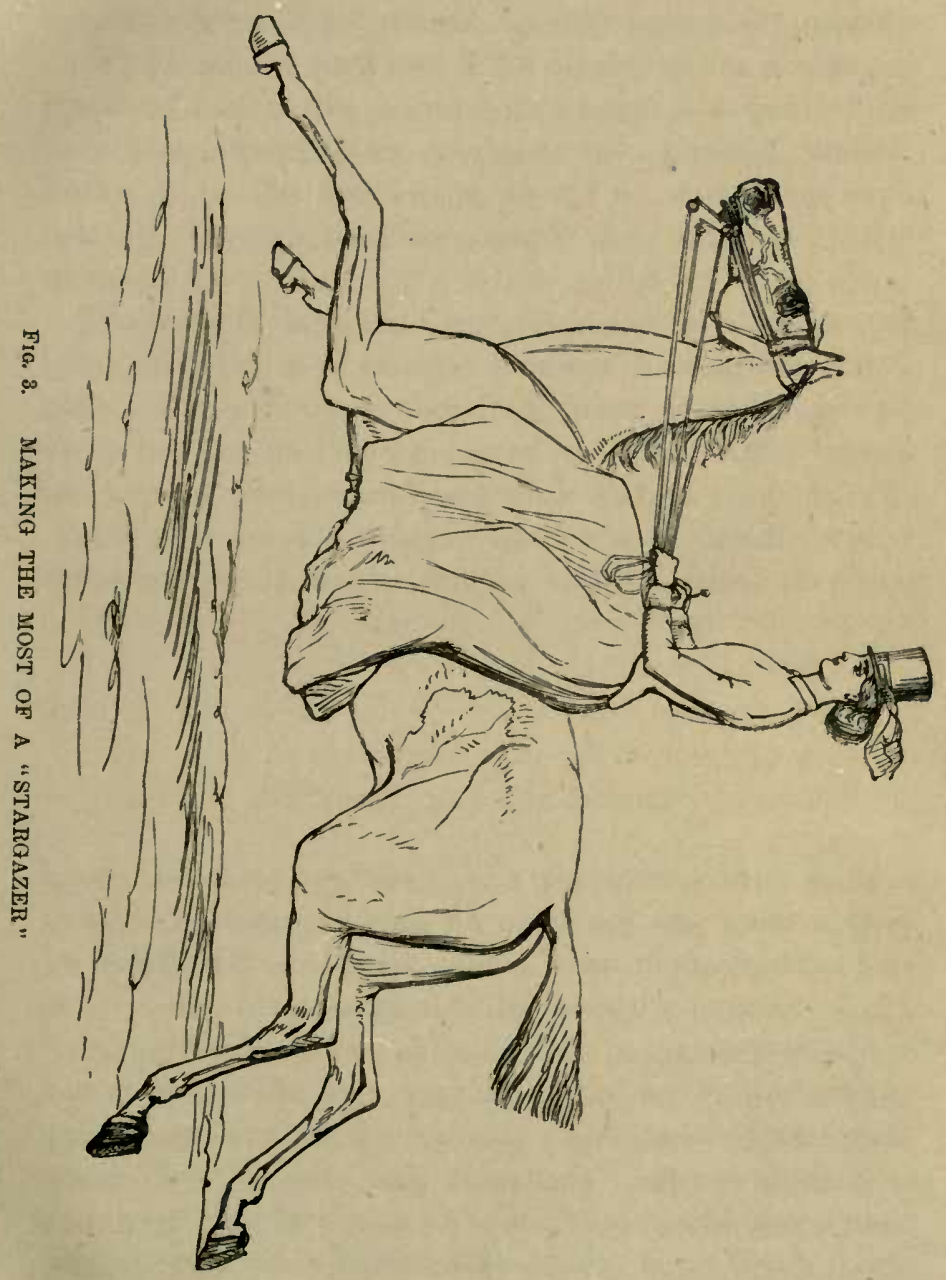



same track, and will turn at the corners of himself, cutting off a goodly allowance, if permitted. Of course he is not suffered to do this. When he is reconciled to keeping on the same ground, he may be turned, inwards for choice, and walked round the other way for a change. He should make the corners angular, not round, which be will be certain to try to do, to save himself trouble. Perhaps, for the first lesson, it will be well to attempt nothing beyond walking round the outside of the markers.

The horse is more than any other animal a creature of habit, and very soon will not dream of leaving his beaten path. When he goes cheerfully round it, walking well up to his bit, he may be turned at right angles across the manège, then walked on a circle at the end of it.

$A B C D$ are the original markers. $E$ marks where the sides should be left for the circle $F$, which is better

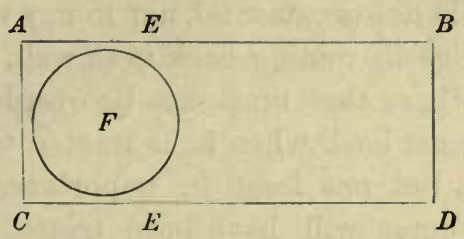

inside the outer markers. The man giving these lessons must wear spurs, though he need not use them much; he should also hold the snaffle reins in the hands separately. He must remember to keep the horse attentive by a light feeling of the bridle, and a gentle pressure of the calves of the legs, varying according to the temper and disposition of the animal. The pace of the walk should be "decided and animated," but not too fast, or the horse may break his walk and begin jogging - a most unpleasant and objectionable habit in a lady's hack. 
Having gone through the lesson at a walk, circling to both hands, the horse may be urged to the trot, repeating the turnings as in the walk. The trot must be moderate in pace, and the horse should be slightly restrained by the bridle and urged by the pressure of the legs, so as to make him bend his neck and throw the weight more on his haunches--the two great desiderata.

The trot must always be of an even and regular pace; he must never be allowed to "scuttle" arvay at one minute and then have to be sharply pulled up to a jogtrot again. On the other hand, if the pace be too slow the horse will go to sleep over his rather monotonous work, and may fall down. I need hardly observe that these lessons are on no account to be continued till the horse grows dull and tired; he will in such a case take a disgust to the whole thing. Besides, when he is tired he will probably hit himself or cross his legs, and a chipped knee is not ornamental, nor in any way desirable. A little practice in reining back is as well, but it is the thing of all others that must not be overdone. Still, a lady's horse must back when he is wanted to do so.

Last of all, but not least in importance, comes the canter. The horse will have been trotted and walked both ways round the manège; but he must, for obvious reasons, only canter to the right. In the canter the horse's neck must be bowed and his head drawn in. His forehand should be rather raised, and he will have most of his weight on his hind legs. He must learn at last to start from a walk to a canter; but at first the easiest way to make him canter with the off leg leading is to start him at a trot to the right, and press him into a canter at the corners. He will then seldom fail if urged at the right moment, and with a strong pressure of the 


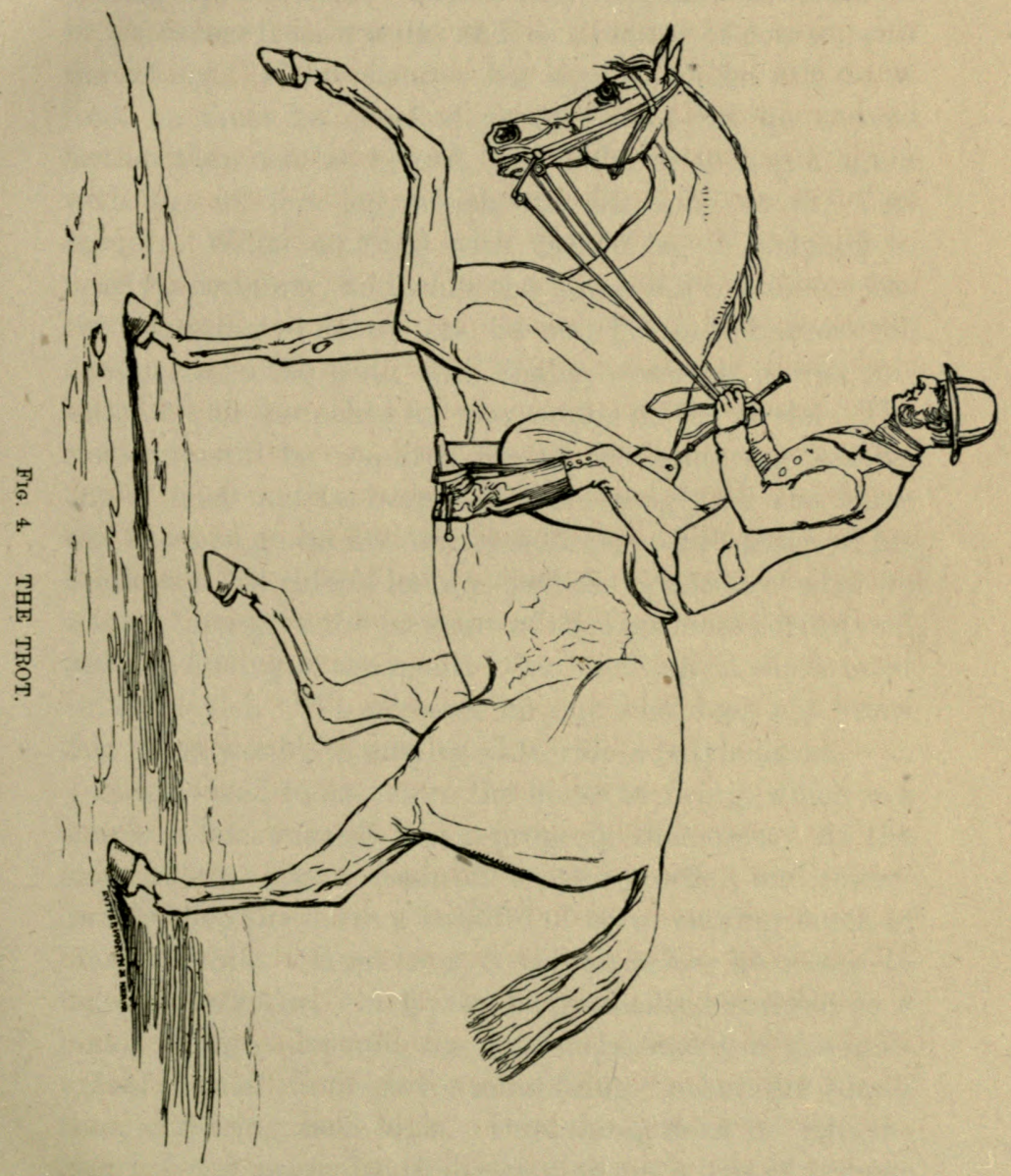



rider's outward leg, to lead with the inward or off fore leg. This must be done by degrees, and he may be cantered round the manège several times, occasionally pulling up to a walk. Before very long he will strike off in his canter from a walk, and, as a matter of course, with the off leg. If he changes his leg, which he will do at first, he must be checked at once-not let go a yard farther than can be helped, and induced to begin again with the off fore leg, which can be done at the first corner. When starting with the off leg is reduced to nearly a certainty, and when the horse will continue without changing to canter on, he may be turned across the manège, as in the trot; and, finally, when he is well collected on his haunches he may canter on the circle. The curb-rein will be required for all the cantering lessons, but it must not be borne on too strongly, or the horse will learn to go on his own shoulders, and to hang on his bridle and his rider's hands-just the opposite of what we want. Therefore the pressure of the legs must correspond with the feeling of the mouth; fine handling, in short, must be employed. We presume no one who does not know this much would be employed to ride a lady's horse.

It is as well to accustom the horse to firing, which is a simple affair enough when properly managed. At the close of the lesson flash off a little powder, and immediately give the horse a handful of corn, making much of him the while. How long it will be before he ceases to mind the powder, which may be gradually increased to a pistol charge, depends on the temperament of the individual animal. Some never mind firing; others are a long time in getting used to it. One thing must be remembered if the horse be timid-a moment's loss of temper or violence in the rider may throw the horse's education 
back for weeks. The horse being perfect in his paces may be ridden with something flapping about him, to use him to a habit, if such a proceeding be considered necessary in these days of short skirts. Individually, I have never seen but one horse who objected to the habit in my life, and he was in every way too "scarey" for a lady. Of course the horse will finish his training in the bridle he is to wear with his mistress. The saddlery question will be the next for discussion.

Figs. 4 and 5 show the position to which we want to bring the head and haunches in the trot and canter; the latter not an easy thing to draw.

For London work, our hack, after the course of training recommended, will have completed his education. It will, perhaps, be well, in addition to what I have described, to show him some volunteers, who, as rule, make a point of appearing on any scene where a timid rider and fresh or startlish horse are the actors. For the country there is another thing needful. Even if the lady never intends to leave the highway, and though there may not be a pack of hounds in the county, the lady's horse should know how to jump to the extent of a sheep hurdle or small open ditch, and especially the latter. In the country it is nearly impossible to confine one's ride entirely to the high road, at all events when any farming or similar business has to be done. Most gentlemen have some such pursuits in the country, and if she declines to go off the road our fair friend's ride has to be put off, or she must find a special escort, which is not always so easily. done in a rural district. She need never jump a sheep hurdle unless she chooses, as these will always pull up, but many grass fields are intersected with little ditches for irrigation, \&c., and the latter, which a 


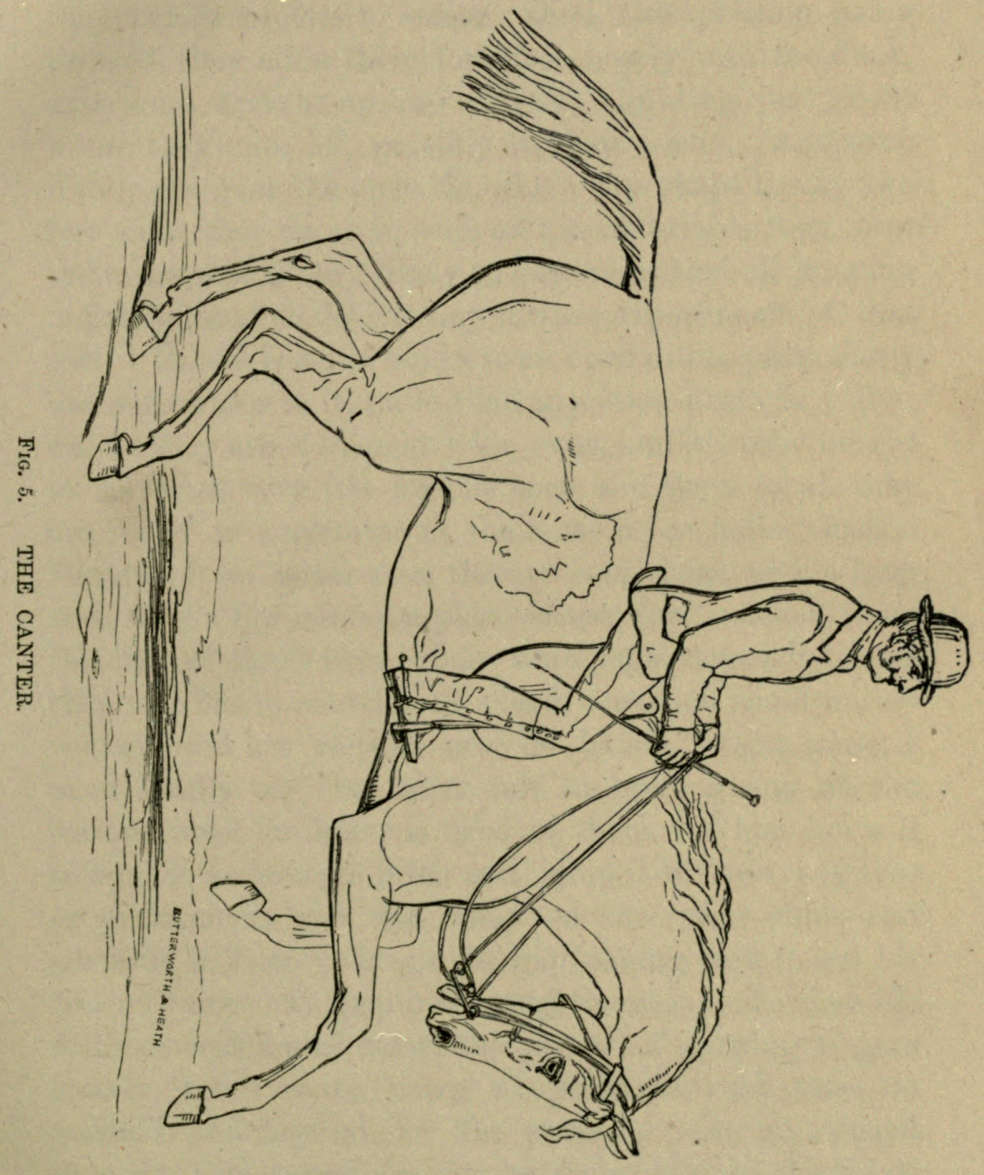



horse accustomed to them can hop or step over, are the cause, be they ever'so small, of trouble and possible grief to horses which have never been jumped at all. First, they usually profess to refuse; then, the question being pressed, they slide their fore feet nearly into the ditch, and jump straight up into the air, alighting just about where they took off, possibly on their heads. And even if they get over the obstacle, which is perhaps hardly two feet wide, they do so in such an uncomfortable form that their mistress is very likely to determine that all jumping is hateful, and to decline any further experiments of that sort. Horses seem to object to an open ditch, particularly one with water in it, more than any other obstacle. But, unless they are ridden at wide ones, and thereby taught to refuse, a very fow lessons accustom them to all they are likely to encounter in their career as ladies' hacks. I know of no better plan than to lead them, with a long rein, over a few common-place fences, just to teach them the use of their legs-their hind legs especially - and then ride them, not without a lead, over such small watercourses and low rails as may be handy. Care must, I need hardly say, be taken not to prolong any of the lessons until the horse is tired of them. When he will trot up to a common ditch and jump it without any fuss or excitement, and trot away on the other side; and when he will creep through a gap, taking care to get his feet well over any grip belonging thereto; and if headds to these accomplishments the power of opening a gate quietly, he is fit to carry his mistress, and may be saddled and bridled for the purpose. Or, on second thought, this operation may be deferred until the lady's hunter puts in an appearance, also ready for his work.

The purchase and training of a hunter to carry a lady 
differ but little from the proceedings requisite to provide her with a hack. A very few words will describe the course of action necessary, but the business itself is more intricate, by reason that a still more perfect animal is required in this instance than in the last. The lady's hunter should be just as perfect a hack as the less ambitious animal who only aspires to fame in the park or on the road. A little less knee action, and an inch or two of height in addition, with size and power in proportion, are the only external differences. Power is indispensable, as a lady's hunter, of all others, must be well up to his rider's weight. Well up to a given weight $I$ have heard defined as two stone over it. Allowing this to be an exaggerated definition by a stone-in fact, supposing that we require what is usually considered a thirteen stone horse to carry twelve stone-the following facts may be (to some) instructive. Ladies are not of necessity feather weights; the most mignonne damsel who ever engaged herself for a cotillon probably would have scaled in her ball dress something between 8st. and 8st. 7lb. The majority even of light ladies are perhaps a stone heavier than this, from 9st. to 10st.: say 9st. A habit skirt is a heavy thing, and a side-saddle will weigh 15lb., or thereabouts. While to a man's walking weight one stone is always added to arrive at his riding weight, it is not too much to add three stone extra to a lady's weight, in a common dress (in a Court dress I am not sure that two would not suffice); and then the horse should be well equal to at least a stone over the load by these means arrived at, and as much more as is convenient ; for ladies seldom have a second horse out, and cannot jump off to ease their horses and rest their backs, in the impromptu manner occasionally (though only too seldom) adopted by 
masculine owners of small studs. In short, a lady's hunter for a flying country ought always to be a 13st. horse.

'The lady's hunter must be, as a hunter, perfection, just as the hack must be the best of that description of animal ; but the former must be both. It is not pleasant for a man, much less for a lady-herself rather tired-to ride a stumbling brute home after hunting; still more is it out of the question to allow a lady to appear with hounds on a horse that refuses, hits timber, kicks at other horses or hounds, or indeed performs any of the antics which so frequently excite the wrath of a master and the derision of a field. He should be bought as a perfect hunter, with, if possible, a good character of two seasons; a horse under six years old has seldom developed talent or experience enough to justify his being intrusted with so precious a burden as a lady. For it should never be forgotten that a lady is on no account to have a fall. Putting out of the question the danger of her being hurt-which is at least twenty times as great as in the case of a man-ladies' nerves do not, as a general rule, bear shakings and even harmless tumblings with the sangfroid of a boy or man. And I do not wonder at it. At the same time I do not for a moment mean to flatter my sex by even insinuating that all men disregard falls. I have far too pleasant recollections of the good society in which I have so often, on a good scenting day, assisted to block up bridle-gates, thunder down roads, smash locks of gates, uproot twist and bounds, and generally to utilise "Shuffler's Bottom," to malign them in any such way. All honour to the noble army of shirkers! Still no one can deny or be surprised that a casualty, such as a heavy fall or two, goes a long way towards reducing any lady's ambition to 
lead the first flight. Exceptions here, as always, prove the rule, which is that (luckily for our peace of mind) few if any ladies go on "bruising" across country for any, very extended time, though they may ride well, gracefully, and I may say reasonably, to hounds for a lifetime. But here I have decidedly run off the line, and forgotten the horse in attention to his rider-a thing which $I$ have the consolation of knowing has been done before, literally as well as figuratively.

We must "hark back," as the old phrase goes, to the point at which it was determined that the hunter must be preternaturally clever, and a stone over his mistress's weight. To get him handy he may be ridden in the manège, like the hack, with this difference, that he ought to be cantered to both hands, as a hunter must be equal to any emergency, and ready to change his leg or lead with either as circumstances of the most impromptu nature may dictate. The saddlery in which he is to perform differs only in one or two very small details from the Rotten-row kit. In both cases simplex munditiis is the preferable form. A hacking bridle may be allowed a standing martingale; not to keep the head down-he is no lady's horse who puts it up-but as a check, in case a fly, or such like cause, should cause him to toss it about at all. A hacking bridle, too, may have a little more ornament about it, a branch bit not being wholly inadmissible; but the hunting bridle should be a refined likeness of the plain tackle with which the sterner sex control, or attempt to control, their fliers-rather thinner reins and a general increase of elegance being the only difference. As to the bit employed, that depends altogether on the horse's mouth and disposition. An extremely light-mouthed horse is a bore-that is to say, a horse of whom one is 
told that he will only go in a snaffle; for this is a bit no lady can safely use, and indeed very few men, on still fower horses, with comfort, even if they manage personal security. There are moments in every run when a snaffle fails in its effect. When the horse is half blown and much excited, it is indeed seldom that a snaffle can collect him on to his haunches for a large and intricate jump-say a double at the bottom of a hill and the last three fields plough! A Pelham bridle (no favourite of mine) will suit such horses for a while, at all events: I call it "no favourite" because almost all horses, sooner or later, get to lean on it; and I use the phrase "for a while," as when the Pelham, after some use, becomes dead and heavy in the mouth, a light double bit will frequently be borne, or, if that be too severe, a shifting Pelham, which is a really serviceable bit, but liable, though in a very much less degree, to the objection entertained towards the simple Pelham. I am rather an advocate for what only just falls short of over-bitting a horse, when the rider's hands can be depended on, and especially with a double bridle; for in such a case there is the bridoon to hold on by at fences, \&c., while the bit, which need seldom be used, is still available in case of sudden excitement or a long career down hill. As a rule, the common double bridle, or the double bridle with a shifting bit, suits more horses than other contrivances-at all events for cross-country work. For hacking no invented bridle makes a horse bend and show himself more than the Hanoverian Yelham, which may be of several degrees of severity; but it is usually too much of a bit for hunting, and is only to be used on the road by ladies whose hands are first-rate-and at the risk of being called uncomplimentary, I must observe that light hands 
are not given to all ladies, though the majority certainly do possess this most desirable qualification. I say nothing of gags, segundos, Bucephalus nosebands, and the like, because a horse requiring them is not a lady's horse. Having, then, considered with some care all the bridles with which I am acquainted, I see nothing that I can recommend for hunting except, as I have said, the Pelham, shifting Pelham, and double bridle (Dwyer pattern preferred), for the degrees of very light mouth, medium, and pleasant ditto. The latter is marked "pleasant," as being the least likely to pull its owner into a ditch-supposing the rider's seat, and, as a consequence, hands, to be for the time astray. The Hanoverian Pelham, for road work, has been glanced at, and I really think a horse who will go in none of these is unfit for a gentleman, much more a lady.

The lady's saddle has been much improved of late. The addition of the third pummel is worth anything, as it gives a firmer seat than a man's. The latest fashion also does away with the off side-crutch-another advantage, as not only is there one protuberance the less to run into anyone over whom the horse may roll, but its absence allows the right hand to be got down lower than was the case with the old fashion. A strap, too, now goes all round the horse, being a continuance of the stirrup leather, which can thus be lengthened or taken up by the rider herself. (See engraving.) As regards stirrups, the old slipper is exploded, and the iron is the shape of a man's, with stuffing inside to protect the instep. Many theoretical plans have been made patent for safety stirrups which are not to drag their unlucky proprietor, when he or she is down and "parts company ;" but they do not seem much used, nor are they even advertised for very long. Messrs. Davis, of Aldershot, have invented 
the last, which has been described in The Field, and which looks useful if it will promise to keep in order and never let the foot out at the wrong time. For hunting, the side-saddle must have a breastplate. With one the girths need not be so tight, which is rather au object. If a felt saddle-cloth can be so managed as not,

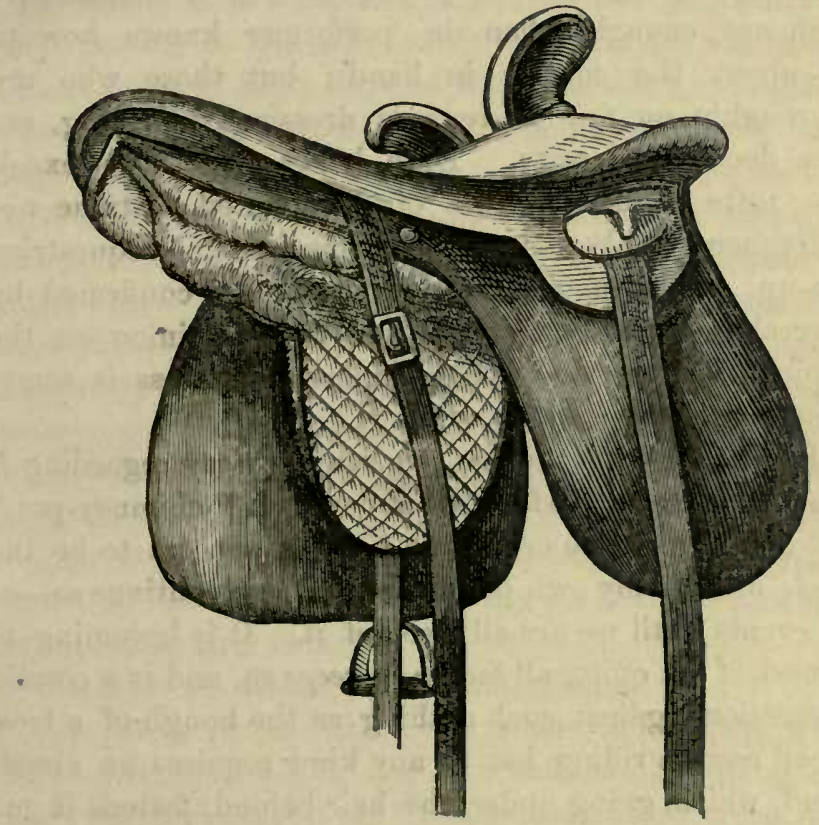

under any circumstances, to show, it will be found useful, a lady's sideways seat being highly conducive to sore backs. Of course the horse should not be singed under the saddle; but this point is conceded in most men's stables now. The saddle must be looked to, as to its stuffing and panelling, just twice as often as a man's saddle. 
With the right bridle and a new-fashioned and wellfitting saddle, both properly put on, our horse may be brought round to the door; and it only remains to dress the lady and put her in the saddle.

Whilst the lady's horse was being saddled, it is to be presumed that the proprietor was costuming herself for her ride. This, like everything else, is a simple performance enough when the performer knows how to go about the matter in hand; but those who are thoroughly au fait as regards dressing for riding, are in a decided minority. Even ladies who have excellent taste in all questions of dismounted costume not unfrequently make sad guys of themselves in an equestrian get-up. I am of opinion, and my idea is confirmed by several individuals best entitled to an opinion on the subject, that the most handy and simple dress is something as follows :

Beginning with the hat, we can only say regarding it that whatever is (the fashion) is best. A "chimney-pot," not too high in the crown, at present appears to be the mode, and for my own part I hope it may continue so-at all events until we are all tired of it. It is becoming to almost, if not quite, all faces; it keeps on, and is a certain protection against such a thing as the bough of a tree. In all cases a riding hat of any kind requires an elastic band, which, going under the hair behind, fastens it on; and a narrow velvet band sewn on to the lining, so as to intervene between it and the head, will greatly aid in this object. A chimney-pot hat has the advantage over others, that when it fits perfectly it may be worn without one. A veil is generally part of the head-dress, and people may please themselves as to colour, quality, and, indeed, shape and size-a black veil with "tails," which 
goes over the face or not, for choice. For ،hunting, a "shaved" hat looks rather "workmanlike" for a lady, though hideous for a man, and it preserves its appearance better in a wet season. No lady's-maid knows how to brush a hat, much less how to iron one after a deluge of rain.

The fashion of doing the hair varies too frequently for any remarks on the subject to be useful. I will merely observe that in these days of chignons a net, invisible or otherwise, is nearly indispensable, and quite so for hunting. It is possible to trust to the maid's talent to keep up the hair in an ordinary ride, but too much to expect the same success in a day's hunting. All chignons are quite real-of course, we all know that; but even of a bona fide one the "puff" is an indispensable part, and is not pretty when viewed amidst the dishevelled wreck of ever so perfect a chevelure. It has been stated that the more mécanique there is in a chignon the less liable it is to come to grief; and I can well believe it-though of course it may come off bodily, as the one of which we heard so much last season in the park was erroneously supposed to have done.

Neckties are affairs of taste and climate.

The body of the habit will make or mar the whole effect. A good-fitting one is obtainable by going to a good maker; but, without being invidious, I must say I only know of three makers in London who build a really clever one, though scores profess to do so.

Habits resemble top-boots in this sort of monopoly. A habit is a costume with which it is possible to come to a very reasonable understanding, and consequently one in which those ladies frequently look the best who do not, as regards figure, distance their fair rivals so immea- 
surably in a ball-room. The skirt must fall smooth and even from the waist. This result is arrived at, as I am credibly informed, by having the skirt "gored" all round the waist-a performance of which I only know this much, that it has no sort of connection with a mad bull. The habit-maker is no doubt better informed.

The length of skirt varies a good deal; for town it may be rather longer than for country work; for hunting, if it covers the left foot well, with a few inches to spare, it will be long enough.

The material of which the habit is made admits of still more variety. For the park it must be something light; and, obviously, the same habit will not do for both summer and winter. Some people like remarkable colours and extensive braid; and there is no sort of reason why they should not please themselves in any startling manner they like, from green velvet upwards.

Perhaps the most stupid and frightful addition that can be made to a skirt is an edging or border of leather, which renders being dragged a certainty, if the rider falls and the skirt gets caught. A lady looking after a steed who is rapidly retiring with her skirt caught on the saddle, while she remains costumed in her body and continuations only, is no doubt in a somewhat false position, whether the accident happens in the park (a thing I have seen) or in the hunting field. But how preferable this is to being dragged by unyielding leather at speed over stones, \&c., with no one able to help you!

I have known ladies who thought they were keeping themselves warm, and perhaps also guarding against an accident of the sort just alluded to, by wearing a petticoat, or more than one. This has the effect of utterly 


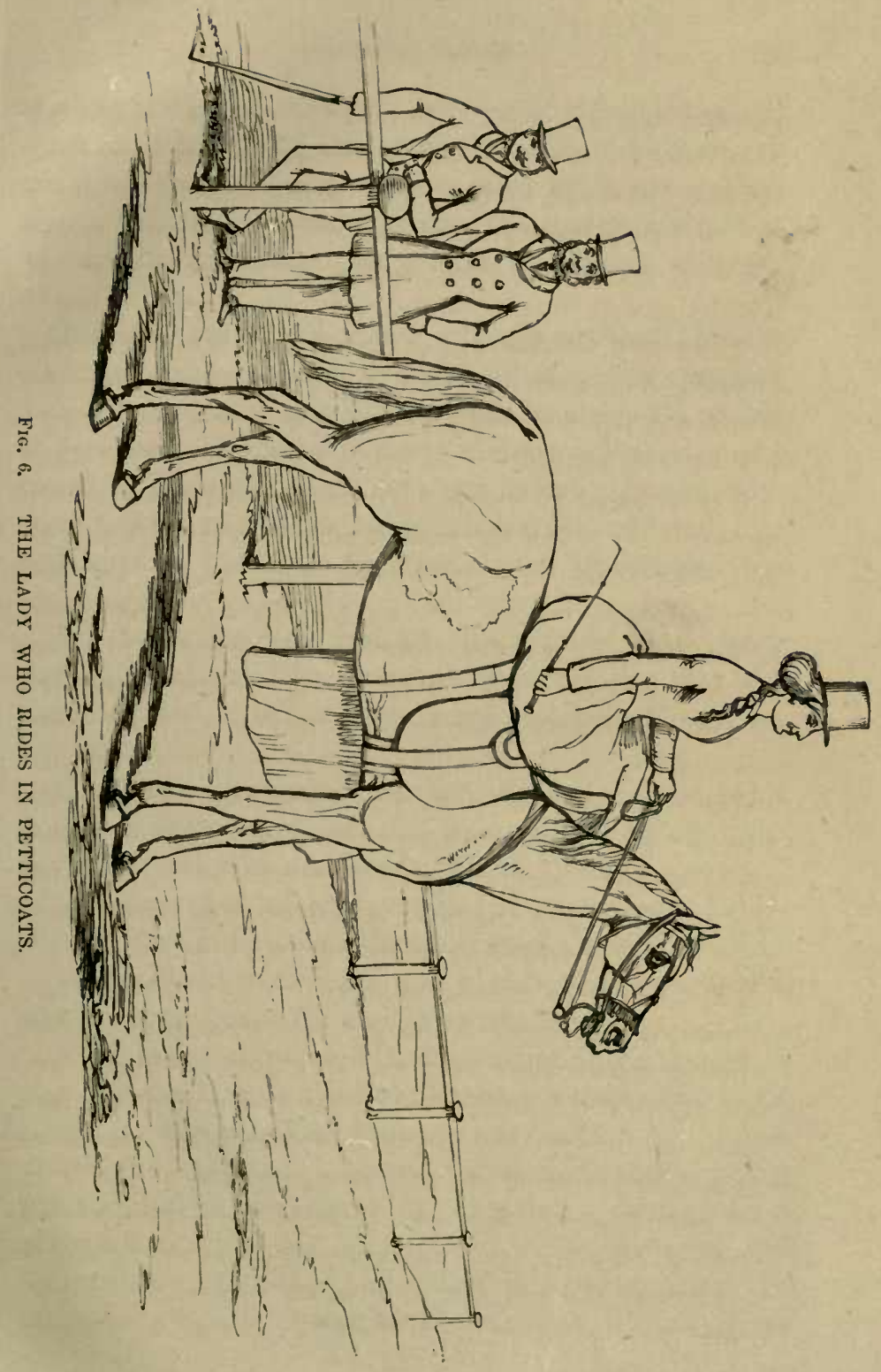



spoiling the set of the skirt, and also of looking frightful when any opening of the habit discloses a hideous red petticoat, or an equally objectionable white one. Such things are not to be thought of ; and, indeed, far from adding to propriety, they have a directly contrary effect. (Fig. 6.)

Of the next article of dress I will only say that it or they must be of the same colour as the habit, and be strapped under the boots, so that the strap can be depended on not to give way. Nothing is more unpleasant than this last casualty, especially when far from home. I have seen such articles as I have darkly alluded to, leathered, like a dragoon's, just over the foot, but I cannot see the advantage.

The boots that look best are Wellingtons, made large enough to admit of warm and thick stockings; they not only look neater, but are more comfortable in riding than any other.

For hunting in rough weather, the body of the habit must not be too tight, and if it be not an absolutely tight fit, it will allow of a knitted woollen "chest preserver," which in every point except material resembles a habitshirt. It makes all the difference in the world on a cold day, and, as far as warmth goes, beats all the petticoats that ever went over (or under) a crinoline.

Most horses require a spur out hunting, though I should not call them "ladies' horses," if they want much rousing. The old-fashioned spur was buckled on the foot and worked through a hole in the skirt, the latter being secured round the ankle by a string, which, where appearances were an object, had to be fastened and undone after mounting and before descending from the pigskin. Of course being tied to one's skirt by anything 
more than a bit of elastic is most clumsy and unpleasant. A later form is a box spur, the point of which often goes through the cloth of the skirt; and I can hardly fancy that it improves it. With a short skirt, however, the spur may be used without damage to the cloth.

Whips must not be mere toys. A lady has not a man's right leg and spur, and her whip must as far as possible supply their place. They are made of every colour and of all manner of materials. If a lady carries a hunting whip, it should be strong enough to open a gate in case of necessity.

Tolerably thick dogskin gloves, and, in cold weather, mittens or muffatees, are desirable for hunting. In town, weather being mostly warm, people can please themselves; and many seem to think that dirty white kid gloves are pretty-chacun à son goût. Out hunting it is always a wise precaution to take a pair of knitted or woollen gloves: they can go in the pocket of the saddle, and make a great difference in the warmth and comfort of the hands. If it begins to rain, which it is likely to do on nine hunting days out of every ten, the reins, when wet, can be held firmly with woollen gloves, but will infallibly slip through leather ones.

A waterproof coat is as great a comfort as it is possible to have. The groom can carry it, or it may be rolled up and put on the off side of the side saddle. They are generally made double-breasted, and of the shape depicted in the sketch. They must be "plenty large enough," otherwise there will be some trouble in putting them on and off without dismounting. They don't protect the knees, but the skirt of the habit can always be "dipped," as men's red coats are, which process makes it waterproof, at all events for some time. It will turn many showers, 


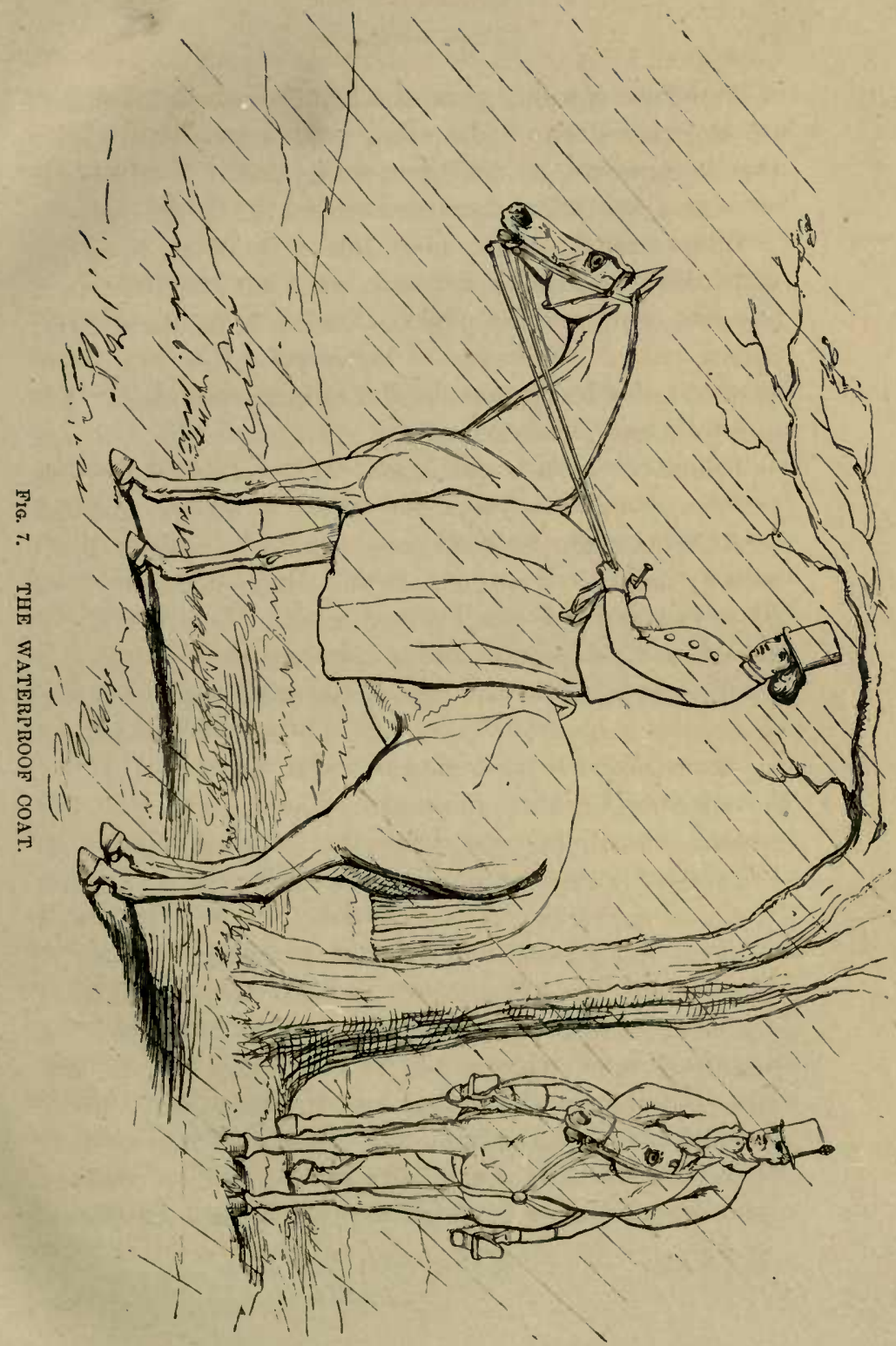


The right leg being put over the pummel, her foot is placed in the stirrup. She stands up in her stirrup for a moment, and during this space of time her habit-skirt is drawn smoothly under her to the near side; she receives her whip, adjusts her reins, and all is right.

The matter is not always so successfully managed. If the lady's spring and the gentleman's assistance are not quite simultaneous, the lady only gets half way to her saddle; or if she arrives at the desired eminence it is with an unseemly scramble, and most likely with one foot kicking helplessly in the air behind her, which gives an effect at once ludicrous and painful, sometimes even involving a sprained knee. It is of the first importance that the horse should stand still, but most of them will do that much after a time or two, especially if the groom stands in front of the horse with a rein in each hand.

It is always very convenient for a lady to be able to mount by herself, but wonderfully few can do it. It is neither difficult nor ungracefnl, so why the doing it should be so rare an accomplishment is a mystery that remains to be fathomed-by me at least. For a lady to mount by herself on a tall horse, the stirrup should be let down as low as is convenient for the foot to be placed in it, and the performer gets up as independently as a man does, with one hand, of course, on the cantle of the saddle. When up, it is now as well, if not a necessity, to take the foot out of the stirrup to put the right leg over the pummel. Then, if she chooses to be very independent, she may herself shorten the stirrup to its accustomed length by means of the strap which goes round the horse for that purpose, and there she is.

Her position should be sitting well down on her saddle, 
and with her shoulders square to the front. The left knee must touch the so-called third pummel, and the right should hang easily over the other crutch, not sticking out the right foot, or the hold will not be firm. This seat when correct, is firmer than that of any man. Above the waist there should be no more stiffness than is necessary to keep a square and upright position, and while the shoulders are right the arms will hardly go wrong, unless, as sometimes happens, any extraordinary position of the whip hand is indulged in; but the more the elbows are carried back and inwards the better the effect, provided the attitude is not stiff.

The military directions for holding the reins are to place the bridoon rein, apart from the bit, aross the palm of the hand, quite loose. The bit reins are divided by the little finger, and the thumb, closed firmly on them to keep them in their place. This of course applies to riding on the bit alone, which a lady seldom or never wants to do; but the method has this advantage, that by drawing the bridoon rein through the hand it is taken up at once, and you have an equal feeling of both reins, which is what is usually wanted in hacking or hunting. A beginner, after taking up her reins in the first-named manner, may with her right hand draw the bridoon rein on the near side tight, letting it hang on the off side. The off rein she can take up to what length she prefers with the right hand, and she will then be riding with both hands on the reins in a manner that will be found useful in more than one way. It will keep the rider straight and square in her saddle, and she will be able to turn her horse more readily.

Very few ladies pull the right rein when they want their horse to turn to the right. A well-broken horse 
will turn right and left when the rein presses the reverse side of his neck; but then you are riding on sufferance merely. If the animal declines to obey this intimation of your wishes, you cannot make them do it. With both hands on the reins you can pull his head round; and, unless he be really restive (in which case he is no lady's horse), it is only fair to expect that his body will follow suit.

Ladies should, in learning to ride, practise shifting their hands on the reins. It looks very bad when this is constantly done during a ride, but it ought to be done easily when any emergency requires it. I have seen ladies whose hands were to all appearance glued to their reins, and who were helpless in a degree corresponding with the rigid nature of their clutch when their horses shied, \&c. Indeed, it is rather alarming to contemplate the number of ladies who, riding constantly and habitually, are still entirely dependent on the good behaviour of their steeds; which, however, to their honour be it spoken, seldom betray the trust so blindly reposed in them.

The whip is usually held pointing towards the near shoulder of the horse, sometimes the contrary way, but convenience may be consulted about this so long as it stops short of any decided gaucherie.

Ladies, and gentlemen too, should, when mounted, always start at a walk. If they start in a hurried manner their horses will look forward to going off with a rush, and they will very soon cease to stand still while they are being mounted. If the start be made at a walk, that pace need only be continued for a few yards to have the desired effect on the horse. To start him in the trot a very slight rousing is sufficient. In the trot care must be taken to preserve the position. 



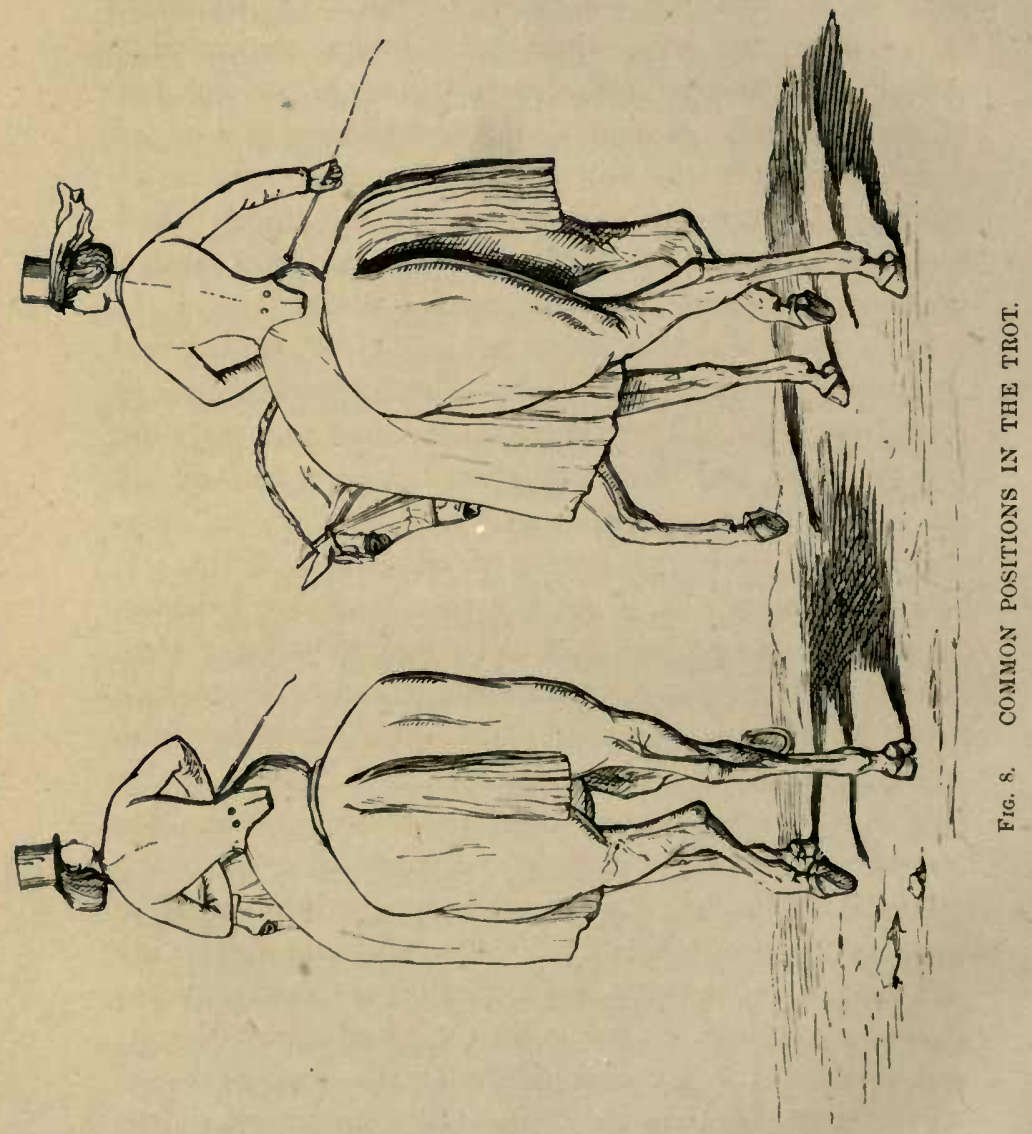


Some ladies, from fear of overbalancing on the off side. lean over to the left, which has a shocking effect; others think they are correcting this fault by leaning their heads to the off side, their bodies meanwhile inclining all the same to the near side-a position even more painful to look at than the last. (Fig. 8.) Others, again, while trotting, hold their whip out, as if it were possessed of an infectious malady. Amongst unskilled horsewomen a kind of double rise in the trot is equally popular and unbecoming. In fact, there is no end to the things which ought not to be done at this pace. A portion at least of what should be done is something as follows:

The horse should be up to his bit; if he be "behind his bridle," as they say in the school, the rider has no control over him. The elbows ought not to be too far from the sides, and the wrists should be rounded and not stiff. The figure may lean very slightly forward, and must rise lightly in the stirrup to the horse's action. If the stirrup be not the right length this cannot be done, but no one except the lady herself can tell for certain whether her stirrup is right, though spectators can make a shrewd guess, when too much "daylight" appears or the reverse, what is the remedy required.

To start in the canter it is always well to take the horse up rather on the bit, then to touch him with the heel, and if he be well trained no further signal is . necessary for him to strike off " true and united." Care must be taken not to let him go on his shoulders, and to ride him even more up to his bit than in the trot, for the prevention of the last-named fault. It is easier to sit well in the canter than the trot. The figure may, of the two, lean rather back than forward, shoulders always square, and the seat steady. Nothing looks worse than 
to see the lady bumping up and down in the canter. It is a fault usually caused by too short a stirrup. A roughgoing horse will throw the best rider about more or less, and is, therefore, unfit for a lady. If the horse shies at anything, if possible ignore the circumstance. If he stumbles, never omit to punish him by as sharp a "chuck" of the bit as his mouth and temper will admit of. Don't hit him with the whip, or next time he stumbles he will also bolt forward. Having returning home, dismounting is a very simple thing. The lady takes her foot out of the stirrup, lifts the right knee off the pummel, places her right hand on the pummel as in mounting, and her left, if she chooses, on a gentleman's shoulder, and then slides gently down, not forgetting to bend her knees on arriving at the ground to a degree proportioned to the extent of the drop. She thereby avoids a jar which is always uncomfortable, and sometimes produces a headache when the descent is from a tall horse on to pavement.

It is always well to pet one's horse as much as circumstances allow of. The advantage of one's horse knowing one's voice and one's self need no demonstration. In any emergency, if the animal adds fear of his rider to other excitement, grief is a natural consequence. In town it is not so easy for a lady to pet her horse. Mews are not quite the places for ladies, but they can make friends at the door. Last season I used daily to see a young lady come in from her morning ride. She used to dismount, and a very pompous butler, after opening the door, descended the steps with becoming gravity, and handed her a piece of sugar, which her horse anxiously awaited, and usually, by reason of his bit, failed to get the full advantage of. The principle was sound all the same, 
though I fear Mr. Bottles considered his dignity rather compromised by his share in this diurnal piece of petting.

In the country a lady can always go to the stable. I don't like, however, to see them go up to a horse in the stall. A touch of a crinoline (reduced as these are), the rustling of a silk dress, or fifty other things, may startle a horse, and a frightened horse is the most fearful of wild fowl, and quite the most inconsiderate of created beings. It is safer to bring their heads round preparatory to giving them the piece of carrot, apple, or whatever the present may consist of.

And now a word of advice on the subject of hunting to any ladies not accustomed to that sport who may do me the honour to read these lines, "if any such there be" (I mean readers). Never, if you can help it possibly, go out hunting without a groom. Make up your mind before you start whether you mean to ride the run or to be a spectator. If by any mischance your groom is not to be had, and you don't want to go in the first flight, don't allow your cavalier to ride anything but a bonâ fide hack. On a hunter the mildest of men may try some short cut which may not suit you. Don't go even to the meet on a horse who is not at all events a little used to a similar scene. The quietest horses sometimes become ungovernable on their first introduction to the chase. Never go near the hounds, unless you know from personal experience that your horse won't kick them. Learn to open a gate for yourself. If the huntsman is ever such a friend of yours, don't speak to him after the business of the day commences. He has as much to think of as the conventional "man at the wheel," who is addressed by no one, even on business. On the same principal, don't be angry 
with the master if he neglects to return your bow as he canters past. He probably never saw you, being perhaps looking at that man shooting over dogs a field off the gorse, or at that gentleman who, trying the speed of a dealer's horse, is rapidly circumnavigating the covert, apparently with the unconcealed intention of spoiling his own and everyone else's sport. Though able to open your own gates, make some one do them for you ; then, if the gate is an awkward one, it isn't your fault. If you mean riding, have a pilot, but don't follow him too closely. Give everyone room to fall. I was once ridden over by a lady who is the ornament of every society she appears in. I had rather it had been she than a bagman out for a holiday, but on the whole the sensation was unpleasant. Don't go and do likewise.

Remember, and, so far as possible, act up to, the proverb concerning discretion. If you see men, unless you know them them to be very bad form over a country, avoiding a place, don't have it. There is very likely a danger that you don't know of. Even if you get over and pound them, you will only excite the admiration of such as are on the right side. The others will never forgive you. Keep as much as possible out of people's way; you will get $x$ voos for not giving trouble. Your escort, however, is an exception to the rule; make him useful; that is what he is there for. Don't let him persuade you to go on when you are tired, or to do anything you don't like; at the same time, if he says don't jump any particular place, humour him, unless you see your way unusually clearly. In charging a fence ride on the snaffle, and don't interfere with your horse. If he is fit to carry you he will know all about it. But when you know it to be a wide place you may rouse him a little, 



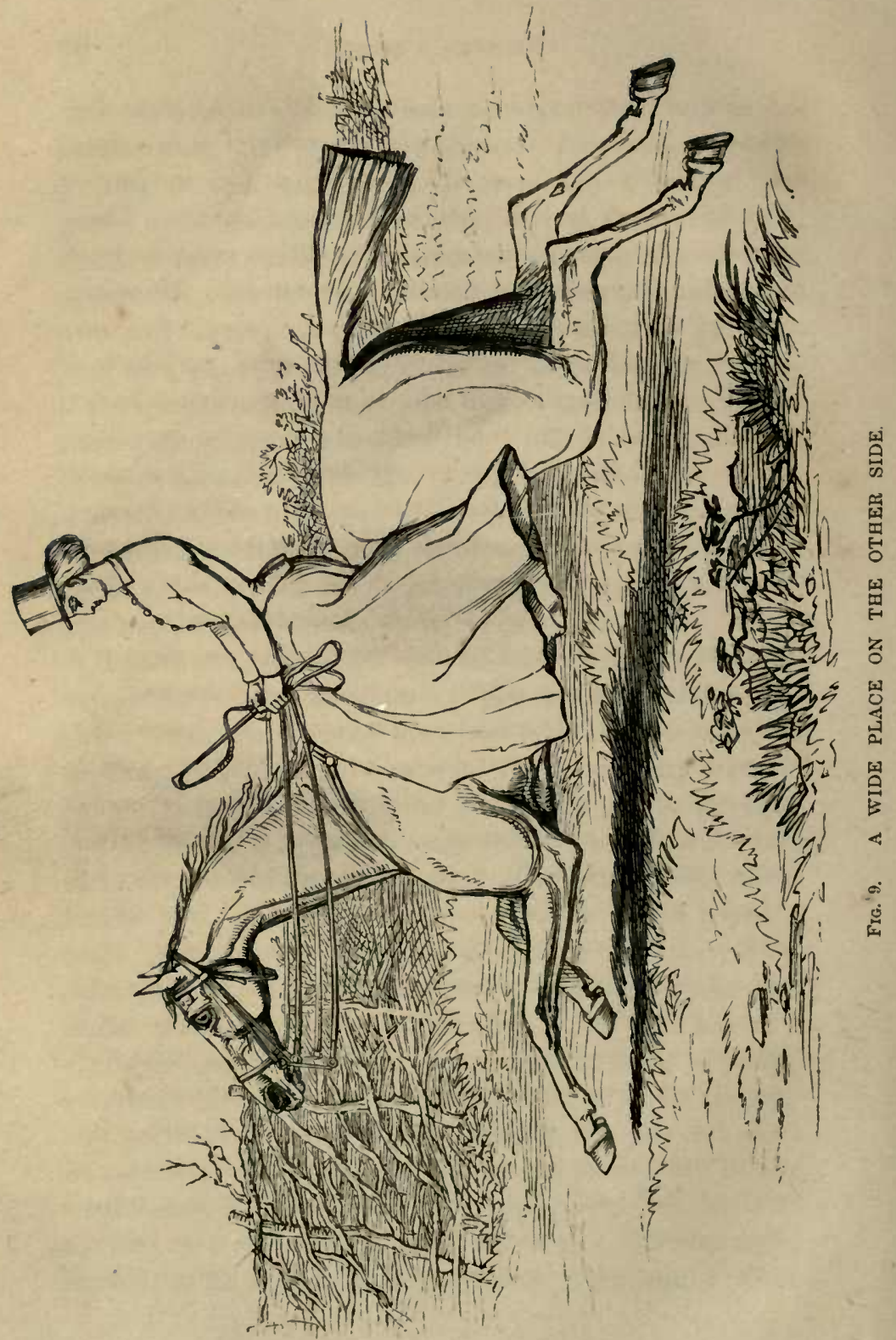


the less with the rein the better. Sit back, bend the right foot back and the left knee forward; if it is a deep drop, a rein in each hand will steady you and the horse. (Fig. 9.) Don't let other ladies ride your hunter. Their ways can't be quite your ways, and next time you ride, your nag may not understand you as well as usual. He won't confuse you so much with a man, so your papa, soupirant, brother, or husband, if equal to the occasion, may have a mount now and again, and will do more good than harm. A hack ought never to be fresh, and may be exercised ad lib. by a trustworthy groom or friend. Less neck depends on his talents, and there is no greater nuisance than a hack which is too fresh. Your hunter is presumed to be a perfect timber jumper. Nevertheless, don't jump it when you can help doing so, and never when your horse is at all done. A fall at timber is mostly a crumpler. Water you are less likely to be hurt at, but getting in is not pleasant, nor is getting out becoming. When the brush is presented to you, say "Thank you!" but don't take it yourself. Make your groom or escort do that, and stand no such folly as fixing it in your bridle. Horses cannot bear the smell of blood, and are very apt to begin plunging when a "mask" or brush is stuck on them, unless they are used to it. The second whip to be sure, carries the fox's head; but his horse is used to it for one thing, and, for another, the kick is usually out of him prior to the death of the fox. Likewise, remember that though your horse does not usually kick hounds, he may do so, excited by the aforementioned bouquet, when they are breaking up their fox, or when they have. just done so. Always drive to the meet when you can, and home again. When one is tired nothing is enjoyable. Never keep your escort waiting in the morning, unless 
he be your husband, and consequently not licensed to complain.

Of vices in the horse I have said nothing, because it is inexcusable to put a lady on one that is not known to be good-tempered and quiet. If your horse kicks or plunges from fieshness, your groom should "catch it." If he rears, hold on to anything you like, bar the bridle. A horse who has reared twice in a decided and dangerous manner should be parted with at once. And here I come to the end of my lucubrations, trusting that, though there is much good advice on this subject which my ignorance has prevented my giving, yet that I have advised nothing dangerous or impracticable.

Mechanical contrivances, such as martingales, punishing nose-bands, and running reins, I have said nothing about, considering that an animal requiring such tackle, or possessing any temper or restiveness whatever, is a brute quite unworthy of mention in an essay upon "The Lady's Horse." 



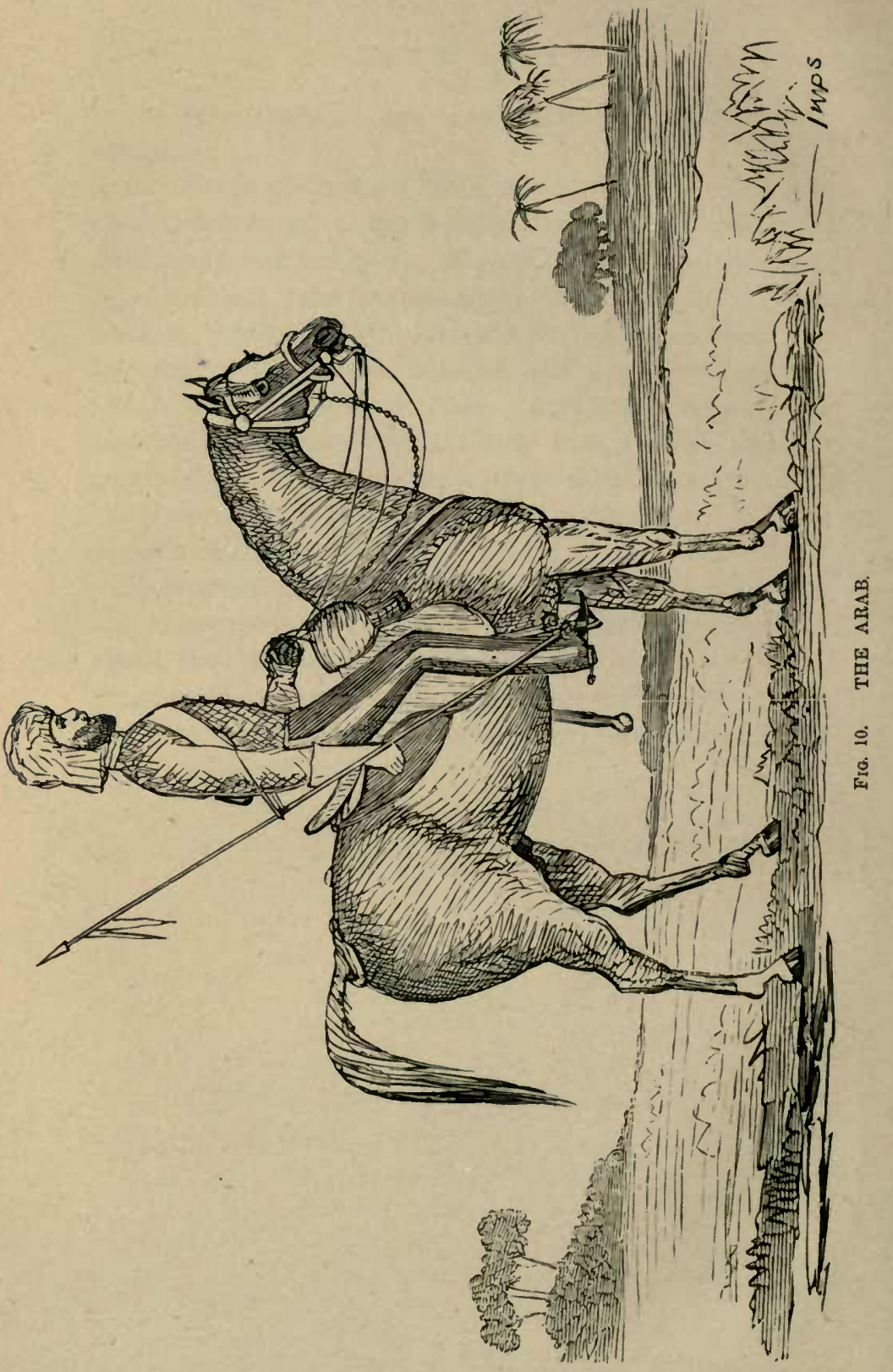




\section{VARIETIES OF THE HORSE.}

\section{THE ARAB.}

As the success or otherwise of breeding horses in England for particular purposes is to be ascribed in a great measure to the grand principle of "fluking," as it is termed by some-or, as the thinking portion of the community have it, to Providence-the writing of an essay on the varieties of the horse, in England at least, is an undertaking fraught with a certain amount of difficulty. Even the uninitiated can understand this when it is explained that horses bred for one purpose, and found at maturity to be wholly useless for such object, may nevertheless take honours as first class for other purposes entirely different from their original destination. For example: the object of every horse-owner in the country is to get the best-bred animal he possibly can for his own particular purpose-that is to say, at any rate, every horse-owner whose work is not of that sort absolutely the speciality of the cart or dray horse. And as horses of similar breeding, half-breds especially, vary much, both in appearance and powers of performance, it happens at length that the varieties of English horses are not so much varieties of breed as of individual form and qualities. Take the thorough-bred horse for example. In his best and most successful form he is a Derby winner, and progenitor subsequently of a numerous and distinguished family. If too slow for racing, he is probably a bunter. 
When too small for the field, he is a hack. With shape that makes him undesirable as a saddle-horse, charger, hunter, or hack, and good action, he may be a phaeton horse. And failing all these careers of usefulness, there are open to him others tolerably numerous, and at length when he has nothing particular to recommend him, there is the never-failing profession of the cab rank. We have thus already at least five different trades for horses who may be own brothers to each other, and they will be so far different in appearance that no tyro would mistake the hack for the hunter or race-horse; yet they could hardly be called varieties of the English horse. Varieties they would be, but of the English thorough-bred only.

Leaving the stud book, endless different types are noticeable, though here too it is less the breed of the horse than his form and appearance that qualify him for his particular walk in life. A direct half-bred may be a weight-carrying hunter or a slave in a van. The object of the following remarks and sketches therefore is to show as prominently as possible the differences of form, and, to a certain degree, of family. These, while rendering a horse invaluable for one purpose, may disqualify him utterly for another; and if these papers succeed in dissuading even one individual from putting his horse in "the wrong place," the writer will have his reward. How often have we all seen a man the possessor, say, of an animal the real thing for a brougham, disappointed, nay disgusted, because a too discriminating public has declined to buy him for a charger, or vice versî-perhaps with no better reason than because the animal's dam was a charger or trooper. Breeding for a particular purpose is a lottery, and especially the breeding of half-bred horses. 
Try to breed a hack from a hack mare, and a coach-horse may be the unsatisfactory result of your experiment. On the other hand, I have known, and still know, a hunting mare, who, with a variety of mates, persists in presenting to her persevering owner a succession of small covert hacks. Some day I firmly expect that she will astonish him with a London cabriolet horse. The lower we go in the scale of breeding the more uncertain is the result, until the actual cart-horse is arrived at, and there the result is easier to be calculated on. The only sort of horse which has through ages preserved its distinctive type is that which is supposed to be the progenitor of all others, viz., the Arab, whose merits we may now proceed to discuss, as he is an acknowledged ancestor-founder, in fact, of the family - of our race-horses, and consequently, as remarked above, of our superior hunters, hacks, chargers, and light harness horses. The Arab has been talked and written about very frequently; but the number of his historians who know anything about him is indeed in a minority, as compared with the hosts who have alternately maligned and over-praised him; for he is not quite perfection, and I have yet to see the animal that is. Most people who have given the Arab horses a thought know that there are several varieties even of them; but what these are is a hazy matter of conjecture with many who might know better. The knowledge would profit very fow people, and for common purposes it is enough to know that the Nedjedean horse is to be considered as the purest type, and that the nearest approaches to him in appearance and certain qualities are the most valuable. A recent and well-informed explorer has stated that the horses of Nedjed are not to be bought. If so, and if they be otherwise inaccessible, it may be consolatory 
to some to know that a good imitation is procurable by a good judge who will pay for his fancy. Whether or not a fresh infusion of Arab blood would benefit our racers is a point not likely to be settled as long as really wellbred Arabs are not imported here; but I cannot but think that our saddle-horses, and troop-horses especially, would be improved by it. There are men, and lots of them-some decent judges, too, of English horses-who can be persuaded that any under-sized long-tailed animal, particularly if he be a grey, and in possession of all his faculties, is an Arab. Think of the brutes brought over by officers after the Crimean war, which were dignified with the name of Arabs, and whose numerous faults were brought forward in evidence against the real son of the desert. A Turkish pony is a good beast; his feet and legs are capital, his appetite good (often better than his temper), and he is an enduring sort of slave; but the best of them cannot hold a candle even to an inferior Arab horse. The well-bred Arab is an example per se. For his apparent size there is more of him physically, and more spirit, gameness, and strength, than in any other horse. If well bred, he is much more likely to be under than over $14 \frac{1}{2}$ hands; but when on him you don't feel as if on a pony. His head is a picture by itself-so fine at the muzzle as to make the cheeks look almost coarse ; the nostrils wide, eyes prominent, mild, but bold; with little ears that, seen alone, could be taken as bail for the family of the owner. The neck is strong and muscular, without being heavy or "beefy," and the head nicely put on. Shoulders well laid back, looking rather thick, and none the worse for that when nice and free at the points. Girth deep, and back ribs of enormous depth; so big are all the ribs as to make the saddle- 
girth seem carried forward, whence the idea common amongst those who know a little, and only a little, about shape and make, that Arabs are bad-shouldered horses. (Some are, of course; so sometimes are winners at Newmarket and even Epsom.) The croup is high to. a degree seen only in horses of this high caste, and the tail is set on very high, and carried right off the back. The fore-arms of the Arab are remarkably muscular. Very short from the knee downwards, he has great flat clean legs, that no ill-usage can cause to puff. His feet are high at the heel, a little "donkeyfied," but hard as flints, and with as much wear in them. His thighs are to match his arms. His hind legs are well under him, and his hocks often turn in a little. He is hard as nails, will eat anything or nothing, and you may ride him for a month at a time. As a charger he is best. Intelligent and obliging as a poodle, he is still bold and resolute. When he once sees what vagaries are required of him, he will perform them. He is startled at neither lance-flags, sword̀s, firing, nor music, nor any of the bugbears of English remounts, but he hates a camel* (small blame to him) and mistrusts an elephant. He will fast as long as you like, and you may tire him if you can, being careful not to fatigue yourself in the attempt. He is not perfect, owing to bad breaking; his walk is often a shuffle, nor is his trot even. He sometimes "runs," and mostly stumbles. Good riding and English bridles improve all this, though. His fast pace is a nine miles an hour canter, at which he can stay till the week after next. Among other horses he is, though entire, quiet;

* Oddly enough, English horses have not the same objection to a camel that the Orientals have; in several instances I have observed this rather unaccountable difference of taste. 
quiet also to saddle and groom, unless ill treated. As a race-horse he often knows too much; but he has many qualities that, disseminated among our saddle-horses, would make the possession of a stable less of a care than it often is.

\section{THE BARB.}

WHILE on the subject of foreign, and especially Eastern, horses, it would not do to pass the Barb by without notice, the rather as he has had to do quite as much as the Arabian with the foundation of English thoroughbred horses. The horses named in the earliest pages of the "Stud Book" are called Barbs, Turks, and Arabians, the Barbs rather predominating in numbers. It is likely enough that the imported horses, of early days were often wrongly described; and the north of Africa being, in those days, much more accessible than Arabia, the Barbary horse must have been easier to get than the true Araba state of things still existing in these days of steam and telegrams. The Barb stands higher than the high-caste Arab; he has good shoulders, and carries his saddle in a better place than the Arab, but this is usually the result of his middle piece being deficient. He falls away a good deal behind the saddle, and does not carry his " flag" like the Arab. His quarters are sloping to a degree that distinguishes him at the first glance from the Arab, whose tail is set on so remarkably high. The Barb is very fast, and also very quick. He, no doubt, improved the English racehorse-once upon a time, but he is little or no good now on English turf, and has especially proved himself incompetent to win the Goodwood Cup. The size of Eastern horses, or rather their want of it, has always 
been given as one reason why the best of them cannot run up amongst even indifferent English horses; but this cannot be the reason, or anyhow the only one. There are many Barbs, and Arabs too, as big as Lecturer; but what an example the game little son of Colsterdale* would make of the best field that ever assembled on an Indian racecourse. Barbs are very handy as chargers, particularly in stopping short, and being such quick beginners that from standing still they may be extended in about three strides. They are a peculiar type of animal, and no others resemble them excepting the Spanish horses, who are evidently very near relations, with the same lofty crest, thick neck, and drooping quarters. The Spaniards are the best of hacks, but do not stand very much squeezing. Of other Eastern horses the only ones worthy of note are the Persians, Syrians, and Turks, which are coarse likenesses of the Arabs, with more size and knee action, well calculated for troopers and light phaeton horses; and the Turkomans, which are said to be good, but three-cornered looking, but of whom I have no personal knowledge. Other Asiatic horses are only descendants of English and Arabs, like the stud-breds of India; and without constant infusion of fresh blood they degenerate. The same remark applies to the Cape and Australian horses, whose good constitutions hardly counterbalance their bad shoulders (as compared with the generality of English horses), and their vile tempers and tricks. A Cape horse can rear and buck worse than any other horse in creation bar one; that one is the Australian or "Whaler," who seldom considers that he has handsomely disposed of his rider unless he sends the saddle flying after him (the rider) over his (the horse's)

* Written in 1867 . 
head. The Australian stock riders are said to be the best horsemen in the world, and they need be. We have got a long way wide of the Barb; but, after all there is little to be said about him, beyond that he is a gentlemanly little horse, with a great deal of good about him, but inferior in all respects, except trotting action, to the true Arab. He is a nice lady's horse, and a nice park hack, and very good in his way. The greater part of the stories which we have so often heard about the wonderful performances of Eastern horses are to be placed in the same category as the tales of the Rhinoceros Major in a certain monthly periodical. As chargers and troopers, in the way of roughing it, Orientals will beat English horses; but, on the other hand, the best of them that ever went could not get over an "oxer" at the end of three miles, best pace and ridge and furrow.

\section{THE RACEHORSE.}

HorSE-RACING throughout all ages and in all countries has had professedly for its object improvement in the breed of horses, until lately, when the question has been raised whether racing, as now conducted, does not have the opposite effect, and actually cause our breed of thoroughbred horses to deteriorate. Much has been said for and against this view of matters, and an impartial individual, having heard the arguments on both sides, will be very likely to find himself as regards opinion much where he was when he began. There is, and can be, no doubt that thoroughbred horses of power are the exception; also that the best racehorse is frequently, as a sire of horses 
intended for general purposes, inferior to others who have made no name on the turf, though as the progenitor of racehorses he may be first-rate. In the present state of the turf-a state in which the love of gambling predominates over that of sport-the best racehorse is the one out of which most money is to be made; and a worthless animal which by any means can attain the position of favourite for a race of importance, is just as good a friend to some parties as a real flyer whose light is dexterously concealed under a bushel is to others. Shape and make are things of less consequence in the racehorse than in any other sort of animal devoted to sporting purposes. As a yearling, pedigree and looks will fetch a price, as anyone may see who attends either of the great annual sales of yearlings; but how often is the spirited purchaser of an animal, whose family alone ought to be bail for his winning the Derby, disappointed in his purchase when it is put into training. As a twoyear-old the colt's looks are comparatively of no moment if he can only move; and if he performs fairly in private, he will soon make a reputation for himself which may later on be lost or sustained, as the case may be, when he comes out in public. If the colt be sound as the proverbial roach, hardy as a donkey, quiet as a sheep, and able to stay at his own pace till that day twelvemonths, he would be by many considered an animal likely to "improve the breed of horses ;" but if he have not speed (and the standard of speed in a racing stable is a trifle higher than in most other places), he will never have the chance of doing so. He may be the best hunter or steeple-chaser of his day; but, unless he be sold to the foreigners, he will be incapacitated for parental duties almost to a certainty, and so his good qualities will be 
lost to posterity. On the other hand, let him be a bad feeder, infirm in temper and on his legs-let him be a savage in the stable and a practical joker out of it, and, as they "go in all forms," let him be as bad a shaped one as is compatible with his ever having been bought or kept at all-but give him the power of staying at his best pace, and let that be a good one, for a long distance-he will be the apple of his trainer's eye, watched by touts, criticised by "special commissioners," idolised by his master and his master's friends; and if he have the luck, assisted by all the skill in training that England can produce, and by the best of riding, to run well in good company, all his faults will be forgiven him. If he wins a big race he will be the lion of the year, and when he is hopelessly screwed up-a consummation to be looked for at latest about his fifth year-he will be a popular sire, licensed to transmit all his faults to posterity, and forgiven for so doing if with them he passes on his speed and staying powers. He may be the sire of successful racers, but he can hardly be said to improve the breed of horses. Of course no horse is the worse for being good-looking, though many winners have been out-of-the-way plain ones. Theorists will say a racer must have certain attributes, such as good shoulders, girth, back and loins, hocks, \&c. How often, though, they can perform when possessed of no qualities taking to the eye; and who thinks of their looks then, unless later in life they may have the misfortune to appear at a "horse show?" and even there, if the judges do not approve of them, the public probably will; while if the crowd of spectators pronounce them to be brutes, they may calculate with some certainty on receiving prizes, or at least honourable mention, at the hands of 



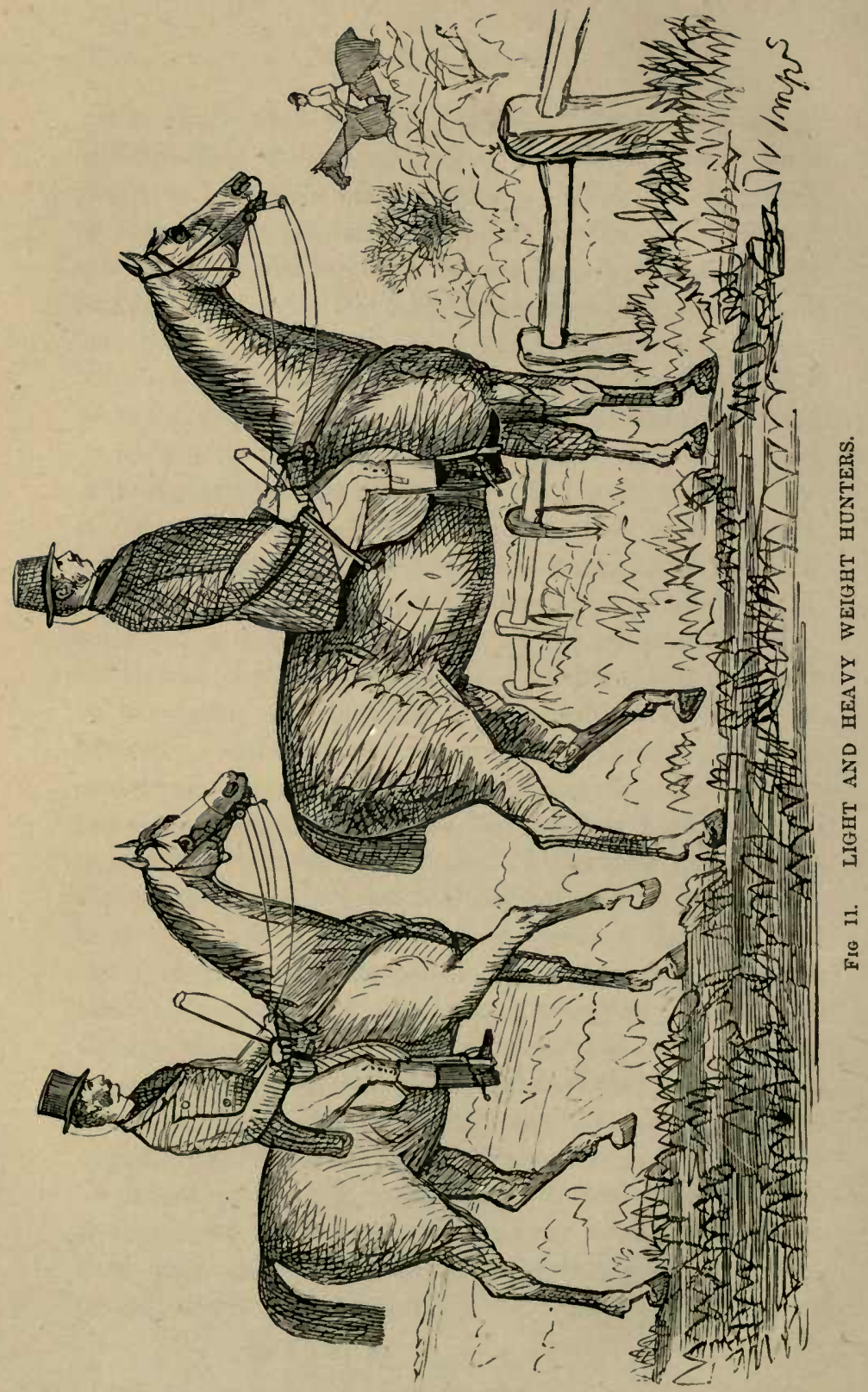


the judges. In fact, the successful racer may be considered in the majority of cases as an embodied "fluke"the rather as, in these days of objections and reversed decisions, the words and meaning of the old song, to the effect that "the horse that's first will win, sir," just stop short of being a dead letter, and an absolute myth.

\section{THE LIGHT-WEIGHT HUNTER.}

THE light-weight hunter is either thoroughbred, or with a slight stain in his pedigree; and there are not wanting many good judges who prefer the animal with a stain. There are many arguments against thoroughbred horses as hunters, but most of them are, when analysed, arguments not against the horse himself, but against his past education. A horse which has been in training generally has some faults peculiar to animals who have passed through that ordeal. He often pulls in his gallop, he frequently kicks at other horses, and be is, as a rule, more or less irritable in his temper. But these faults arise not from his breeding, but from his training. Cocktails who have been trained, especially for steeplechases, have often all the above-mentioned faults of the more aristocratic horse without his virtues; the temper of the half-bred one who has been severely trained is far more likely to be upset for life than that of a thoroughbred; and, it may be added, his constitution also, but that is not the present question. A horse which has been trained as a two-yearold always is a trouble to make a hunter of. The style of galloping which has been encouraged in the trainingstable is not the best adapted for getting through plough, or over ridge and furrow, and, from going habitually 
in that extended style, a horse at first finds great diffculty in collecting himself for his fences. Indeed, ex-racehorses are proverbially prone to running through their fences, but for the reason just given, not because their names are in the Stud-book. A clean-bred horse who has been treated like a half-bred one, and led a private life, will make as good and pleasant a hunter as a cocktail, and probably a better, as liberties may be taken with him in the way of pace, and days of work, with short allowance of rest between, which could not be stood by the lower-bred horse.

In one respect the thoroughbred is almost invariably superior to any other horse, and that is in the clearness of his wind. In the power, too, of "coming again" when half-beat, "none but himself can be his parallel," and gameness under difficulties of all kinds is one of his most distinguishing characteristics. But he is so seldom up to any weight, that riders who are not too heavy for him are the exception even among light weights. A thoroughbred well up to 12 stone over the shires is not so very common, one really well up to 13 stone is very uncommon, and so on. Now, a horse up to less than 12 stone can hardly be called a hunter at all. For a few days an apparently weedy blood horse will carry a rider whose weight is evidently beyond his powers, better than many horses who combine more power with less breeding. But he cannot go on for long doing it, and is soon worn out or screwed up. When, however, a clean-bred one knows his business, and is not overweighted, nothing will touch him as a hunter. In fact, as it has been observed, a thoroughbred hunter is " either worth his weight in silver, or not worth his corn." The latter class preponderate. The light-weight hunter must be fast; a good weight- 
carrier may be pardoned even if he be a little slow, provided he be sure; but a light-weight horse who cannot gallop is no good to anyone.

In teaching young horses to jump, I am a strong advocate for the leading rein to begin with. Beginning with very trifling obstacles, he may gradually be led over stronger and more awkward fences, but not until he knows how to manage them. Falls discourage a young one. Scrambles, where he recovers himself, do him good. A regular turn-over is often a useful reminder to an old horse who is growing careless or too clever; but it gives a colt a distaste for the amusement of jumping. In no case, however, must he be allowed to break any timber. He should grow up, if possible, with the idea that all rails are of adamantine strength and consistency. When he is first ridden over any fences, he should have a lead from an experienced horse, whom he will probably be quite happy to follow. It is important that he should not learn to refuse, and it is better to make him creep throngh, or in and out of, a fence then to let him turn away. When he will jump a little-and jumping in cold blood must never be overdone-he may see the hounds, being kept well out of their way, and he will be content to follow the field of horses anywhere that he can. A young horse ought to be taught "water" last of anything, and he must have confidence in himself and his rider before it is fair to ride him at it. It is the thing of all others he is most likely to refuse, while it is most important that he should not do so. It is worth while to arrange a ditch of running water for the instruction of a promising colt. Many never see water till they come to it in a run when half beat, and, with a horse refusing in front of them, they probably take a dislike to the element 
which lasts them their lifetime, and depreciates them infinitely in value.

The make and shape of the light-weight hunter only differ from those of the weight-carrier in the amount of physical strength represented by each. In the thoroughbred hunter, as in the case of the stronger one, shoulders are of the first importance. No horse with short or straight shoulders can stretch himself out over an unexpectedly wide ditch : or, if he does manage it, he will probably overjump himself, and give his rider a disagreeable fall. A strong back and loins, with hocks well under him, are necessaries to any horse who has to go across country. Deep back ribs almost always denote the good doer; light ones the reverse. The foot, for heavy or light weight, must have plenty of horn, and be pretty strong at the heels. A perfect hunter should have a perfect temper, must never refuse, nor kick hounds nor horses, and, after the day is over, must hack pleasantly home, and eat his corn and lie down when he gets there. But perfection among hunters is uncommon, and most sportsmen will find themselves forced to put up with the nearest approach to it that they can find, in the possession of which they had better " rest and be thankful," instead of wasting energies and money in the pursuit of the unattainable.

\section{THE WEIGHT-CARRYING HUNTER.}

THE great criterion of a hunter's value for sale is the amount of weight he can carry. Clever jumping weeds are to be had every day, and almost everywhere, at little money; but a horse up to weight will always command a 
price. The choice of a weight-carrier is a matter requiring more judgment than the uninitiated would think. Beginners are apt to confound size with strength. They are two very different things. Indeed an overgrown animal has himself to carry; and when to that load is added a heavy rider, the total becomes considerable. Compactness is the first quality to be looked for by a sportsman who, riding sixteen stone or more, still is determined to see sport. Long backs and long legs are unpardonable deformities. A well-set-on head and light mouth are desirable, but the want of these may be excused if the horse be good in other respects, and the rider really heavy. A muscular neck generally accompanies muscular development elsewhere, and so is to be desired; but it must be light at the throat, and not too loaded on the crest. The best of shoulders, it is needless to say, are indispensable; no horse can do the trick across country without them. They must not only be oblique, but long, and to carry weight rather thick, though with a tolerably broad chest. Broad-chested horses are supposed generally to be slow, but narrowchested ones are very apt to speedy-cut and hit themselves, under weight. Round the girth a heavy-weight hunter should measure as much over $6 \mathrm{ft}$. as possible. Light-girthed ones with staying powers are the exception. No hollow-backed horse will ever do any good with a real welter weight. The back must be short, the loins strong, and the hips wide, and as ragged as you like. A tendency in the direction of what is elegantly termed the "goose rump" is no disadrantage, rather the contrary. The deeper the ribs are, the more valuable the horse. For muscular thighs and hocks well under him, the merest tyro can see the necessity; also for arms to match, and big 
bone below the knee. The feet must not be too small; at the same time, narrow feet wear far better than flat wide ones.

They must have plenty of heels too ; feet low and weak at the heels will never stand battering with ordinary shoes. Good temper is a most important requisite. A horse with sixteen stone or more on his back cannot afford to take anything out of himself by quarrelling with his rider. He should be able to gallop, and at a fair pace, but he need not be a racehorse. A clever fencer he is presumed to be. Possessing all these virtues, he is worse than useless, if he have not clear wind, and this is just the very thing which he is most likely to want, as these large and valuable horses seem more liable to go roarers than others. If the pipes are clear, and he can gallop, jump, and go on with a heavy weight on his back, he may be pardoned many shortcomings. He may be the vilest of hacks on the road, threatening to break his knees at every step, he may be a bad walker, he may brush or cut-boots and bandages are not expensive (nor always efficacious?) - he may be a kicker, and, if he is one of a large stud, he may even be an indifferent feeder. As a great deal is required of him in the run, an equal amount may be excused him on the road.

His education is not quite complete unless he will jump a fence in hand. As I have remarked àpropos of the covert hack, this performance is usually considered a dangerous one, and so it is unless horse and man understand each other. But it is very easy to teach a horso not to come till he is told, the danger being of his jumping on his master, and the accomplishment is well worth the slight trouble involved in the acquirement of it. When there is time to spare a deep drop into the road 
without a weight on his back is an affair of no difficulty or danger to speak of to the horse. With a heavy weight, it is quite a different thing, and may lay the foundation of numberless foot complaints. I would not counsel anyone to be always getting off his horse, were he Daniel Lambert himself; but in exceptional cases it is a wise proceeding. No one should attempt it who is not sure of his horse, as no one would like to place himself in the position of Mr. Jorrocks, as he appears in that charming sketch by John Leech apostrophising the recreant "Artaxerxes." Weight is too often brought forward as a reason, if not an excuse, for not attempting to ride straight to hounds; and weight unaccompanied by a corresponding depth of breeches pocket undoubtedly is so. But to the ponderous and youthful Croesus, who is in every way but his weight qualified to shine in the field, I could mention many names of men, over fifteen stone, who, when hounds run, insist on being not only thereabouts, but there; and it has been said that "whatever man has done man may do." At all events he may try to. Let any one who doubts the power of heavy men to get across country treat himself to a day with the Pytchley,* and see the example which, if there be a scent, the gallant master and huntsmen will make of the feather weights, the rather if the line be really a strong one. Let him consider the performances of Lords Sefton and Alvanley in bygone days, and of Mr. Gilmour and Sir Francis Grant in our own time. Or, to vary the country, let him go out with the Duke of Beaufort's or Sir Watkin Wynn's hounds, and he will be convinced that real love of sport can more than counterbalance heavy weight. Weight, when the horse is equal to it, is a positive advantage in

* Written in 1867. 
getting over a strong country. The bullfinch which would hang up in its branches the nine-stone man and his thoroughbred will open like a door before the determined charge of fifteen stone, who will also smash a rail like a stick of sealing-wax, that would turn over nine stone, to the detriment if not fracture, of every bone in his frame from the neck downwards. But the horses to do all this on are difficult to procure, even at a high figure. One comfort remains to the happy owner of such : they can always, if good for anything, be disposed of, usually at something like a fancy price.

\section{THE PARK HACK.}

"SHow me your hack, and I will tell you what you are," lately wrote a remarkably keen observer of human nature, sporting and metropolitan; and assuredly a man's park hack affords more often than not an index to his character. Certain animals seem to the most casual observer suited for certain purposes, and for such purposes only. For example, how out of place would a 16 -stone cob look carrying an average subaltern of Life Guards; and, on the other hand, what diocese could put the slightest faith in a bishop who habitually appeared on a weedy thoroughbred with a habit of lashing out? "Everything has its place," that nobody can deny; but to follow out the instruction of the old saw, and to "put everything in its proper place" is not always easy of accomplishment. If it were, the number of badly mounted equestrians to be seen in a morning's walk in town would diminish considerably. What a hack should be is one thing; 
what he often is, is quite another. People who are particular about appearances like something of the following description: Height from 14 to 15 hands; a horse much taller than this has seldom the activity and handiness required in town, where wildly charging vehicles are to be avoided often only by a sharp turn on a slippery crossing. His temper must be perfect, or he may resent being pulled on to his haunches to accommodate a perambulator; or, his normal condition being one of greater freshness than most horses, he may play tricks which will be more appreciated by the spectators, especially those sitting on chairs, and therefore themselves out of the way of danger or responsibility, than by the rider of the playful animal. He must be a good walkernothing is more detestable than to be on a brute who breaks into a jog-trot every minute because his companions are walking away from him. His head must be in the right place, or there is no comfort to be had on his back; shoulders, if he has free use of them, need not be so good to look at as those of a hunter; many good hacks have only moderate shoulders; but, whatever the action may be, it is uncomfortable to ride on straight shoulders, let alone that the saddle cannot then be in its proper place; and, after all, good action is not to be looked for in an animal whose shoulders are really bad. Very straight shoulders are, therefore, out of the question, but they may be a little thicker than a hunter's. Action is the sine qua non in a park hack. The knee should be visible to the rider beyond the point of the shoulder; the height to which the knee is to be lifted is a matter of taste. Young gentlemen must have it up to the curb chain, but such an excess makes the animal, as often as not, rough and unpleasant. A medium which combines 
show and safety is, when procurable, to be preferred. Of course the foot must be put down properly; a liack who stumbles is only fit for the boiler. A park hack should canter nicely and slowly, well back on his haunches. The walk and the canter are the most comfortable paces for Rotten-row. Of course he must not hit himself anywhere; boots and bandages would be unpardonable in the park. A fidgety horse is a nuisance on a hot day; so is a slug. Here again the happy medium must be sought for. Action in front will avail him but little if he have not the use of his hind legs. There are few sensations more unpleasant than that afforded by a very high stepping animal, who lifts his foot to an amazing altitude, and puts it down again in the place from whence he took it up. The colour of a London hack is quite immaterial. Even piebald is perfectly permissible, if the animal be good-looking in other respects ; but he must always be what ladies call "pretty." Ribs and constitution are of less consequence in this kind of horse than in most. His work is not severe, and with decent grooming even an indifferent feeder may look well when only out for an hour or two a day, and that not every day, thanks to our climate. As good a bridle as any for London is a Hanoverian Pelham; if the rider have hands, the horse will bend to it more than to any other with which I am acquainted. A standing martingale is a matter of taste: a nice hack does not require one, and it is no ornament. The hack should be something as described above, though such animals are not over common, and command a price whenever they are to be disposed of. The season of park hacks is now over, and who can tell if it will ever return? Another year may see the Row given over exclusively to the lovers of 
democratic oratory, and in that case the occupation of the park hack will indeed be gone (1867).

\section{THE COB.}

THIs is essentially a fancy article. A cob is, compared to other horses, much what a "concentrated luncheon" lozenge is to a vol au vent. He must have as much breeding as possible, combined with the power of a carthorse. It is not everyone that is a judge of a cob. An underbred, under-sized, thickset punchy horse is not of necessity a valuable cob, though the owners of such beasts (when they are for sale) are sometimes very hard to persuade of this fact. Cobs are usually ridden by a class of men who can afford to pay for them; and as the demand is always in excess of the supply of these animals, they generally have to be paid for pretty freely, supposing them to be really good. But without a long list of virtues, a cob, however powerful, and in its own grotesque style handsome, will never fetch a price. To begin with, he must be perfectly quiet on all occasions; not inclined to shy; and possessed of a certain sedateness of character and demeanour, as it is his peculiar province to carry gentlemen of a certain age and weight, and usually of a position in life which renders their personal safety a matter of interest to the community at large.

The cob's mouth must be good, not hard or deadened, as many gentlemen like a snaffle bridle for this description of animal ; and none like to be pulled or bored at. No horse with a badly set-on head can have a really 
pleasant mouth; so this is important. Make and shape, in perfection, are much the same in all sorts of horses; so the same sort of shoulders, back, loins, and hocks, which have been already insisted on as necessaries for almost every horse, are equally needful for the cob. A cob who is not a good walker is of about as much use as a young lady who does not valse!

He must be particularly safe in his trot, and he is none the worse for being fast in this pace, though if a really fast trotter (that is, fast enough to be matched) he will be most likely unpleasant to ride. The canter, as in all hacks, must be even, and well balanced. The gallop matters but little, as it is a pace not much affected by the majority of riders of cobs. To be perfect in the country, a cob should let his rider kill a brace of birds right and left off his back without winking. Even if he be not wanted as a shooting pony, his nerves must defy alarm or excitement at any unexpected sight or sound, especially connected with guupowder; for in these days of revolvers and rifle practice a quiet gentleman who never goes near a battue may, in the course of his ride, whether in town or country, find himself almost at any moment in a "warm corner," as far as numberless discharges of firearms can constitute one. Therefore the points most important in a good cob are strength, good mouth and slow paces, soundness (of course), good temper, moderate height, say 14 hands, and perfect steadiness and tractability. If anyone who may do me the honour to read these lines possesses a cob up to 16 stone, who can walk four miles an hour and trot twelve, with a good mouth and amiable disposition, who fears nothing, and never stumbles, let him, if a rich man, keep him-he will not get another such in a hurry; if a poor one, let him, 
in offering him for sale, fear not to "open his mouth" boldly, and demand for him a price which shall make a difference in his (the owner's) year's income ; for people must, and usually are ready to, pay for their fancies, and a good cob, as already remarked, is, of all the equine race, essentially a fancy article, and one too for which the demand is always brisk.

\section{THE CHARGER.}

There are few things more difficult to procure than a perfect charger--that is to say, a cavalry charger. Any neat-looking quiet hack will make a charger for mounted officers of infantry; but the dragoon's horse is another affair. He must please a good many people-the commanding officer as regards his appearance and action, and the regimental vet. in the matter of soundness. The groom of the intended purchaser will doubtless have some opinion to express on the animal's probable constitution, \&c. ; and as to the officers of the regiment generally, the buying of a charger by one of their number usually affords a fine example of the truth of the proverb, Quot homines, tot sententice. The buyer's opinion may be kept to himself-no one will listen to it. He has had time to make up his mind before he introduces his choice to the notice of his corps, it is to be hoped, or some confusion may arise in his mind from the quantity of good advice he is likely to receive.

A great many qualities are indispensable in a charger. Appearance, to begin with, is of the first importance. A pretty head and neck, and showy action, and a well set- 
on tail, are de rigeur. His shoulders must be long and oblique, or nothing but his ears will be visible to his rider in front of the cloak and sheepskin, which gives an insecure sensation. Without hocks well under him he will not be able to turn handily across the school, and will rarely canter well. His action must be good before and behind; the knee more bent than in any other description of horse, with the exception of the park hack; and the action, however extravagantly high, must be smooth, as the animal has to be ridden not unfrequently without stirrups. A light-bodied charger looks very bad; he must be possessed of deep ribs and a good appetite, for he must always look big, whatever work he may be doing. His work is mostly on the hardest of ground, so his legs and feet must be unexceptionable; and, lastly, his temper must be perfect-that is, a mixture of courage and amiability. A hot horse is unbearable on parade, where an officer has plenty to do without rough riding; a fiery charger is suited for the pages of a bygone species of novel, but not for real life. A slug is preferable, though unpleasant in his way; and an animal in whom docility is not a very strongly developed quality will be likely to object to jumping time after time over an unnatural-looking obstacle, in the shape of a "bar," which he can run round. If the charger is also a hunter, he will be the safer and more pleasant in rough ground or among ditches, \&c., which have often to be crossed on duty; and there is every probability of being ridden over in the event of a fall in front of a squadron-though that is not the certainty it is when the fall is in front of a crowd in many fashionable hunting countries. In some few regiments first chargers have been hunted from time immemorial, but this is not according to the law, and is 
quite the exception. As a rule, they are not allowed to be singed, probably in consequence of their having to stand about in cold weather; and as the troop horses are never clipped or singed, a clipped horse in front of the line would spoil the uniformity. Colour is a matter of taste. Everyone knows that the Household Brigade ride blacks and nothing else, and the "Greys" grey horses, the "Bays" probably bays; but in other regiments all colours excepting piebald are to be seen. Many colonels will not have greys, especially as first chargers, and no doubt they are conspicuous, and spoil the look of the line. The nearer approach to thorough-bred the charger is, the better. Thorough-bred ones are much bolder among "sights and sounds" than half-breds. The height must be, unless for a very diminutive officer, 15.2. It need never be over 15.3. Indeed, with length and power, the lower in reason that a charger is, the better will he look, unless the rider be unusually tall. One more thing is most important. He must not have a notion of rearing; or, if he be possessed of anything like a mouth, that accomplishment will be developed, to a " moral," by his course of training in the school.

\section{THE COVERT HACK.}

If the park hack be a luxury, which he undoubtedly is, his brother, the covert hack, may be considered as a necessary of life to the hunting man. Modest men may walk in the park, may sit on chairs, or may stay away altogether, and in either case exist and enjoy life without the possession of a London hack; but the hunting man of 
the present day might as well be expected to clean his own leathers as to ride his horse on to covert. Time was, at least so my seniors have informed me, when sportsmen were not too lazy to rise and ride their hunters, at a leisurely pace, on to the meet; and the performance was the more meritorious as the hour of fixture was considerably earlier in days of yore than it at present is. Also, the steed had his heavy winter coat on, a circumstance that must have increased the responsibility of tho undertaking-Nous avons changé tout cela. Young and old, feather and welter, customer and shirker, all agree in the impossibility of hunting a horse that has not been conducted to the place of meeting in the orthodox manner by a groom. The master has to go to the same spot as best he can. A brougham is a luxurious conveyance to covert, especially on a wet morning; a phaeton, with a clever pair, an exhilarating one; a coach, with a merry party perched thereupon, a sufficiently cheery one; but according to my own taste all these ways and means of encompassing the desired end fall short in amount of enjoyment compared with the journey on a really nice hack. He must, however, be the real thing, or there is no fun at all in this mode of transit. To labour through deep lanes mounted upon an undersized pony is trying to the temper, even as it is to the appearance of the boots and breeches. To hammer along a hard road upon a coach horse is a comfortless, if not an alarming, mode of progression. The covert hack is neither of these extremes. Fourteen hands to fourteen three should be his height, with power suited to the weight of his master. He cannot by any possibility be too well bred, but he need not study appearances like the park hack pure and simple. He must have good temper and good paces. 
He has not to do much walking, but still a bad walker is a continual bore. He need not exhibit the gaudy trotting action desirable in Rotten Row, but he must trot fast. Here action behind is of the first importance, indeed quite indispensable. He must further be able to canter with ease to himself from nine to twelve miles an hour, and to go on doing so as long as he is wished to. $\mathrm{He}$ must open gates artistically, and, if required, he must be able and willing (which is often another thing,) to jump any small fence alongside of a locked gate. The immortal "Mr. Sawyer" was obliged to ride his hauk over the gate itself, and an "oxer" or so into the bargain, but it was hard lines, even upon him, to be dependant for pilotage on such an undefeated customer as "the Honourable Crasher!" I should individually be satisfied if my hack ean be depended on at a hurdle, or small fence, nor should I when it could be avoided trouble him even with these, and in any case I should leave gates and "oxers," in cold blood to the attentions of my betters, in the way of nerves. The covert hack ought to be, and indeed generally is, the animal most fit to go in the stable to which he belongs. His work is regular, and not liable to be stopped by accidents, like that of the hunters, his stable eompanions. Indeed he must be pretty fit, to go fast to covert three or four days in a week. Nobody ever has too much time to spare on a hunting morning. The M.P. must write eertain letters; the steadiest going sporting squire is liable to arrest at the hands of his bailiff, just as he ought to be starting; whilst ardent youth is not only, to a certainty, late for breakfast, but if there be daughters, or other young ladies, in a country house, it is fifteen to one at least, that when he ought to be miles on his way to covert, ardent 
youth aforesaid is to be found in a conservatory, superintending the choice and adjustment of a bouquet for his button-hole, an article without which it would appear no young man can mount his hunter in comfort and safety. If our youthful hero hails from his hotel or lodgings, he is still later, as having most likely sat up over night a deal too late, and breakfasted before dressing for hunting: a fatal proceeding when time is an object. All which affect the hack. Don't condemn the wearing of flowers, however, by the first flight, as the remains of the bouquet may act after the manner of buoys in an intricate channel of the sea. If you be not absolutely first, and the way out of a field be intricate, a white camellia, perched on a thorn, close by a bit of red cloth, will indicate the spot where you are to have the obstacle which has not succeeded in pounding your predecessor, and, trusting to the adage that "whatever man has done, man may do," I sincerely hope you will get over, and, finding your friend on his back in the next ditch, assume that place which it is the desire of all customers to fill, first of the first flight. And never forget the high authority who has spoken to this effect, if the words are not quoted quite accurately, "Better thirty yards before the hounds, than one behind the throng?"

\section{THE HARNESS HORSE.}

THE above can hardly be considered as a variety of the horse, harness being a trade which may be followed by any and every one, of the varieties already noticed. Any- 
thing quiet in harness is a harness horse as long as he is attached to a vehicle of any sort, though out of leather he may be a "polo pony," a charger, hunter, or anything else. London carriage horses certainly follow no trade but "leather," and would mostly be wholly unfit for any other employment. The 16-3 or 17-hand steeds, who, matched to perfection, clamber about the streets of London, or stand still, trying in vain to reconcile comfort with a tight bearing rein, could not possibly be used for any other purpose than that fulfilled by them, unless it may be that they might conduct a plough in light land. Phæton horses are another thing. They should not, to my mind, much exceed 15 hands in height, and should give the general impression that they ought to be hunters in a close country, were their action different, for a really clever phæton horse's trotting action would be intensely out of place in the field; nor is such action usually accompanied by speed in the gallop. Barouche horses are larger, indeed, much what has been described above. Team horses are phæton horses rather enlarged; but tastes differ here, some people liking large horses, others smaller ones. Mr. Moritt's team of roans is a fine specimen of what may be termed the useful style; Mr. Hope's blacks representing the florid ditto.

Stage coach horses must have legs, wind, good temper and constitution, and pace and breeding, as an indispensable accompaniment of the last-named quality. Appearance is a matter of little moment here, although all the coaches running in and out of town at present (1872) have neat teams enough. Where looks can be combined with utility, why all the better for the spectator as well as the owner. Last on the list of harness horses come 
those who take us, all sooner or later, on our last journey. For any other purpose they would be wholly useless. With an appearance sufficiently imposing to the unlearned eye, they combine almost every fault of shape that a horse can reasonably be expected to possess. They are all exactly alike, too, the only difference I have ever noticed between any one and another being length of mane, which is not uniform, their locks being cultivated to the greatest possible length-also some difference in action. How their attendants know them apart in the stable is a mystery to me, perhaps they don't; or experience may give them the power of distinguishing one from another, as it is said to do to monthly nurses, who, I am informed, profess even to see a difference in babies, a talent not given to any ordinary mortal. Circus horses have not been alluded too, as they are selected for colour, and are consequently no particular sort. However, it is a good thing that there should be that market for fancy coloured horses, as they would otherwise be slightly unsaleable. I once, to be sure, saw a piebald horse at the covert side-in a crack country too-but he was, as far as my experience has gone, the exception that proves the rule. There is a wonderful difference in the extent to which performing horses can be trained, and many people may be surprised to learn that a "trick horse," one who retrieves, jumps through hoops, \&c., is more easily to be taught, and consequently less valuable when taught than a good "bare backed horse." The latter seeming to exhibit no talent as he canters round and round ih ring, witli heaven knows what acrobatic performances going on, on, or off, his back. He really has an immense responsiblity. A change in his pace, a hanging back, or rushing forward, would play the mischief 
with the talented games proceeding above him. Of troop horses enough has been said in the chapter on "Light Horse," and such being the case, I think the varieties of the English horse are about exhausted, as cart horses are not objects of general interest. 


\section{“ II A N D F U L S."}

As the season of the Epping Hunt-an institution now no more-approaches, the number of incompetent sportsmen to be met with out with hounds invariably increases. Why persons who are unaccustomed to hunting (to put it mildly) should make their first essays in the art almost invariably at that time of year when the ground is hardest, and when as a natural consequence, falling must be most unpleasant, is a problem far beyond my powers of solution; and, speculation not being my forte, I shall leave the causes of this undoubted fact to be discovered by abler hands. To see a muff out hunting is generally amusing, provided his ignorance inconveniences no one but himself. Some slight inconvenience to himself is indispensable for the thorough enjoyment of the sight to the spectators, all human creatures being by nature charitable, and by habit and custom sympathetic! Actual danger is another thing-where it exists no people are more unselfish and prompt to aid than sportsmen, but the human mind is so constituted that it takes an unconcealed delight in watching the harmless difficulties which have to be surmounted by a tyro in any art of which the looker-on is a master. And this brings us to the subject of "handfuls." To see a friend on a "handful," if his neck be not in positive danger, is exhilarating to the possessor of a well regulated mind. How much more delightful, then, is it to watch the efforts of a person that one dislikes to control a refractory or too ardent steed ! 
But although it is a noble sport to mark the incompetent rider, and, if possible to incite his steed to further insubordination, it is universally conceded that the delights of the game are one-sided, and that it is excessively poor fun to be the object of this sort of attention-which is incontestibly pleasanter to give than to receive. Therefore let us consider how, in the event of finding one's hands full in face of a critical assembly, it is feasible to combine safety and self-respect, and to prevent the latter quality from dwindling to the dimensions which it is apt to assume under the circumstances aforesaid. And let it be remembered that whatever in reason the horse does, if the man only looks happy and comfortable, he will be regarded with admiration, or, at the worse, as one suffering in a good cause. Far different is the case when his appearance shows him to be at once aware of his danger and unable to see his way out of it. Now there are several kinds of handfuls-several ways in which hunters, without absolutely jeopardising one's life, can make it for the time being a burden to one. The most pleasing variety (to one's friends) is the course of action taken by a horse who is exceedingly fresh. A steadygoing individual, possessing a proper regard for comfort and appearances, need never mount one of his own stud who is suffering from suppressed vitality, so to speak. But there are dangers which no one can be guarded against: there are such things as country-house visits and lawn meets, at the end of frosts of more or less duration; and when his host kindly offers to mount, say, Mr. Brown, who is known to be a keen foxhunter and decent performer (on an easy and confidential nag), how can Brown decline the honour? He is fond of hunting, he is away from home; here is a new pack to see, and a 
horse provided for him! What more could he wish for? Not much more, perhaps, yet possibly a little less of kindness. For though the animal be described, and justly so, as an excellent hunter-nay, even though the daughter of the house may have ridden him in the capital run which heralded the appearance of the late frost -that performance is a fortnight old. Tempora mutantur, et nos mutamur in illis. "Confidence" is a very different animal now to what he was two short weeks ago.

Who could honestly lay his hand on his heart and affirm himself ambitious to change places with Brown? Fancy him as he stands on the door step, attired in shooting things (not expecting this pleasure, of course he had brought no boots and et-ceteras), and listening to the playful squeak with which his monture announces himself; observing also the somewhat ungraceful curl with with which he carries his tail over his back, frisking around his groom the while! We needn't follow him. We all-that is all who have arrived at years of discretion have experienced the sort of thing, and know that there is no conceivable folly, from kicking a hound to leaping into a quarry to avoid a falling acorn, that a "fresh" horse will not commit, nay, make a point of committing. Still what is danger to Brown is sport to the rest of the company, and these evil habits may make a horse equally a handful to his rider, without affording so pleasing a spectacle to the looker-on. A fidgety horse is a great bore: he won't stand still. He sidles under a tree, as if desirous of clearing up once and for ever the doubt whether it is possible, in these days of close-cropped hair, but flowing whiskers, \&c., to suffer the fate of Absalom. He turns his tail studionsly to each and every one with whom his rider is desirous of holding 
converse. He backs with one or both of his hind legs into a deep ditch. At length you lose patience- "cob" him over the ears, or "chuck" him forcibly in the mouth. There we will leave you, the chances being slightly against your having "bettered yourself," as the housemaids call it. Joking apart, if you are patient with such a horse, he very likely becomes no better; if you are hasty, he certainly becomes worse; and in a choice of evils it would be preferable if the lesser evil could be arrived at by some action. This it cannot in the case just quoted. The very fresh horse and the fidgety one are pieces of enjoyment the full fruition of which comes to an end more or less soon after a fox is found or goes away. There are some handfuls which begin their games at this point, where the others leave off. When hounds are getting away the refuser is in his glory. He won't jump out of the lane by the covert; he won't leave the second horses, and the ever-present crowd at all covert sides of those who don't " mean it." Spur him, and he kicks, endangering your neighbours. Strike him with the whip, and he rears, endangering yourself. You will most likely have to go with the stream, and then the contrary beast will further commend himself to your affection by the perfectly clever manner in which he hops over such gaps, \&c., as have been made long ago by the first or second flight, in neither of which will we back you to be. Your horse is a rogue, and refuses from his innate roguishness, and severe measures are likely to be the only effectual ones; and the same course of action is needful if he refuses in the middle of a run, supposing that there is no mistake about his being a rogue. But there are many causes for refusing besides temper and cunning. Young horses will do it from nervousness; patience, 
and lots of it, is the remedy here. "Pitch into" a nervous young horse, and if you keep him long enough you will be possessed of a still more undesirable old one. Unsoundness will cause a horse to refuse a drop or a jump on to hard ground; and here humanity would probably take one course, and vaulting ambition another, both widely differing. When, however, a good horse takes to refusing for no ostensible reason, do what not quite everybody would do under such circumstanceslook at the saddle! If it pinches him, if he have a sore back or the beginning of one, or if his saddle hurts him in any way it requires no great stretch of intellect to imagine the sensation produced by the bumping down on it of a weight varying from ten to fifteen stone; and the majority of riders do not sit over a fence as if they were a part of the horse. A well-developed chaperone, perched upon one's favourite evening boot on a crowded staircase, very likely produces, though in a far less degree, a sensation similar to that which the horse attempts to avoid. A horse may refuse certain kinds of obstacles; some object to a bullfinch. I once owned one who hated timber, and about j0 per cent. of hunters decline water. The last fault is usually the result of unskilful handling; sometimes it is caused by an unavoidable but never-forgotten ducking. If a horse jumps every sort of fence but one readily, try mild measures first; these failing, it becomes a questiou of comparison, viz., whether he objects most to the thorns of the bullfinch or the rowels of your spurs. At water, however, a cutting whip (vulgar though its appearance be) has often a more persuasive effect than the spur; besides, while applying it you can " sit tight," and if the nag refuses after all, this may be an object. 
Now turn we to the consideration of pullers, which may be "handfuls" indeed, exhausting themselves as well as their riders with their misplaced zeal. There are pullers with hard mouths, and pullers with light ditto, the latter being the most difficult to manage at the beginning of a run, and the former at the end of it, when their mouths become dead, and they begin to go upon their shoulders. No bit and no bridle can be recommended for any but individuals. I have seen a Bucephalus noseband have a good effect in a few cases, and fail in many. Messrs. Langdon's noseband is a Bucephalus put a good deal lower down than usual. It is apt to pinch the corners of the mouth, between itself and the bridoon, and, while it maddens some horses, deadens the mouths of others, and stops some few.

Most horses are amenable to a gag. One made in a crescent shape, with no joint in the middle, is preferable for many horses, as it is less severe than the common gag-snaffle. But the objection to a gag is that, if used with a curb, you have no bridoon-at least no light one; if two snaffles are used, you have no curb, and under these circumstances most horses put their heads up more than is comfortable or becoming. Major Dwyer's bit is a very powerful instrument, but, unless exactly fitted, more than likely to hurt the horse's nouth. All the bits on this principle which I have seen have been severe ones; of course, with less "port" they would be easier. I have not had an opportunity of seeing one tried on a regular runaway, such animals being luckily not very common; but moderate pullers certainly cannot hold their own against it, and it is to be specially recommended for ewe-necked horses. But when all is said and done, it is the hand that holds the horse, not the 
bit; and there is no bit which will make a muff master of a real "handful." Horses that kick at others, or at hounds, cannot be called "handfuls;" they do not endanger or trouble (very much) the rider. Kicking at other horses is quite incurable, and a quiet horse may be taught the art in one lesson; kicking at hounds is another thing, and may be cured in almost, if not quite, all cases by patience and time. Time is a grand thing - no man should ever be in a hurry with a horseunless he be riding him at water: then, $O$ ingenuous youth, blaze away; keep him going; squeeze him the last three strides; remember that Chandler jumped 39 feet, and that your horse, if he tries, can very likely jump 30! Don't be alarmed if you can help it, as the best actor cannot conceal the unworthy sensation from his steed; and when landed safely, and you hear your nearest and dearest "go flop," don't chuckle too soonnot, in fact, before you are over the next fence; for though your horse cleared the brook and galloped on, he may have ricked his back. After all, is anxiety a. pleasurable sensation? and what pursuit produces it more freely than fox-hunting? 


\section{THE SEASON OF THE YEAR.}

Is old times, in the dark ages of sport, sporting chronicles were few, and sporting writers as inaccurate as they were rare. Consequently it is well to take such accounts as have been handed down to us cum grano. But, putting details aside, one general impression is apt to be left on the mind of the searcher into sporting antiquity, and that is, that individuals gave themselves up to one sport to the exclusion of others. "Venator" was one man, with his own interests; "Pisca" or" another, considering his peculiar pursuit to be perfection; while "Auceps," again, wedded to his own sport, had nothing in common with either of the foregoing. Each had his own season of enjoyment, prolonged as much as possible, and the season of the year to each was, of course, the season best suited to his especial vanity. All this is now changed. Men must do a little of everything. Ere hunting is well over, "Venator" rushes off from his winter quarters, and appears on the bank of a salmon river in the character of "Piscator." Supposing that racing does not engage his attention, it is probable that deerstalking does; and long ere the season of salmon or trout fishing is over, he is busy at another game, shivering in a mist behind a rock, crawling like a serpent in the bed of a burn, to the prejudice alike of his wardrobe and his epidermis, and at the close of the day either in the seventh heaven of ecstacy or the lowest depths of despair ; the question of which it shall be mostly depending on the state of his nerves when within distance of his 
evasive quarry - whether, in short, the power of holding straight remains to him after a rapid journey performed for the most part upon his waistcoat buttons, and enlivened by mental anxiety to match the physical discomfort, or whether the sights of his rifle insist at the critical moment on performing a spirited version of that once popular dance "The Cure." But the 12th of August is at hand, and our sportsman is hard at work with what our American friends would describe as "a scatter gun and smell dawgs," the result being, it is to be hoped, the transmission of many a neatly-packed hamper to friends at a distance. Then the scene changes again as September arrives, for the birds are now so wild, and, in consequence of improved farming, covert so scanty, that, excepting by driving, birds are hardly to be got in comfort after the third week in which their destruction has become legal. Then we come to October, which is, in my humble opinion, the pleasantest month of the year. Partridge shooting is still going on, while it is not forbidden to bowl over an outlying cock pheasant as he rises from a hedgerow. Grayling are worth catching, and cooking too (if there be much difficulty about the first performance, try the "Francis" fly, and hard are your lines if you do not fill your basket), while cub hunting increases in interest every day that the hounds go out. If I am not mistaken, it is that keen observer, Mr. Whyte Melville, who accounts for the fondness of some few people for cub hunting, by the reflection that the pleasures of hope are superior to those of memory-consequently that the very beginning of the season is preferable to the middle or end; and also by the further consideration that the sportsman need not ride over the fences. 
But, after all, the number of people who get up early for cubbing is but small, and all the better for the huntsman that it should be so; the whole performance is naturally a very slow one to anyone who is not immediately concerned in it. The owner of the coverts is delighted to see a good show of cubs, and the master and huntsman to observe the début of their young entry, but there is little to reward anyone else for the exertion of an unusually early turn-out. Our imaginary sportsman, indeed, is still shooting, and will hardly think of hunting, before the end of November. But because cubhunting is a duty, as far as the officials are concerned, it does not follow that it is properly performed, any more than any other duty. There was an amount of truth that is rather melancholy in the remarks of a correspondent of the Field some time ago.* That time and money should be spent in an endeavour to show bad sport sounds hardly credible; but really it is often the case that this happens, though not intentionally. It happens simply wherever there is a huntsman who is deficient in sense; and that every huntsman is not a Solomon is a fact needing no demonstration. Whether hounds are to hunt a fox steadily through all opposing difficulties, and account for him at last, or to lose him in fifteen minutes, is, bar accidents, an affair of treatment and training. Many men seem to consider that a pack of hounds is a machine that will hunt the line of the fox as an engine will progress along a line of rails whence once startedthat they may be shunted, so to speak, by being lifted and started on the line again, ready to go along it as smoothly as ever. They forget that hounds are dogs -that, mutatis mutandis, the same rules apply to 
them that apply to retrievers, and that they are equally to be made or marred by injudicious treatment. Is it reasonable to expect that hounds who are always going to holloas should trouble themselves much at a check? Would a retriever persevere in snuffling about dry turnips, if the "runner" was constantly pointed out to him? But on the other hand, as it is the nature of the dog to hunt, if he finds that he, and not his master, is going to do the active part of the pursuit, he will devote all his energies to the business in hand, whatever he bewhether a foxhound in covert or the open, a retriever in a field of mangold, or a schoolboy's terrier hunting a water hen round a pond.

Take another instance. The orthodox greylound expects to have his game found for him; ask him to draw for a hare, and you will be disappointed. But he keeps an uncommonly sharp eye upon the beaters; he knows they will find the hare, and he is ready to do his part. But give this well-meaning dog to a poacher, or take him constant walks with yourself, and don't interfere with him at all : you will find that he not ouly looks out for himself, but that he will soon learn to investigate likely-looking bits of covert for himself, and in the majority of cases to use his nose in so doing. Why then, in the name of common sense, should it be wanting too much if we expect every pack of hounds to put down their noses and hunt? That they do not do so is the fault of the huntsmen. Many have absurd notions about being quick or slow, forgetting altogether the proverb of "more haste, less speed." Before the hounds have made their own cast at a check, the huntsman makes his, which may be right or not: but next time, especially if the cast were right, the hounds look for him naturally. 
When I hear a huntsman constantly complaining of a lack of scent, I usually think that something besides scent is wanting. And after all, with a burning scent any hounds will run hard, without a huntsman at all, if the scent be really first-class; but it is the killing a fox on a bad-scenting day that is the test of huntsman and hounds.

No doubt the present system of farming is not favourable to scent. Draining is in many places overdone, so that a dry summer produces an outcry about want of keep for stock, and a fine week in March makes the fallow in most countries as dusty as the desert of Sahara. How do we meet this deterioration of scent? Common sense would reply, by getting hounds with increased hunting powers. But what is the fact? Why, that we are actually encouraging them, year by year, to have less; A great deal of nonsense is talked about fast and slow hounds. I am no friend of the old Towlers; but surely most hounds of the present day (I may almost say all) are well bred enough to go, with a good scent, fast enough for any horses. It is the keeping on going that stops the horses. Bluecap and Wanton themselves would be no further from the horses than the slowest old blue mottles if they had overrun the scent and were casting about to recover it. It is going steadily on that reaches a given point in quick time-not flying for five minutes, and checking for ten. What does it matter how fast hounds go on a scent, if they are off it every three fields from over-running? No, all hounds, in condition to go, can go fast enough if they keep on going; and if anyone doubts the fact, let him, if he can, persuade a master of harriers to run a drag straight for four miles. Let him take his best horse, and say at the end whether he 
had a fast gallop. The difficulty would be to find the accommodating master of "jelly dogs," whose pets would not be worth much for some time after such a performance-the timid hare would have the best of them for some little time. Of course, I do not mean by this that harriers could kill a fox (though such a thing as that has happened); but that, if harriers running a drag can go fast enough for any horse in reason, slow foxhounds, with a scent that enables them to keep going, can do the same. And, indeed, there cannot be very much difference in the individual speed of foxhounds. Of course, in a woodland country a hound who is slow from age can go on hunting longer than he could in the Shires; but that does not prove that the young hounds of the provincial pack could not go across grass with a good scent as fast as a corresponding number taken from the Quorn or Pytchley kennels. The slowest hound in view is often the fastest on a scent; wherefore, what I am endeavouring to show is, that it is the steady line hunters, who keep pegging away and never leaving it, that kill the fox, and make the customers look anxiously for their second horses-not the flyers who go like a flash of lightning for a mile, then put up their heads and are lifted for a mile, and then give up their fox and try for another!

So much for the hounds themselves. Now a word about the men. The passion for being quick is the prevailing fault of most servants at the present time. The huntsman not only makes his cast too soon, but frequently does not give time to the pack to try while he is casting them. Who has not seen a swell huntsman casting at the rate of ten miles an hour round a field, with an equally swell whip rating and flogging 
behind him? How can hounds, under such circumstances, put their noses down. Many foxes, I am persuaded, are lost when the huntsman's cast has been right, by the hounds having been hurried over the line without time being allowed them to own it. And I have often seen a sapient whip flog a hound on who showed an inclination to stop and show a line. What his idea (if he had any) was I cannot say. Possibly he thought, if he thought at all, that the place for hounds during a cast was close at the heels of the huntsman's horse; or again, he might have had a notion that all hounds' noses are alike, and that if Concord, Countess, and Caroline have passed over a spot of ground without noticing that the fox had been there, Dorimont or Driver have no right to impugn their decision by seeing for themselves. Yet I, and I presume others as well, have seen every hound but one or two pass a place in a cast, where the one or two have eventually proclaimed a discovery, the profits of which their more hasty comrades were only too glad to share with them.

If a cast is to be made, the huntsman should make the ground good every yard he goes. And a word to the whip. When the huntsman blows his horn, it is his clear duty to put the hounds to him, and quickly, but yet to exercise a little discretion, and not to nearly "cut in two" old Solomon, with a stern request to "get on hangin' about," because that elderly sage has a notion that, with the combination of his nose and brains, he has discovered the line of the fox, opposed though his opinion be to that of the huntsman-who, however, uses the last-named organ alone, and not the first, in the chase. Some men have the talent of making dogs fond of them, others not. I have seen many packs who never 
seemed to be going to the huntsman, but always from the whip. This is clearly wrong, and sport with such an establishment will be rather the result of good luck than good guidance. Another favourite excuse for bad sport is that the hounds are pressed upon. Now, in most cases, this is the master's look-out. If he does his duty (of course tempering the fortiter in re with the suaviter in modo), the field will usually do theirs. But the office of M. F. H., and the pains and pleasures attended thereupon, is not a subject to be lightly entered upon.

Judging from many letters in the sporting papers on the subject of hunting, it would appear that I am not the only person who takes exception at the too common way in which hounds are handled in the field. This is decidedly a case in which, as the proverb says, "lookers-on see most of the game," being less likely to be prejudiced than persons directly connected with any establishment that may be undergoing criticism. But there are many causes which militate against good sport with foxhounds besides the want of science on the part of the huntsman. The "raw material," for one thing, is deteriorated-the fox himself is not the animal which he was in the days of the great Meynell. Times are changed, the face of the country is very much altered, and the character of every wild animal has to be accommodated to the existing order of things. Without entering on the rexed question of foxes versus pheasants, I may say that the mania for slaughtering half-tame game is the principal enemy with which a master of hounds has to contend. Some owners of coverts will not have them drawn until shooting is over; some allow the hounds to come, but do not find them a fox, or at all events a fox worth having; while others, 
and these perhaps the most honest of the three classes, simply say the hounds shall not come to them at all. Every man has (at present, for it is hard to say what we are coming to) an indisputable right to do what he likes with his own; and, as foxhunting is a sport which exists ouly on sufferance, and pheasant shooting is one which is protected by law, it is easy to see which amusement would go to the wall if there were a question of either doing so. But this is not the question at issue, and it is only alluded to in explanation of the altered character of bold Reynard.

The excessive preservation of game leads to the unfair destruction of foxes-of good foxes-and to the replacing of them by bad ones. There are, no doubt, more good foxes about than it is generally supposed that there are. If a fox be lost after a pursuit of fifteen minutes, it is impossible to speak decidedly of his qualities. It is obvious that any remarks upon a fox's "goodness" must be pure speculation, if made before the animal is accounted for. If he be killed in ten minutes, it is clear that he is a "bad" one, or that circumstances were against him at all events; if he be marked to ground ten miles off the place where he was found, it is equally plain that he is a good one. But, though there are probably some good foxes left, and, as I have said, more of them perhaps than most people think, there are, beyond all doubt, a great many bad ones; and it would be next door to a miracle if there were not, as long as the plan of turning down foxes is followed to the extent that in many countries it is. It is a custom that causes many evils - not the least, perhaps, being the probability of a litter turned down in one country having been stolen from a neighbouring one. Nay, more, such a thing has 
been heard of as for a master to purchase cubs originally stolen out of his own country. They are turned down, but how often they are never heard of again, or only found once in cub hunting. Where every fair play is allowed to them, the latter misfortune is a very common one. They live in clover through the summer in a snug gorse, and are well fed with no trouble of their owu. Consequently they stay there as long as the residence is made pleasant to them. But when they have been once disturbed and horrified by the death of a relativeespecially if the unpardonable error of breaking him up in or close to the covert has been committed-it begins to occur to them that the locality is an objectionable one, and that there are many reasons against remaining there, while hardly any exist in favour of a continued residence in a spot which has been proved to be dangerous. It is not their home, they were not bred there, and what pleasant associations are connected with it have been done away with. They know the covert as a place where hounds come, and it has no attraction to counterbalance this ugly fact. Consequently they more, and lie out, exposed to the several dangers of guns, sheep dogs, rabbit traps, and greyhounds. So, whether they survive or not, it is probable that they are not found-at any rate, when they are wanted-by the hounds. If the best happens that can be expected, and they are at their posts when required, what can turned-down foxes be reasonably expected to do? They have never had any occasion to roam far from home, so they know no country, and probably run rings over what limited area of ground they are acquainted with, showing almost less sport than a good bagman, who would probably go on down wind as long as he could pretty straight, until his fate was 
decided one way or the other. So much for turning foxes down in a gorse or outlying covert. When they are turned down in a woodland, the chances of seeing them again are increased, though even there they are likely to make a home of some unsuspected and inac- : cessible rabbit-hole or drain, and live there unmolested, until by some chance one of them is run to ground there -a thing that may not happen the whole season through. In any cases foxes must survive a spring and its dissipations before they are likely to be well acquainted with the extent of country which is desirable for an animal to know who has to provide a day's amusement for hundreds of larger animals than himself, and, if possible, at the expense of his own life.

We have here reasons enough in all conscience why good sport should be rare. With bad foxes, flashy hounds, and wild huntsmen, what can be expected? And there are yet plenty of others. Want of savoir faire on the part of the master is as telling as it is common. A master of hounds requires to be possessed of most of the qualities of a great general, with certain additions, such as pleasant manners, which are not indispensable to the wearer of the cocked hat. He must arrange the plan of operations for each day-where to draw, where to go if the first covert be blank, where to go for an afternoon fox, \&c., instead of losing time holding councils of war during the day, when time is of value. And, on the other hand, he is so far absolute that he can change the programme at a moment's notice, if circumstances arise to make an alteration desirable. $\mathrm{He}$ is accountable to no man for his actions in the field; but at the same time he should temper decision with consideration. He should hunt his country fairly, taking 
rough and smooth together, and not shirk going to unpopular places. Foxes vanish occasionally from coverts where the hounds never come. Above all things, he should be punctual; he has no right to keep his field waiting, even if he has not a subscription. He should, above all things, remember that it is to the farmers that he is indebted for walks for his hounds, and land to ride over, and that, though hunting is not a bad thing for agriculture, yet turnips, seeds, and in wet weather wheat, are not improved by being ridden over; also, that it is not pleasant to have to send into the next parish but one after stock which has wandered away through gates left open, or gaps made by the followers of the pack. These inconveniences farmers put up with uncomplainingly every hunting day in the year, and they deserve some acknowledgment and thanks. A wise M.F.H. will buy horses in his country as much as he can; it must indeed be an unpromising land where the farmers do not breed something oecasionally good enough to carry a whip, at all events-though, by the way, they often spoil their own sales.

How many masters are possessed even of the qualities above mentioned? Many of them are not even keen sportsmen. Men take hounds for all manner of reasons, besides being fond of the sport, or knowing anything about it. Some do so to achieve social distinction; others to obtain political consideration; others, again, to live, if possible, out of a subscription. The last variety of master is the natural sequel to either of the first two sorts, who, when their object is achieved, have no further interest in their hounds : hence countries are constantly changing hands, men cease to be masters before they have had time to learn their work, countries go begging, 
and the itinerant variety of subscription master increases and multiplies. Bad sport is the inevitable result. On the other hand, there are establishments where everything is as it should be; but these are the exceptions.

Time goes on surely, and not particularly slowly. Hounds and foxes ought by the latter end of October to have learned their lessons, and happy is the M.F.H. who, having killed a sufficiency of cubs to blood his hounds, has a good show of foxes still remaining. I have heard discussions as to whether "blood," as the killing and eating of the fox is elegantly termed, was an indispensable necessary to the due performance of hounds' work in the field. I cannot myself see how there can be two opinions about it. Hounds who are accustomed to losing their foxes must expect to do so; they will never persevere heartily in what they consider a losing game, and in this respect they are like all other dogs Pointers do not tear their game to pieces; at all events, I think I can guess what would be "Idstone's" opinion of one that did so: but they must have game killed to themmust see that the partridge has not "bested" them. Seeing the bird fall and be bagged is to them what tearing and eating the fox is to the foxhound. Eating the fox is no doubt an acquired habit. Some houndscapital hunters-will never attempt to break up anything, though they will attack and kill the fox if they get the chance. What was the origin of eating the fox is beyond my knowledge. It is certainly the most convenient way of disposing of the worthless carcase, which while alive was so valuable, and it makes a spirited finale, besides affording unlimited delight and merriment to all rustic beholders of the scene. I have known masters of harriers let their hunds break up their hares, with the notion that 
it made them more fierce in pursuit; but a hunted hare is usually considered too valuable an article to be so treated. If each and every hound in the pack knows that the object of pursuit has been caught and killed by them, they are cheerful enough without absolutely devouring the fallen foe. Staghounds rarely get blood, yet they are fond enough of their pursuit, and they will kill the deer if they can; but they are quite satisfied to see him produced, as he usually is at the end of the run, with a rope round his neck and an official on each side of him. Staghounds are but foxhounds, after all. They are more highly trained in one way, as they are taught to stop, which foxhounds are not. That the latter could be taught to do so there is no donbt, but their dash and "drive" would suffer, and the fox would benefit. Staghounds may go a dusting pace, and get along quicker with their stag than foxhounds with their fox, and yet be totally wanting in the dash and continual perseverance in driving the scent forward, which is the characteristic of the foxhound. Their work is much easier, they have no drawing for their game, the scent is almost invariably good, and they know that coming up with the unantlered monarch sooner or later is almost a certainty. If the stag ran them out of scent three times out of four, the hounds after the first burst would be as disinclined to puzzle on as a pack of fox or hare hounds who are habitually beaten by their game. They don't care so much about eating him, but like to know that he is theirs. Otter hounds do not eat their prey, but they like to kill him, and there is no scent which hounds enjoy more than his. Riotous hounds, by the way, will usually eat a hare or rabbit; but they are pot-hunters.

How little foxhounds care for eating a fox is patent to 
everyone with eyes, who has seen a fox who has not been that minute killed given to hounds. They will hardly look at him. More than once I have seen one fox chopped just as another went away, and the dead fox brought on by a whipper-in, and eventually given to the hounds after they had lost the other; but they have in each case declined to eat him. Yet, if they kill their fox in a thick and inaccessible place, if huntsman or whip does not look sharp in getting to them, very little fox will he find. This is partly, at all events, education ; for if a huntsman gives a fox to the hounds in a slack and careless manner, they will deal with him in a similar spirit, hardly tearing him to pieces, and they will probably hunt their fox in a style that will save the huntsman the trouble of giving them many foxes to break up. The closing scene should be above all others one of spirit; if hounds are accustomed to leave off winners, they will ignore the possibility of being beaten, and persevere till success crowns their efforts. When hounds are not in earnest, how can success be reasonably expected? When they are so, and backed by a huntsman with a head on his shoulders, not a mere cap-block, it is odds against bold Reynard. Hounds who have marked their fox to ground are pretty well satisfied; they will go home cheerily, as knowing that they have done their "possible." If he always beat them by going to ground, it would be another thing. No one can be more heartily opposed to the murder of foxes than I am, but to keep hounds in good heart they must kill; and I should say a fox for every three times that a pack goes out is a fair allowance, and a fox per week, supposing each pack to hunt two days in the week, not a bit too liberal a one. A fox a month is the common average with some packs that I 
could name-after Christmas, at all events. Of course, the more numerous foxes are, the harder it is to kill them fairly, as hounds seem often to take a pleasure in changing, the scent of the fresh fox being usually better than that of the run one, besides the hounds being at first closer to the former. The hare-hunter has an advantage here, as his wise little dogs prefer the hunted hare to a fresh one, unless they view the last named, and for reasons the opposite to those which causes the foxhound's mistake. The scent of the timid one generally improves on acquaintance, until she gets quite beat, and then I fancy the scent of all hunted animals decreases. That of a fox certainly does in many instances.

I once saw a curious and interesting instance of the fidelity of the harrier to his first love. After running one hare for some fifteen minutes, the hounds proceeded through a turnip field, and chopped a frosh hare, whose form the hunted one must have run exactly over. The little hounds hardly stopped; they evidently knew the state of the case, and in less than half a minute were towling along after the original "Sarah," whom they eventually caught triumphantly!

The better the hounds and the other accessories of sport which have been considered above, the harder will it be to see that sport in a satisfactory manner ; and this consideration brings us to the stable-an edifice of no small importance at this "season of the year," both to officials and amateurs. 


\section{THE STABLE IN A FROST.}

A VISIT to one's stable is a pleasant thing on a mild winter's evening, with perhaps a light rain beginning to fall, a promise alike of a wet night and a fine day for the morrow's fixture. Under these circumstances there is no small satisfaction to be obtained (the pleasures of Hope being confessedly superior to those of Memory) from the inspection of the favourite, on the back of which, by the kind permission of the stud groom, one contemplates a performance on the morrow-to look at him as he presents his well-squared tail to view, his head being half concealed in the manger, and to speculate, hoping the while for the best, as to whether a sufficient proportion of intimate friends will have the opportunity of regarding him from the same point of view next day.

Few places look more cosy than a well-littered loose box at such a time, the very bloom on the horse's quarters suggesting notions of warmth and comfort, besides condition; ditto the demeanour of the stable cat, who sits perfectly still in a corner, or even on the back of the flier, with the grave air of one who, perfectly snug and happy himself, can yet give an occasional pitying thought to the lot of less favoured creatures. But with what different feelings, in a frost, does the owner of a stud slip and skate across the yard to pay a visit of duty to his animals! Buckets full of ice are only cheerful objects when they are seen in the company of champagne bottles; and the other inanimate furniture of a stable yard is 
never calculated to give a "sensation" one way or the other. Nor are half-frozen sparrows lively-looking figures; and the robin himself, a sporting little bird, whose sympathies are ever with hunting weather, at most only sets the example of making the best of a bad bargain, as, sitting on the top of the frozen pump, with feathers puffed out to their full extent, he "favours the company" with his sweet but plaintive little song. Arrived at the stable, we seat ourselves on the corn-bin, and give ourselves over to tobacco smoke and meditation - the latter not of the merriest description. Our seat itself reminds us of the price of forage-an unpleasant recollection, which carries the mind onward to thoughts of the blacksmith's bill, then the saddler's, then again the weekly nuisance of helper's wages; and heterodox thoughts are usually likely to creep into even the well regulated mind, to the effect of whether a similar outlay might not afford amusement equal in quality to foxhunting, and less dependent on weather; and this train of thought leads to "crabbing" the noble science itself.

The "deterioration of our saddle horses" here occupies our mind for a space. We of course consider our present stud to be as useful a lot as other people's, but too well we know their shortcomings, and have only too lively a recollection of the trouble and cost involved in getting them together; also of the number of brutes we first bought, and then had almost to give away, before our present moderate establishment was complete-for this is supposed to be one in which no cats are tolerated who neglect the capture of mice. And the more we think on the subject, the more are we convinced that this deterioration is an accomplished fact. Where are the shortlegged, weight-carrying hunters of former days, who 
combined strength and breeding? Where, again, is the thorough-bred hunter who is honestly up to a greater weight than twelve stone-that is, to carry it, and go on doing so, coming out in his turn?

Out of a given number of hunters, picked at random out of good studs, what is the percentage of those who do not "hit themselves" somewhere? And what fault is much worse than this? How many are there equal to the old-fashioned work of going fourteen miles to covert, hunting, and returning the same distance three days a fortnight?-this, mind, in a good country. There are some woodland and such like districts where the actual hunting is the easiest part of the day's work to the horses of the field. Kennel horses have a day's work each hunting day, whether the meet be at Waterloo Gorse or on the side of an unpronounceably-named Welsh hill; but they have shorter distances to covert than the others, and always, where it is feasible, draw homewards. The hunter of the present days goes to covert by rail as often as not when the distance exceeds tcn miles, and the same accommodating conveyance not unfrequently takes him home again; and even if he does go by road, the roads of the present day are rather more easily travelled over than those of fifty years since. Shoeing is improved; but are not unsound feet as common as ever, and more so? The fact is, as has been remarked already by a talented sporting author, that we have a breed of horses selected for weediness and unsoundness. Farmers, and others who should know better, use the cheapest sire, who is also the most unsound. Like begets like, and screws are sown broadcast. Q. E. D. But is it only our hunters that have deteriorated? How about foxes? How many runs of twelve miles from point to point are there in any 
country in the course of a season? Can such a performance be expected of a turned-down animal, fed with rabbits half through the summer, and who has never had occasion to go more than two miles from home for refreshment or dissipation?

The hounds, too; but here, if a friend be present, we are interrupted-" "They, at all events, have improved." To which we make answer that we are not quite so sure of that. In looks, no doubt; this, indeed, is almost overdone. Are perfectly straight forelegs the best for years of hard work? Do they never show the work by standing over, like a groggy horse? Is not muteness a fault? and is it uncommon? and do the hounds of the present day puzzle out a bad scent like those of our forefathers? Here we are corrected again-" No one wants them to." But still a long slow-hunting run on a bad scenting day is at least as good fun, even to the hard men, as three or four scurries of three fields each after different foxes; and with a good scent all hounds go fast enough. And the process of agriculture is unfavourable to hunting. They talk of a reaction in the matter of arable land, and of grass being laid down, and we hope it may be so; but the effect of draining is seen in the whirlwinds of March dust, which make hunting in that month usually a delusion and a snare. Well, at all events hunting has been improved for ladies, if not for men. The invention of the third pummel is one of the most useful of modern days, and though a horse may roll over his fair burden he cannot possibly drag her by her stirrup, if she be provided with the admirable safety stirrup of Mr. Davis, nor with a third pummel can he dislodge her from the saddle. As far as men are concerned, however, we appear to have demonstrated that 
hunting is gone to the bad, and is a sport no longer worth pursuing. But here come the men to stables. "What do you say, John? Raining? and the wind gone round to the south ?" We will see what we think of hunting, three days hence, before condemning it irrevocably. 


\section{NEW BROOMS.}

"New Brooms sweep clean," says the proverb, but proverbs are not infallible, and it would be more correct to say that new brooms start on their career with the intention of sweeping clean. It is not at all certain that they will succeed in so doing.

At present (A.D. 1869) we have "new brooms" everywhere, and the political, social, agricultural, and sporting floors may equally expect a thorough polishing. The schoolmaster is abroad, and no mistake; everything is capable of improvement; no institution is to be left unaltered-no matter whether it may hitherto have succeeded or not, it must do better in future. Is not every innovation a reform (in the eyes of some people, at all events)? and is not this an age of progress? Retrenchment and increased efficiency are the order of the day, and there is no time to waste in the untying of knotty points. Out with the knife and cut them! Has there been a difficulty in finding cornets for our cavalry? What is more simple than to obviate this, by saying that in future we shall only require half the number? We can do without them; at all events, Mr. Cardwell will try the experiment. Our colonies take a great deal of guarding, and the process is expensive. How are we to retrench here? Nothing more simple-let them guard themselves. We can by these means reduce our army considerably, and depend for home safety upon the volunteers. But the people's money must not be wasted upon 
volunteer forces ; the capitation grant cannot be increased. Supposing that under these circumstances the citizen army declines to perform? Never mind, it will all come right in the end; and meanwhile, look at the money saved. The people's pens, even, are no longer to be wasted in Downing-street, and a limit is to be put to the consumption of paper, ink, and, it is to be hoped, red tape. Ireland is to be made a peaceful, contented, commercial, and agricultural land; the sport of landlord and agent shooting is to cease once and for ever; all evils are to be cured by the panacea of disestablishment. What happy days we live in! Everything is about to be made perfect. Everything will be reduced, excepting the skirts of our coryphées : they, like the franchise, will be extended. That terrible scourge, the rabbit, shall no longer rob the farmer in broad daylight of his pasture, his crops, and his fences. Down with the monster! exterminate him! He devours the people's food, and it is convenient to forget that the people devour him, with some appetite too. Passing from the farm to the racecourse, we meet again with the spirit of reform, and wish it every success. In fact, here reform is practicable as well as desirable. If Sir Joseph Hawley succeeds in producing here and there a sound six-year-old racehorse, he will have conferred a benefit upon his country, which ought to command the gratitude of all classes.

The term of "new broom," is, however, hardly to be applied to him. If these articles had performed half their promises, no stable reform would be needed. We were confidently assured some ten years ago that badtempered and vicious horses were a thing of the past; that there was only one way of breaking, or training, a colt, and that Mr. Rarey was, as it were, the prophet of 
this faith. How the public paid its money! How it invested money in leathern straps and instructions for use. How assiduously a few practised the art, and how unanimously and cheerfully the many have forgotten it! Who begins breaking in a colt now on the Rarey system? Echo answers "Who!" That broom had but a limited amount of wear in it.

Take up any sporting newspaper of a bygone date, not of necessity a very remote one, and look at the advertisements. Here are new brooms with a vengeance. Take up one of to-day, and you see that they are supplanted by a fresh series of infallibilities, that will in their turn be speedily forgotten. One undertakes to cure all lameness, another to stop pullers and runaway horses, a third to keep their bodies in constant and unfailing health; but, in spite of all, horses still go lame, still run away (and, indeed, if a horse really means that performance, he will succeed in it-luckily, they seldom mean it in earnest), and still lose condition.

On consideration I think that the greater number of new brooms that have been introduced into the stable have been intended to sweep away from veterinary pockets the profits consequent on foot lameness in the horse. What scores of schemes have been invented, discussed, praised, proved worthless, and forgotten, for preserving in its natural state, or an approach to it, the foot of the horse by shoeing! Not so very long ago there was even a discussion as to whether shoes were necessary at all. A ride on the road on a bare-footed horse convinced those who tried it that that plan would not answer. No end of plans have been brought forward and forgotten for shoeing all sorts of horses, but the common way has hitherto held its own. The notion of 
bringing the frog to the ground was a favourite one some forty years ago. Professor Coleman roundly asserted that the frog must have pressure or be diseased. He invented several sorts of shoes, with the intention of causing the frog to touch something, and obtained patents for them. The one which appears to have had the best trial was the thin heeled shoe. This, being thickest at the toe, brought the frog on to the ground. It also set the weight of the horse on the heel, and strained no end of back sinews. So it passed away. About the same time jointed shoes for the prevention of contraction were tried, and left off, as the stress of the nails on the hoof was too great. Other systems from time to time have cropped up, and returned to their native obscurity. Meanwhile our horses have gone on, some well, some ill, and some indifferently. Horses with sound feet shod on our present plan have remained sound to the last day of their lives; those with diseased feet have been screwed up; and so I imagine it will be to the end of the chapter.

However, the shoes may be improved. That a shoe can lame a horse when it does not suit him, or when it is unskilfully put on, no one will be found to deny; but the number of horses so lamed is something infinitesimally small. Hot stables, bad stable management, injudicious food, and the pace, lame most horses who are lame in the feet. Cart horses are, it is true, very subject to side bones and ring bone, and this I attribute in a great measure to the manner in which they are shod with high calkins; but they are also seldom much attended to as regards their general health, and so are more liable to disease in the feet than they need be.

If our present system of shoeing light horses were so 
very faulty, hack and harness horses would go lame, as indeed they often do, but our hunters would be free from foot lameness. Their work being entirely on the soft, their shoe does not prevent the sole and frog of the foot from performing each its proper functions. But they are lame and groggy as often as other horses ; in fact, many valuable hunters, whom no money could buy, would, if run out on stones, very often be found to go in a manner rather surprising to the owner if he were present. The fact is that hunters seldom work on hard ground at all. They exercise on the soft, they go to coverts along the sides of the road, and come home the same way; but many of them go wrong in their feet for all that. Hot stables and high keep are in great measure accountable for this; and very often hereditary unsoundness: e.g., the stock of Belzoni, that prince of hunter sires, sooner or later went lame-at least, a great percentage of them, and all, they say, in the same foot-and this is not a solitary instance. Sir Joseph Hawley's reform bill may mend matters here.

It being an undoubted fact that foot lameness is not an uncommon thing in England, Mr. Goodenough comes to the rescue, with something like a "new broom." His is the only "humane shoe;" his the system which claims for itself every possible novelty-infallibility amongst the rest! Let us consider the advertisement: "As the weight of the horse is mainly sustained by the crust of the hoof, so this shoe is designed to arm that crust, and preserve, though calked, the true level position of the foot." The old shoe is designed to do all this, and, being uncalked, has perhaps a better chance of doing it. "The level calking prevents that straining and waste of muscular power cousequent upon continual slipping and 
rocking of the foot." Again, "The concavity of the shoe is a safeguard against halting (?) and picking up stones." This can hardly be correct; for, unless the shoe be flush with the sole of the foot (and this it cannot be while the calkins exist) it will pick up any stone that happens to fit it, just like the old one.

I do not wish to take up space by saying again what has been said by other correspondents, further than to agree with one writer, who considered that all the novelty of the Goodenough shoe is borrowed from the Charlier, and to correct Mr. Broad's statement in the Field of Feb. 13, that Messrs. Mavor's patent shoe is as nearly as possible identical with the Charlier. The principles of the two are quite different. Mr. Mavor's shoe has been found useless, and abandoned accordingly - that is correct enough; but the Charlier shoe has yet to be tried in this country.

The great advantage claimed by the admirers of the Goodenough-who consist at present only of American omnibus owners, and Mr. Lethbridge of England (at least, I gather so from the published certificates)-is that this shoe allows the frog and sole to touch the ground. This, by the way, it cannot do with and without the calkins; so either the calks are useless, or the shoe will have to be renewed every twelfth day. Now, the Charlier shoe is from the first flush with the sole, the horse's foot being in the condition nearest approaching to nature of any hitherto arrived at. Much stress has been laid on the lightness of the Goodenough shoe, but the Charlier is lighter still. In the old system, on hard ground, of course the shoe sustains all the weight, and all the wear and tear. The Charlier shoe cannot possibly pick up a stone, nor can it snowball to any great 
extent, in the foot; in fact, it has the advantages claimed for the Goodenough shoe without its drawbacks. Any smith can make a Charlier shoe, and the putting it on is simplicity itself. It has been tried with success on a few cavalry horses, and I have lately seen the shoe in use in a stiff bank and ditch country, where it answered to the satisfaction of those concerned. Granting it to be no better than the common plan, if it be no worse in other respects the extreme lightness is a great point gained. I cannot fancy that the Goodenough shoe is so very much lighter than a light hunting shoe of the English fashion. But the weight of these latter varies a good deal.

Surely, among the readers of the Field, some one has tried the Goodenough shoe besides Mr. Lethbridge. He conferred a boon on the public by stating his experience, and anyone who, having tried the system, will follow his example, will, at the expense of but little trouble, and the wear and tear of pen and ink hardly enough to alarm even Mr. Greg, assist in throwing light on a subject now confessedly veiled in obscurity, viz., the horse's foot, and, in these days of reduction, reducing our veterinary bills, by checking the "deterioration of our saddle horses." 


\section{HOW SPORT IS SPOILED.}

Trw spoiling of sport is a performance only too easy, whether intentionally or otherwise, and whatever the sport may consist off. Sport social, political, or of the field, may be ruined; the court, the camp, and the grove are none of them exempt from casualties.

But it is not of the sport which may be enjoyed or marred in the political arena or the gilded saloon that I would speak. Everyone knows how persistently the wrong thing is said and done in these localities by people who ought to know better, but who don't know and won't learn. It is on the mischief done to the pursuit of the fox by ignorance, officiousness, selfishness, \&c., that I frame my discourse; and really, when the difficulties that surround a master of hounds are considered, not only is it a matter of surprise that any man should be found with sufficient perseverance to enable him to fill the arduous post of M.F.H. for more than one season; but, given the man, it is a still more wonderful matter how he can, in the face of so many obstacles as beset his path, bring his hounds to a covert side at all, much less find or kill a fox. Some of the principle antidotes to sport are the following:

First come landowners who don't care about hunting, and are not sufficiently unselfish to take any trouble in furtherance of a pursuit in which they don't join. They may keop their gates locked, or decline to allow drains or earths to be stopped on their ground, and discourage 
their tenants from "walking" puppies, and in many other almost imperceptible ways do a good deal of mischief, even without being game preservers. This word brings to one's mind that most influential class of men, gamekeepers. In their hands rests in great measure the showing of sport, inasmuch as the existence of the "raw material" is almost entirely an affair of their pleasure and good will. There are keepers doubtless who are really and unfeignedly glad to see their coverts drawn with success; but I much fear that they are the exception, and that their good feeling is in many cases the result of their masters' known proclivities, combined with proper management on the part of the master of the hounds. I do not believe that a keeper exists who, all considerations but his own tastes apart, really likes or admires a fox. Why should he? And, on second thoughts, why should he not do so? What more convenient scapegoat is there in existence than bold Reynard? To an inefficient keeper he is really a friend. "What has become of all the hares ?" is a question from the master that has its answer ready cut and dried: "Those foxes took every leveret in the summer." "How is it," demands the dissatisfied owner of a light bag, "that we only killed so many or so few pheasants today?" "Well, sir, the number of sitting hens that were taken by the foxes is something alarming." Here follow statistical figures, more or less accurate. Yet the majority of keepers have no gratitude towards the useful little animal that bears so much responsibility, but, on the contrary, instead of "speaking well of the bridge that carries them over," they are but too ready to kick down the ladder that has raised them.

Of course the amount of mischief that an ill-disposed 
keeper can do is immense. He can slay the vixen, and leave the cubs to starve. He can destroy the cubs themselves, leaving the parents, or sweep away the whole family at once. Or he may allow the litter to be once found in cub-hunting time, and then dispose of them, with the ready excuse when the covert is blank that the cubs were there, but have shifted their quarters after being disturbed by the hounds. If the owner of a covert does not care about having foxes, the keeper is hardly likely to. No man can serve two masters, and in such a case the M.F.H. and his own master have both to be pleased, and it does not require a conjuror to predict whose tastes will take precedence. In fact, in talking about foxes to a keeper whose master is really very fond of covert shooting, I attach exactly the same amount of credence to his statements that I should to those of a young lady who chooses to tell her present admirer of her past " experiences" - with the one trifling difference, that I should acquit the damsel of intentional misstatement; not so the guardian of the preserves. Some coverts are so popular with foxes that to them they will resort, whatever treatment they may meet with; and the number of foxes that may be killed in such places by an evil-minded man would seem almost incredible to the uninitiated in such matters. And these men are seldom caught out, as the coverts are only blank when they are drawn unexpectedly. Fair warning being given, a fox will be forthcoming, and a wild fox too-this being only a question of time to allow him to take up his quarters. To turn down a bagman is perhaps the greatest insult that can be offered to a foxhunting establishment, and it is a trick, generally speaking, easy of detection, because the victim, after running in a suspicious manner, is almost sure to be 
caught, when the hounds tell their opinion of the whole thing pretty unmistakably, as they won't eat him, unless they are used to bagmen; then they may not show their disgust quite so openly. But very few packs, it is to be hoped, answer to this description.

I have hunted in countries where the keeper sent in regular-bills-so much for a litter of cubs (their existence, that is), so much for each find, \&c.; and probably, had this black mail been done away with, the finds would have been like angels' visits. A keeper who has shown foxes through a season deserves a recognition of his services at the end of it, as foxes of course do some mischief to game, and there is often further trouble caused by earth-stopping, and so on. Yet it seems more according to the fitness of things that this recognition should be the spontaneous act of the M.F.H. than a right claimed by the keeper; besides, in the first case, the matter will not impossibly receive more attention. There is no doubt that the keepers are the most important class of men in any hunt, but a little diplomacy will do wonders among them.

Next to the keepers come their masters-for really I think in many cases the owner of the coverts plays but a secondary part as far as the preservation of foxes is concerned. He says, "I must have game ;" the M.F.H., "I wish for foxes;" and the keeper provides what he chooses of either or both. Vulpecides are of different degrees. Some, while speaking fairly enough to foxhunters, tell their keepers they don't want too many foxes; others say nothing, but their wishes are understood; whilst others give the order "Kill and destroy." But even the latter don't confess their crime. In fact, I don't think that there exist three men in the United 
Kingdom who, living in a hunting country, would have the face to say openly (say at a dinner table, taking all chances of whether the party was one of sportsmen or not), "I shoot foxes!" The pheasant is the fox's worst foe, and the rage for "newspaper bags" is not the most pleasant trait in our present national character. And I make this remark being personally as fond of shooting as my neighbours, and anything but an admirer of Mr. Peter Taylor, M.P.

However, given the fox and the hounds, friendly owners of coverts, and keepers who treat Reynard fairly (and there are such, though they can hardly be considered a majority), many other ways exist of "spoiling sport. Next in importance to owners of land come occupiers of the same. (This is the present arrangement, but it will ere long be altered, I make no doubt.) Now, no sport can be shown in any country without the hearty co-operation of the farmers thereof; and, luckily, 999 out of every 1000 farmers are sportsmen at heart, if not practically, and consequently the warmest supporters of a hunt. If it were otherwise, hunting would ceasedie a natural (no, an unnatural) death. Nothing but locking gates and wiring fences is required to make any country impassable: very simple indeed all this is. And damage is done by foxhunters, and that to a considerable extent. That the presence of a pack of hounds benefits a country is equally indisputable; horses and stablemen must eat, as well as their masters; and, whether a farmer grows beef or bread, there will be a market for his produce when the population is increased by a neighbouring town being full of hunting gentlemen. Yet the damage done to a field of wheat or turnips by an army of careering horsemen is obvious and visible, and it requires 
a certain amount of philosophy to gaze unmoved upon the same, remembering to console oneself with the reflection that everything consumable fetches a better price in a populous neighbourhood than in an empty one, and that the damage and demand are caused by the same institution. And here I may as well observe that the damage done by foxhunters is not to any great extent the act of those who ride to hounds. It is caused chiefly by muffs, townspeople, retired tradesmen, \&c., who don't know one crop from another, and who pull down a fence instead of jumping it; and in the crack countries by the second horsemen. These last really are mischievous in the extreme: as to shutting a gate or keeping in a furrow, unless for their own convenience, they would as soon think of flying. And it is too much to expect of anyone that he will put up with wilful damage.

A great deal of sport is spoiled by the field. Where the master is energetic and understands his work, he will not allow the fox to he headed by hard riders-who would, if permitted, in their extreme anxiety for a start, creep on to the very spot where a good fox would go from. In the same way he will not allow the covert to be surrounded by people to whom a start is no object. But the plans of the most knowing master may be unavoidably thrown over, in the earliest stage of the day's proceedings. He may collect all the field who are present, on parade as it were, into the desired corner; he may place his whips most artistically; yet how can he prevent Tomkins (who is always late) from coming scuttling up on his hack, just as the fox is on foot, and meeting that well-meaning animal face to face? or how can he see through the black bullinch that conceals Lady Julia Gadabout and her latest admirer from the 
gaze of all eyes excepting that one piercing pair, which should in the general interest be hookwinked? In either case the fox is headed, perhaps chopped. Other misdeeds the field is prone too. Without counting jealousy and riding over hounds, the list of crimes is long. The hard riders are bad enough, but as a rule they are not the earliest offenders. The people who don't ride are specially fond of "cutting off the hounds." For example, a fox goes away from a gorse; a minute or two elapse between his departure and the coming away of the pack; he, like time and tide, waits for no man, and is over half a dozen fields in no time. In the sixth he is viewed by a rustic, who holloas himself hoarse, just at the moment when the hounds take up the scent. Immediately the cunning riders are off up the nearest road to the holloa, and when the hounds get there, on the line, they find between them and their fox some forty horses.

Now, neither the ability nor the desire is given to most packs to hunt steadily through a steaming phalanx of horses, many of whom, as their instinct teaches them, are handy with their heels. There are packs (like Mr. Tailby's for example, or the Pytchley lady pack in Lord Spencer's mastership), whose normal condition (no fault of the last-named master's by the way) it is to be among horses, and they are not much more upset by having horses in front of them than behind or on either side: and such packs will endeavour to work on through the crowd. But even here the fox gains an advantage which his astute nature is quick enough to profit by; while if the hounds are afraid of the horses, as most hounds are, the run is over, or at least it degenerates into that melancholy performance, walking after a fox, without any chance of improving one's acquaintance with him. 
The hard rider's chance of spoiling the fun occurs chiefly at a check. While the huntsman is casting they will keep poking on after him, foiling the ground and distracting the attention of the hounds. Another fault, which ought to be punishable by law, is the habit some men have of sending their second horse to some covert which will be drawn for a second fox. A good fox hears voices and perceives the well-known bouquet of singed horsehair, and begins creeping about the gorse. He peeps out, sees the coast more clear than usual, and is away. On the arrival of the hounds the covert is blank, while a few tongues serve to raise never-to-be-gratified hopes; and the thinking portion of the field, hearing hounds speak and seeing no fox, go away condemning the pack as riotous. "Pack of brutes! got running a rabbit in So-and-so Gorse! wasted half an hour, and then went home" - there being perhaps nothing else to draw. When hounds are at a check on a road, anyone can spoil sport, and, as rule, every one combines in doing it. Without thinking one way or the other of the hounds, A. keeps on, wishing to sell his horse to B.; C. just moves out of range of D.'s horse's heels ; E. wants to ask F. about a servant's character; while G. sees $H$. talking with animation to Miss I. - a proceeding that must be stopped at all hazards. Meanwhile the hounds are miles over the place where their game left the turnpike, and the latter sits down and waits for them, of course!

So much for the field. Now, cannot the master spoil sport? Of course he can, though he doesn't often do it. Disagreeable manners, jealous riding, and, above all, not being possessed of the faculty of remembering people's $\mathrm{n}$ ames, will make a good sportsman unpopular, and so the sport will suffer. Above all things, a master of 
hounds should recollect that "language was given us to conceal our thoughts." He may let out now and again at a detected evil-doer; but even then he must be guided by prudence, remembering that the safest object of attack is the individual who has no friends. Not that a man is to be pitched into merely as being a stranger; for, in these days of peripatetic scribes, said stranger might prove to be a "Special Commissioner," in which case the master's character would be shortly given to the world, as viewed from a point from which neither he nor his friends ever regarded it.

And who else spoils sport in the hunting field? The huntsman frequently, no doubt, owing to the strong objection the fraternity appear to entertain to letting the hounds hunt the fox-but, this not being an essay on catching the animal, I say no more on that subject.

But I am sorry to say, even at the risk of forfeiting my character for politeness, that some sport is spoilt by ladies. Not by the ladies who merely come out hunting, and whom everyone is delighted to see, so long as they can either take care of themselves or have someone with them who is equal to their charge. Ladies are an ornament to the hunting field, as to any other place that they honour with their presence, when they are properly dressed and understand the game they are playing at. Their commonest fault, by the way, is not giving one time to fall; and though, having tried both, as I have stated in a previous chapter, $I$ am in a position to state that it is more pleasant to be jumped on by a countess than by a cotton spinner, still it is preferable to receive the attentions of neither in this way. Also to see a lady get a fall is most unpleasant; even if she be not hurt, the spectators are bound to be alarmed; 
and, again, ladies are more likely to be hurt than men. A loose horse with a side saddle on is as unpleasant a sight as can be seen in the hunting field; and, even if the fair rider be not hurt, is it desirable that she should be seen standing on her head (in any costume), crawling on hands and knees out of a wet ditch, or sitting on a stile, perhaps minus her skirt and half her tresses, waiting for her steed to be brought back to her? Still she does not spoil sport, to speak of. The ladies who do so are ladies in authority, e.g., a cold bow from the wife of the M. F. H., in place of a cheery casual observation, has often caused a wire to remain up which would have been banished at once. Subscriptions have melted away on provocation equally small; coverts are blank which would otherwise have held a fox. "Why," says Jones, " should not I shoot to-day? Certainly the hounds will be here next week; but I don't hunt, and if Mrs. Rattlecover is too fine to know me, what do I gain by losing my sport?" An M. F. H. is bound to be hail fellow well met with everyone who owns a hedgerow in his hunt. His wife need not be this; but, if she chooses, she-and the remark applies to the wife of every public charactermay either diminish or increase the popularity of her lord.

When it is snowing and freezing we have time for reflection on all subjects; and some idle moments may be less profitably employed than in consideration on How sport is spoiled." 


\section{THE END OF THE SEASON.}

Aт the end of the hunting season comes the question ef "What is to be done with the horses?" Either they are to be kept through the summer, and brought out for the next season, after all the advantages which accrue from a really good "summering," or they are to be sold, and their summer keep saved. This last course of proceeding is not an uncommon one, among young horse masters especially. What the advantage of it consists in is not very apparent, unless, as has been suggested, horses are sold at the hammer for ready money, and bought from some dealers on credit. With the exception of this decided advantage, the man who keeps his stud through the summer has "a pull," as it is elegantly termed, over the one who has sold, and bought a fresh lot when hunting recommences, supposing the two studs to have been tolerably good to begin with, or rather tolerably good at the end of the season.

It occasionally happens that a man possesses two or three wholly useless brutes, of which he cannot possibly dispose unless he sacrifices their more valuable stable companions; and this is no doubt often the cause why an entire stud is submitted to public competition.

All that the buyer has to do in such a case is to mind that he does not get hold of the wrong horse, which he is very likely to do unless he either knows the animals personally, or has a reliable friend who is acquainted with their merits and failings. 
But the sale of horses is not the subject about to be discussed, so we will take leave of it, with the remark that hunters are so entirely fancy articles that, whilst indifferent animals belonging to some well-known character often fetch fancy prices at the hammer, other horses, superior in every respect, but the property of a nobody, are almost certain to fetch none but the most moderate sums. It is universally allowed to be a fact, by sportmen in "the shires," that two years' good condition is needful to enable a horse to cross those favoured tracts of country with safety to his rider and satisfaction to himself - that is, supposing the rider to be a "customer." Men who don't ride to hounds may summer their horses in the fields, and yet have them equal to the duties they are required to perform. Not but that the shirker does an immense amount of galloping; but still he must stop to open the gates, pull down the fences, \&c., and has in no case any excuse for distressing his horse. It is far otherwise with the first-flight man, who has not only to live with the hounds, but to prevent, as far as it is in his power, any one of, perhaps, two score of rivals getting any nearer to the pack than he is himself.

The two extremes of hard men and funkers are, when working as it were in concert, the fox's best friends. A fox goes away from a gorse, the hounds get away pretty close to him, the "customers" a trifle closer to him than the hounds. The shirkers dash impetuously along some lane parallel to the line of chase. Eventually bold Reynard wishes to cross this lane; he sees an advancing phalanx. Disliking the looks of them, perhaps fearing that they may be attended by a supernumerary pack of hounds, he alter his plans and his course - is in fact headed. Up come the hounds, with the "hard" division 
in close attendance. They wish to throw up, but selfpreservation is the first law of nature. They cannot stop for their bodies to be reduced to the consistency of jelly by the hoofs of the advancing force of cavalry. They dash on for a field or so without a scent, and stop at last. A cast forward is obviously useless, as the fox has not gone that way; a cast back, where the animal really has gone, is equally futile, the horses being all over it; so, by the combined exertions of Messrs. Funker and Crasher, a good run is spoiled, the fox escapes, and the real authors of the mischief, as they trot amicably along together, agree in pronouncing the huntsman a muff, the master an old woman, and the hounds a lot of useless brutes, fit only to be treated as the poor London street curs were last summer, viz., sold by the ton for manure.* This is another digression though, and unpardonable, as no one wants to think, much less talk, about hunting at this time of year.

By this time most hunters have had a month's rest, which, with the assistance of a mild dose of physic where it is requisite (and this is in forty-nine cases out of every fifty), will have reduced their legs to a condition in which damage done to them by their late labours will be easily detected. I always have found it sound economy to have my horses inspected at the end of the season by a veterinary surgeon. The professional eye will detect injuries which that of the amateur is likely to pass over. Still, if the professional be not accustomed to hunters and the ailments peculiar to them, he will not be able to tell a good hunting groom very much, particularly as the groom knows the constitution, and, at any rate, some of the past history of his horse. There are a number of injuries to * Written in 1869. 
which hunters are specially liable, and which may be very well treated by a groom of ordinary intelligence (by this I do not mean every strapper who fancies that he knows "all about it").

Perhaps one of the most common causes for hunters being laid up is a blow on the leg. Indeed, it is rather a wonder that more horses are not lamed in this way, or that any horse should do a day's hunting without an accident of this description. Bangs and blows are either on the shin or on the sinew. In the former case applications of hot vinegar and water will take out the soreness as quickly as anything. A blow on the shin often leaves its mark in the shape of a permanent bony enlargement, which is a blemish, of course, but not otherwise objectionable, unless it be meddled with under pretence of removing it. Such an attempt is likely to produce most acute lameness. Blows on the sinews are more serious affairs. They may either be caused by the contact of a stake, \&c., or by the opposite foot. A heavy shoe is a very common, indeed the most common, cause of this accident in the case of horses which do not hit themselves habitually. A blow on the sinew may lay a horse up for the season, or he may be lamed by it "on and off" --that is, being sound after one day's work and lame after the next. Whether he has been lame or sound, there will be a certain amount of thickening over the seat of injury at the end of the season. At the end of a month's rest, however, the swelling will be reduced enough for an opinion to be formed concerning the extent of the injury. If this be plainly trifling, cold applications and rest will meet the requirements of the case. If there appear to be any likelihood of a callous enlargement forming, a mild absorbent blister will be useful ; in bad cases firing 
may be needful; but, in any case but the mildest, the opinion of a qualified practitioner will be useful. Grooms are always very fond of using blisters, the stronger the better (not for the horse), and many horses have been ruined by this predilection of theirs.

Next we will consider the subject of curbs. "Springing a curb " is a most annoying accident, and the best-shaped hocks are liable to it. By good rights, a horse which has been thus unlucky should be thrown up out of work; but it is seldom that this treatment is pursued when the mishap occurs in the middle of the season. Almost all veterinary surgeons in hunting countries have some preparation in which they believe for application to a curb, and usually the horse is to be worked during the period of cure. Now, this is of course wrong, to start with; still, I must confess that I have followed the plan, and my horse has become sound; and I have seen the same result in many other cases. At the end of the season the question of firing or not will arise. In ninety-nine out of every hundred cases I should vote against the actual cautery. It is a certain blemish-a thing I disapprove of, unless it be accompanied by a certain cure. This is not always the case. I have had a horse who had been fired for curbs in my own stable, who sprung curbs afresh two years after the operation. Mild blisters, applied as often as possible, are in every way preferable. Occasionally firing may benefit horses which have naturally curby hocks, but even then it may be managed so as not to make the usual blemish. There are degrees of curbs. I know a hack mare with decidedly curby-looking hocks. She has never been lame with a curb, but after severe work the seat of curb exhibits heat and a barely perceptible swelling. A 
day's hunting would probably produce a fine specimen of this disease.

Many a hunter is lamed by corns. The smith is in fault here. He is afraid of the horse losing a shoe, and of his own reputation diminishing in consequence. $\mathrm{He}$ therefore nails the shoe too near to the heels, or perhaps puts it on too tight altogether, a corn being the result. A corn must be very bad that stops a horse's work in the hunting season, as it is nearly always possible to work him with a three-quarter shoe, the ground being soft; but at the end of the season corns will require a little attention. Being caused by the pressure of the shoe, the only thing to do is to remove that pressure, which is easily done. In bad cases a bar shoe, which removes the weight from the heels to the frog, will be found useful.

Capped hocks are not to be called hunting accidents. They are very ugly things, and any attempt to remove them is more likely to aggravate the evil.

Horses who "brush" or "cut" generally finish the season with an enlargement around the seat of the injury. This, when thoroughly cooled down, may be reduced by a mild absorbent blister, and to prevent a recurrence of the accident it will be needful to discover with what part of the offending foot the damage is done. The best way of finding out is to pipeclay the part that is hit, and then to trot the horse a little way, when the pipeclay (being damp) will adhere to the spot that does the mischief. Then the shoeing will require consideration. No general rule applies here, as no two horses can be shod in exactly the same way in this case; hardly any two hitting themselves in precisely the same manner. 
Ringbone, sidebones, and ossification of the lateral cartilages, lame many a good hunter. Firing used to be the general remedy for ringbone, but the biniodide blister has nearly supplanted it. A blister, applied in good time, will often stop the progress of a bony deposit. The other two evils happen mostly to horses possessing "strong" feet. When once the cartilage is turned to bone, any attentions are thrown away upon it, but mild and repeated blisters will stop the progress of the disease, if applied in time. The shoe should be taken off to allow the foot to perform its natural functions as much as possible. I may here mention that I have seen two cases of incipient ossification of the cartilages-one, indeed, a good deal more than an incipient case-cured by the use of the Charlier shoe, without either rest or blister.*

Sandcrack will have stopped the horse's hunting when it appeared. It is a great nuisance, taking time to mend; but the advice of a vet. is indispensable here, so I will say nothing more about it.

Spavins are of different sorts. Sometimes they don't lame the horse ; then let them alone. Oftener, however, the horse is lame, after work especially, and at first starting. There are many remedies which profess to cure spavins without firing-blisters of different sorts; and, when used on the first appearance of the mischief, they may sometimes succeed. When the diseaso is decided, I know of no remedy but firing that can be depended upon; nor is that always infallible. If the horse must be fired, there is no reason that the whole of the inside of the hock should be scored over. A few lines drawn with the iron just on the seat of the bony * And since the above was written I have seen tro cases more. 
enlargement are sufficient, and this moderation saves appearance, as well as pain to a noble animal, whose sensations are but too little considered.

Stringhalt is ugly, but incurable.

Sore backs ought never to be seen in a hunting stable, but they sometimes do appear there. At this time of year they will cure themselves, time only being required. Of course the clothing must be taken off, and an astringent lotion will have the best effect, if not too strong. Salt and water is as good as anything, and more attainable than lotions which come from the chemist. A "sitfast" will probably require more decided treatment than the great majority of grooms can be trusted to attempt.

Thorns which have lain hid all the season will work their way out of the skin during a summer's rest, or when the horse comes into work again. When their presence is suspected, poultices should not be spared, and when very deeply seated the use of the knife may be needed.

Thorough-pins and windgalls so seldom lame a horse that they need not be considered. They are not pretty, they come to please themselves, and occasionally depart without apparent reason.

I have now considered most of the accidents commonest among hunters from a stableman's point of view. A groom should only deal in mild and simple remedies, and should never forget that nature is at least as clever as he is.

Concerning general management during the summer, little is to be said. For horses which are to hunt in fast countries I should consider any green meat undesirable; their interior economy can be sufficiently well regulated with bran mashes. I prefer sawdust for the bed, or sawdust mixed with tan; but the sawdust must not be 
obtained from green wood. If the animals would promise never to parv their bed away, I should take off their shoes, but this they will not do; so, to prevent their breaking their hoofs when the feet are very brittle, should either shoe them with Charlier shoes, or with very thin tips-as thin, in fact, as racing plates. Common tips raise the toe above the heel, consequently they keep up a continuous strain on the sinews. Blisters I dislike, and firing I hate. It should be remembered that when a horse is cast for firing there is always a danger of his injuring his back in his struggles, especially if he be an aged horse. About the best and most simple blister for bony excrescences is biniodide of mercury $1 \mathrm{drachm}$, lard 16 drachms. Horses subjected only to gentle remedies are just as likely, with rest, to get well through the summer, and be ready to commence their work in the autumn, as those that have been tortured with violent treatment. Bold measures may sometimes be needful, but they are quite out of the province of amateurs.

The groom whose charges are going to the hammer has little to do beyond getting them very fat. The sounder they run out the better; but corpulence is the great thing. Flesh covers a multitude of faults, so it is quite intelligible that the seller should prefer this state; but why the public should usually decline to bid high for an animal who is not as fat as he can be, is not so easy of explanation. It is the fact though, and therefore the circumstance is worthy of remembrance by the ingenuous youth who purposes realising on his stud at "the end of the season." 


\section{THE CHARLIER SHOE.}

That horseshoes are necessary evils has long been a conceded fact, and it needs no great knowledge of the subject for anyone to assert, without fear of contradiction, that without shoes all horses working on hard ground would be lame. A little further study brings to light the fact that, with shoes, a very large percentage of horses are lame, and lame in their feet. It is not fair to jump at once to the conclusion that all these horses are lamed by their shoes, there being causes of foot lameness quite unconnected with shoeing, of which high keep is perhaps the principal one. This, when aided and abetted by fast work and hot stables, and not kept in check by good stable management, is quite competent to lay the foundation of disease, and lameness is the consequence. Not that all diseases of the foot lame the horse as a matter of course; we have all seen horses going sound with seedy toe, thrushes, and even canker, though of course a day will come when these diseases, if allowed to run their course, incapacitate their victims for exertion.

But, though the unshod foot is not of necessity free from disease, there are disorders peculiar to the foot which has been armed by the blacksmith, the most generally known being corns. An instance of an unshod horse with corns is, I fancy, unknown. Horses used on the road, especially in towns, are more frequently lame in the feet than hunters, though the work of the latter is the most severe while it lasts; and it seems only 
fair to credit the shoes with being in great measure the cause of this undeniable fact, if only the trouble be taken to consider what office the different parts of the horse's foot are by nature intended to fulfil. By the usual style of shoeing it must be considered that, on hard ground, all the weight of the horse is supported by the crust of the hoof. A shoe which presses on the sole of the foot lames the horse. Nothing but the shoe touches the ground, and nothing but the wall of the foot touches the shoe. This is plain enough. But we cannot suppose that Providence furnished the foot of the horse with such a thing as the frog merely as an ornament, devoid of any use. Of what use it can be when raised off the ground is a question which is likely to remain unanswered. Hunters who work on soft ground have a part of their weight sustained by the frog, and they are comparatively free from foot lameness-only comparatively.

Many shoes have been invented and discarded, which professed to give all parts of the foot an opportunity of discharging their several duties. Mr. Bracy Clark's expansion shoe was to prevent contraction of the heels, while Professor Coleman's thin-heeled shoe was to allow of frog pressure. The latter gentleman roundly asserted that the frog "must have pressure, or be diseased ;" but his plan for bringing the frog to the ground was eminently inefficient. A shoe thicker at the toe than at the heels must needs produce a continual strain on the tendons-an evil far worse than the want of frog pressure. Without the latter many horses have gone sound to the last day of a long life; but all the frog pressure in the world will not allow of a leg continuing sound if the back sinews are constantly on the strain, both in rest and motion, which must be the case when the toe is 
higher than the heel. Many other theories have been started and found wanting, but until lately no theory of shoeing which combines the principle of the two above mentioned ones has appeared-namely, allowing the heels to expand, and allowing the frog to rest on the ground.

M. Charlier has grappled, I think successfully, with these difficulties. The idea with which he starts is that Providence intended the horse to go barefoot; not of necessity always upon soft ground, for then the hoofs would grow out of all shape, still less always upon the hard, which would wear the crust away faster than it

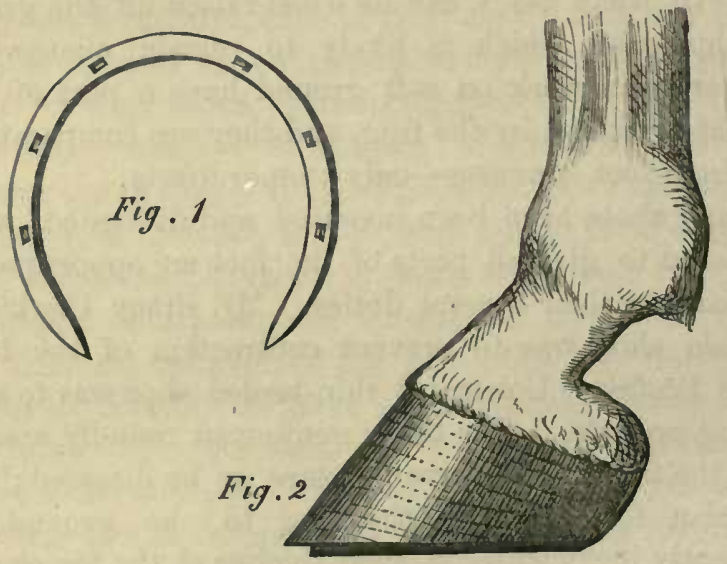

could be reproduced. This, however, being the only evil to be dreaded, M. Charlier guards against in the most simple and effective way, by protecting the crust from all possibility of injury, while the sole and frog remain in an unshod condition. The shoe which produces these happy results is not generally known in England; therefore I give above a sketch of it. 
At first sight it has a fragile appearance, from its extreme narrowness as compared with common shoes; but it is strong enough, being thicker than the usual shoe. Its greatest peculiarity, however, consists in the manner in which it is applied. Instead of being nailed on to the foot like a racing plate, it is as it were substituted for the ground surface of the crust, which is pared away, leaving a groove for the reception of the shoe. Fig. 2 represents the horse's foot prepared for the shoe en profile. The groove should be of the same width as the wall of the hoof, or a little less if the shoe is to be applied hot; no smith with common care can make a mistake here. The shoe must be very accurately fitted to this groove (and here is an advantage-the grooves cannot well be fitted to the shoe), the grooves then being deepened to an extent that brings the shoe nearly, not quite, flush with the sole of the foot. Nothing further is required beyond nailing on the shoe, the last nails being two inches, or nearly so, from the heels. For hunters six nails are preferable; five may suffice for harness work, and certainly for hacking on the road. The shoeing of weak-footed horses in this style demands a little-not much-more care than when a strong foot is the subject; also the exercise of a little common sense. A thin-soled horse, with a deficiency of horn, obviously cannot stand the paring of so deep a groove as a strongfooted one. To obtain the desired effect, the shoo must here be made thinner, so that a more shallow groove should suffice. The shoe, when on, allows the frog to touch the ground-in fact, leaves the foot in as nearly as possible a natural condition. Frog, bars, heels, and crust, all take their share of the work, while the extreme lightness of the shoe has the best effect in de- 
creasing the labour of the tendons. The sole is not to be allowed quite to touch the ground when this is hard and level. It does not do so in the unshod colt's foot, which is the model to go by.

The opponents of M. Charlier's system are numerous enough, but, strange to say, they almost all oppose it on different grounds. Some say that it will never suit weak feet; others, that these shoes cannot stand road work; others again, that the horse wearing them must be lamed if he treads on a stone; and further, a strong party has declared as its unanimous opinion that the shoe cannot be worn by hunters, that it will come off in deep ground, and it will not afford a sufficient foothold on grass and slippery ground. Let us consider these objections separately.

That the shoe does not suit weak feet is a mistake, as such feet improve perceptibly from its use, the weak crust no longer having the whole of the weight to sustain ; and of this effect I will presently give an instance. That the shoes can stand road work is plain enough to anyone who will take the trouble to consider, first, their thickness as compared with shoes made expressly for the road; secondly, the fact that the frog shares the wear with the iron, while in the common shoe the iron sustains it all. Next, that a horse so shod must be lamed if he treads on a stone. This sounds plausible, but reflection will show that a horse shod $\grave{a}$ la Charlier is far less likely to have his foot damaged by treading on a stone than a horse who has his foot pared and shod with the common shoe. The former has the insensible sole much thicker and stronger, it being never pared. It is hardened, too, by constant contact with the ground wherever this is rough or uneven, whilst the frog increases in size and thickness, 
or depth (this remark applies to the sensible as well as the horny frog), thereby forming the effectual and elastic shield to the bottom of the navicular bone which it is fair to conclude that Nature intended it to be. Then that the shoe cannot be worn by hunters is a mistake, as experience has proved the contrary. They are, indeed, less likely to come off than any other kind of shoe, as there is so little suction in deep ground, whilst it is wholly impossible that the hind shoe can catch them. As to horses so shod slipping about, they cannot slip more than unshod horses, who are not remarkable for that failing. No one who has ridden a run after losing a shoe can affirm that his horse slipped more than usual, I imagine; and, on the other hand, the old shoe does not secure immunity from slipping.

Serious, nay, fatal accidents, have occurred from horses slipping at their fences when shod in the usual way. The frog, however, when it touches the ground, should act as a wedge, and prevent slipping. Some horses will always slip, shoo them as you may; others comparatively never.

These remarks apply to the fore feet only. Let us now consider the case of the hind ones.

That the Charlier shoe places the hind feet in a natural position is incontestible, nor do I think that a horse so shod could "cut;" but, from the way in which the hind foot comes to the ground, I fancy the shoe would wear through at the toe rather too rapidly.*

I will conclude by giving three instances which have come under my personal observation, in which the appli-

* Experience has, since this was written, proved the contrary; overreach cuts are colso to the greatest possible extent guarded against. 
cation of the Charlier shoe has been attended with the happiest results.

The first was that of an old horse, who had been lame in both fore feet for years with chronic laminitis. His feet were large but strong. Being equally lame on both feet, he went evenly, but very tenderly. After a month's application of the shoe the action on his road was so far recovered as to pass muster as a harness horse for country use. His feet, which had always been very hot and feverish, were, when I saw him, quite cool.

The second case was a hunter, who for the last five seasons has constantly lost the shoe off one fore foot. The other foot is a tolerable one, but the faulty one has, or rather had, neither sole nor horn. The crust was so damaged by the constant tearing arvay of nails through it, that there was next to nothing to nail a shoe to. This horse was shod with the Charlier shoe, and a worse or more difficult subject for the operation could not be. The effect was immediate. He went through two days' hunting in a deep country without a clench stirring, and then travelled by road for over a hundred miles, going sound all the way, and arriving with the shoes worn indeed, but firm in their places.

The last case with which I will trouble my readers is that of a young horse, who had begun to move his feet in that skating fashion generally indicative of incipient side bones. This horse's feet were shelly and brittle, but well formed otherwise. After a month's wear of the Charlier shoe he stepped with confidence, and exhibited that action which was to be expected from his shape and make. The cartilages too had recovered the springy feel, which they seemed in a fair way of losing.

An idea being very prevalent that particular tools are 
required for this style of shoeing, it is as well to state that the groove can be made with a common drawing knife (common care only being required), but that the operation is more easily performed by a beginner if the drawing knife have a guard on the blade, a moveable one being preferable, by which to regulate the width of the groove. But the width of the horn is sufficiently apparent in all feet.

I do not for a moment hope that foot lameness will become extinct by this or any other mode of shoeing; but $I$ am of opinion that this shoe is more calculated to preserve a horse's feet and legs than any other, the much-puffed Goodenough shoe included; and for the simple reason that it places the foot at once in the position of "unshod nature" - a thing which no other shoe can possibly do.

The horses specified above were all shod by country blacksmiths in different counties; nevertheless, all the experiments were satisfactory.

\section{MORE ABOUT CHARLIER SHOES.}

I thought I had long ago done with this subject; but the original question seems to have cropped up again, with the original amount of difficulty in "getting at the rights of it."

First, let me answer one question which has been lately asked more than once in the columns of the Ficld, viz., Where in London can the Charlier shoe be put on? I saw it some short time ago very neatly applied at a forge in Engine-street, Piccadilly; but I cannot remember the name of the proprietor. It is not, however, likely 
that there are two in one street. Messrs. Stevens, of Park Lane, also shoe in this way, and a set of shoes put on a hack of mine on the Saturday after "Cremorne's Derby" are still on, and, though worn very much, not quite done (July 15).

Mr. Hunting's objection to the system is effectually answered in an editorial note. How such a mistake could be made by a professional man puzzles me, as the chief beauty of the shoe is that it causes the weight to be equally borne by the heels, frog, outside of the sole, and crust; the exact contrary of the common shoe, whose chief fault is that the heels and frog are put out of work altogether. Hence the great benefit experienced by horses suffering from fever in the feet, especially the chronic or sub-acute form of that malady, when shod after the Charlier method.

A correspondent "Kangaroo" very justly remarks upon the impossibility of a horse becoming footsore in the frog, sole, or heel of his foot as a result of travelling barefoot. It is the toe about halfway round that suffers, and this is all that demands protection in the fore feet, whatever the work may be, and upon whatever soil. But I think "Kangaroo" exaggerates the dangers of shoeing a horse $\grave{a} l a$ Charlier and working him at once. That the sole will scale away is indubitable, but I have never found any inconvenience result from the process, as a new sole is ready for use immediately on the loss of the old one. I have shod now some dozens of horses in this way, and in all cases where the frog has been sound they have been able to go on at their usual tasks after a day or two of "feeling their feet." Of course a thin-soled horse should be as much as possible kept off newly macadamised roads, but after a time he will travel over them certainly 
as well as he ever did with the old shoe, and in all probability better. Where the frog is unsound it is another rnatter, as it has a good deal of work to do; but there is nothing like pressure and heel freedom for thrushes, \&c.

M. Charlier's fore shoe extends to the heels, but this idea has been improved upon. Since I last inflicted this subject upon my readers, I have seen a pattern of a short Charlier shoe, as used at Melton, and its advantages are pretty apparent. It extends only to the bars of the foot on each side-in fact, about the length of a "three-quarter shoe" - and five nails are plenty to secure it. It wears much longer than the full shoe, as the wear is divided between the shoe and the heels, which are left in a state of nature. M. Charlier's shoe takes away, or rather replaces, a portion of the bars, which with the short shoe are left in their entirety; and, as they are the strongest and quickest-growing part of the foot, this seoms but reasonable. In fact, in M. Charlier's book (which appears to be about the most inaccessible work extant) a passage to the following effect occurs: "If after a few shoeings the bars, which grow very fast, project below the level of the shoe at the heels, they may be cut off flat." Now it is surely better that the shoe should not meddle with these parts, which replace their own wear so speedily, and a short shoe puts corns out of the bounds of possibility. The great mistake smiths make in this shoeing is to cut too deep a groove. The sole need not be absolutely flush with the shoe, and a too near approach to the sensitive parts of the foot lames the horse to a certainty. And failing this, if the groove be a little too deep, his action is much impaired, and does not visibly improve, and the traditions of the smith 
triumph accordingly. Of course, a short shoe is less liable to "spring out" than a full one; indeed, since I have used them, I have never known one to do so. They would not, I imagine, be so suitable for the hind feet; but the hind shoe can always be made stouter than the fore one.

In case my description of the three-quarter shoe be not plain enough, I subjoin a sketch of it. Fig. 1 shows the foot shod (in profile); Fig. 2, the ground surface of
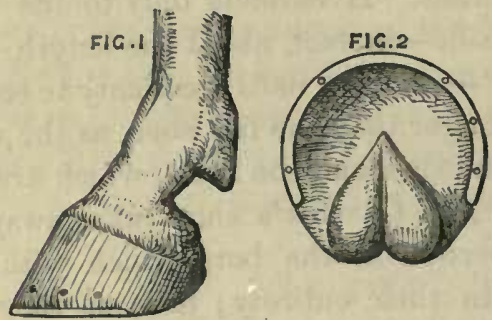

FIG.3

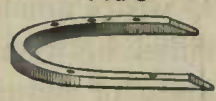

the shod foot; Fig. 3, the shoe itself. I should also mention that my friend who gave me the pattern of this shoe remarked that "the opposition of the smiths to it must be seen to be appreciated, and that the same might be said of most of the grooms."

In speaking of thin-soled horses, I omitted to call attention to the fact that it is only pointed stones that they object to ; London parement they will go over with all imaginable confidence. As to the difficulty of putting on a shoe after a "Charlier" has been lost, I can only say what has happened to myself, and I always prefer practice to theory. Some time ago I lost (or rather my horse did) a hind shoe (I have never lost a three-quarter fore shoe), which was trodden off, as I fancy, in a gateway, being a little too long-such an accident, indeed, 
never having been contemplated or provided against. I cannot say how much hunting my nag did barefoot, but sixteen miles of road he certainly did perform on his way home, through an uninhabited country and in the dark, and no forge discoverable. He was slightly footsore, though hardly lame, the last two or three milescertainly not more-and his foot was a great deal worn at the toe. A groove could not safely have been made, and the Charlier shoe without one, to some extent, is no better than another; so, being far from home, with only a village blacksmith who had never heard of Charlier to apply to, I let him put on a light common hind shoe. In doing this there was no sort of difficulty, and in ten days the foot had grown enough to admit of the usual "chaussure." And this was a flat-footed horse, but one which had worn Charlier shoes for eighteen months.

So much for that difficulty. And it is just as easy to carry a spare Charlier shoe and nails out hunting as to do the same thing with a common one, which any smith can then adjust, no groove having to be made, and no alteration of the shoe being required either, unless to widen or narrow it a little to fit the foot. If it were a full shoe it would be all right for the hind foot; while the reduction of a shoe to a tip, if such were needful, demands but an infinitesimal portion of time, trouble, or skill. Short shoes in front, however, ought never to come off, nor will they do so when properly put on; hind shoes have still less business to be absent without leave. 


\section{ECONOMICAL SPORT.}

"WHAT is a gentleman without his recreations?" inquires one of our deepest observers of human nature; and, indeed, it is a conceded fact that "all work and no play makes Jack a dull boy." A young man starting in life in any occupation which does not of necessity take up his whole time, must have relaxation, and the healthiest amusements to be found are undoubtedly field sports. Field sports, however, are not to be had for nothing; but, as their nature and the manner of enjoying them vary considerably, it is worth while to consider what will give the maximum of enjoyment with the minimum of expense-or, in plainer language, how the most fun is to be had for our money.

To a young man living in the country, the threo sports of hunting, shooting, and fishing are probably more or less accessible; and, although none of the three are to be enjoyed exactly for nothing, circumstances will be found to alter the expense of each. Fishing is undoubtedly the cheapest sport, if one has the water to fish, as the kit and tackle required are not ruinous to buy or expensive to keep in repair. Shooting also, if one shoots one's friend's game, is a moderately reasonable sport; whilst hunting takes money, no doubt, unless one's friends mount one-and then there is the stud groom! Old fogies of both sexes, when they hear that a young man is fond of hunting and indulges that taste, at once either write him down as a rich man, or 
declare that he is outrunning the constable; whereas, as I will presently show, it is possible to see a good deal of sport in the hunting field at a comparatively moderate cost.

Shooting and fishing are no doubt economical amusements when they are found for you, and no juvenile ever yet was considered to be a spendthrift merely because he spent his time in fishing; yet fishing is not always the cheap amusement it is considered. To live on the banks of a canal, and fish therein for gudgeons, is a pastime reasonable enough as far as cost goes; but then a young man good for anything would find this kind of thing rather wanting in excitement. To fish for anything worth catching requires either money or interest. A very small percentage of British youth has free permission at all times over decent water; and, putting this small percentage aside, it will be found that the remainder have to pay something more for their sport than the mere cost of tackle. To belong to an angling club is not a very expensive matter in money; but how much fun is there to be had for it? It is not the price paid, but the value received, that makes an article dear or cheap. Say that you begin trout fishing in March, which is full early-though, of course, rivers vary in being early or late-on a well-whipped club water you will have but little fun after the middle of June, hot days and clear water not being favourable to the feathery impostor, as a friend of mine used to call the artificial fly; so you get but three months' fun for your outlay. It may be worth the cost, but then you have no pursuit for the winter and autumn months, not to mention the hot days of summer. Where there are grayling, it is true some fun is to be had in the autumn, but these fish are 
only partially distributed through England, and, indeed, where they abound the sport of catching them is not to be compared to the landing of the game and resolute trout. Salmon fishers have a longer season, but have to pay still more for it; and, unless young Piscator happens to live near a salmon river, he will find that the getting to it and getting back, quite irrespective of expenses while by the water, make a very considerable addition to the cost of his rod licence and wading boots. If he flies at higher game and rents a river, he says adieu to economy once and for ever, wherever that river may be, whether in Scotland, Ireland, or Norway. But, without going as far as this, the young salmon fisher will find at the end of the season that his days of enjoyment have been limited, and that, even if his expenses have been the same, he still has a good many months on hand in which he will be solaced by no sport; and these are just the months when a good reason for out-door exercise is with many necessary to induce them to take it. No one, for example, whose exercise is a mere constitutional, hesitates much about shirking it if the weather bo wet.

Now let us think of shooting. To shoot on the manors of our friends is economical enough, and the shooting season lasts for five months; but the most popular of youths can hardly expect the time when he is shooting by invitation to equal that when he is disengaged. Also, invitations do not always come when they are wanted, and, when they do, they sometimes arrive two at a time; so that, as I have just said, the man whose chief pursuit is shooting with his friends will find himself with a good deal of time on his hands. If he shoots " on his own hook," he will find his amusement an 
expensive one. If he has a moor he must be well off, and the grouse season is very short, even were the attendant expenses small, which they are not. A partridgo manor is not had for nothing, nor does a keeper do his work gratis. With an average partridge manor you have pretty good fun through September; and during the other months you get a few days driving or hawking; but neither of these games, especially the latter, is to be indulged in too often. In the present advanced state of farming none but a maniac would expect to walk birds up in a legitimate manner after the 1st of October, if they have been shot at at all regularly in September; so the number of days spent in the pursuit of your sport will be such as to leave you a fair amount of leisure. If you go in for pheasants, you will spend a fair (or unfair) amount of money for a very few days' diversion. To be shot twice is about as much as most coverts will stand in a season, and in no case is pheasant shooting a poor man's sport, unless he be asked to shoot with a rich friend; and, indeed, I am not considering invitations which are at the option of one's friends, but the amount of sport which a man, even one who has no friends, can calculate on having for himself, at his own time and convenience. Of course, to speak of deer stalking on the same page as economy would stamp the individual thus exposing himself as a candidate for Hanwell.

Next turn we to hunting. The expenses incidental to the chase can be calculated to a tolerable nicety; indeed, the only thing that would throw a man very far out in this would be the death or permanent injury of a horse. Hunting may of course be done in as expensive a way as anything else. To take a dozen horses to Market Harborough or Melton is a decidedly extravagant business; so, 
indeed, in a general way, is it to hunt away from home anywhere. The moving of horses and servants is expensive in itself, and productive of many other expenses in different ways. With the expensive way of hunting I have here nothing to do; I only profess to show how the sport may be made reasonably accessible. Different people have very different ideas of what is needful for the pursuit of the chase. Compare, for example, the late Lord Henry Bentinck with the master of the Sinnington hounds or the Blencathra; yet all three are, or, I regret that I must now say, were, equally good sportsmen. To be sure, a man who wishes to enjoy hunting at small cost must not be a very heary weight-he ought, in fact, to ride under fourteen stone; and a man of this weight will be able to mount himself sufficiently well for the provinces at a moderate figure, nor need he stay at home, with hounds close by, even if he lives in "the Shires." With two sound horses, and fair luck, a man may hunt on an average three days a week in open weather. His amusement will last for six months in the year, and sometimes more, and he will have the use of his horses during the summer. With a month's rest at the end of the season, a poor man's horses should be sufficiently recruited, if they leave off their work sound, or tolerably so, to make themselves pretty useful in the summer; though they ought not to be exactly knocked about at a very fast pace on the road, neither ought any other horses; excepting perhaps those belonging to country doctors, also butchers' hacks-which latter always work at a fast pace, the former doing so only on occasions. Set off against the economy of hunting the fact that, not unfrequently, it is stopped by frost, and that the horses have be fed all the same. This is certainly a bore; but on the 
other hand, while weather is on our thoughts, think of the sport often to be enjoyed on wet days, or cold raw days, and in every description of weather barring frost. Often the run of the season may be shown on a day on which, but for hunting, you would not have been persuaded to leave your fireside. You cannot fish nor shoot in rain, but you can hunt, even if uncomfortably. The performance at dinner, and the subsequent enjoyment of a night's rest, by the man who has been hunting, should be compared with that of the one who has spent the day by the fire. It will not require a conjuror to tell which is the best business.

The expenses of a two-horse establishment will very little exceed 100l. a year. Even at present high prices, a horse can be foraged and shod for 40l. per annum, especially if the forage be bought at first hand and paid for ready money. Horse keep is expensive when every grain of oats passes through perhaps three pairs of hands, each of which must make their separate profit on it. Straw, for example, when bought from the farmer and returned in the form of manure, comes to a very different figure from what it does when the stud groom buys it of the corn and hay dealer; indeed, in many countries it is to be had for nothing. One man will look after two horses; and here let me advise that he should be a man, even if his wages be a little more, and not a lad. It has been well said that it takes one man's time to look after a boy. £125 per annum should cover everything well, bar accidents. First, however, the horses must be got, and a good judge will find two "useful" animals for 50l. apiece, possibly less. But if the intending purchaser be not a good judge, he should find a friend who is to see to the deal for him. An ignorant youth in 
search of a cheap horse is a melancholy object, and is certain to be done. The man buying for himself must bear in mind certain things. Firstly, he must, intending to hunt regularly with two horses, avoid a young one like poison; the nags must be at least six off. If he wishes to buy a green young horse, and "make" him with a view to selling him at a profit, that is another thing; he may be sure that in so doing he will lose a good deal of hunting, even if he makes some money. Our sportsman of small means should keep clear of dealing as much as possible. When he has a horse to suit him he should keep him. In buying he must choose nags well up to his weight. In all countries a galloper is desirable, though in many a slow jumper can do the trick. He should remember what brings sound horses to low prices : it is either bad temper, bad manners, bad action, ugliness, or age. Let him have nothing to do with the first two qualifications, as he hunts for pleasure, and let him avoid the third; but a really good ugly one will be the thing for him, as he must not go in for appearances ; nor must he decline an aged horse if he be fresh on his legs, and not positively an old one. Naturally sound horses will, when well treated, work on up to twenty years old; and there is no greater fallacy than the rage for young untried ones. A young horse is sound as a matter of course, but how he may turn out is a risk; whilst a horse who is sound at ten years old will probably be sound for from five to ten years longer. Again, a horse may not be sound enough to pass a veterinary examination, yet may be a capital poor man's slave, and never be out of work. There are some few things that cannot be pardoned; a sulky eye is one. Bad shoulders 
must be rejected at once. Short back ribs are usually the sign of a bad constitution, but, if you know the horse to be a "good doer," this fault may be pardoned. "Sickle hocks" are not to be bought at any price; sooner or later they will go-either spavins or curbs will be their ruin. Of course a horse who makes the slightest noise should be declined; he will never get better, and may probably (will too) get worse. But one thing which is invariably condemned by people of little knowledge or none at all should not be an obstacle in the way of the poor man's purchase-I allude to "archy" knees, as those fore legs are called which stand over. Worn-out legs are another thing, but I should not decline a lowpriced horse for this fault if his action were good, and if his fetlock joints and feet were fresh and sound. Such horses are generally cheap, in consequence of the prejudice against them, and therefore suitable to our present purpose. The back sinews of such legs hardly ever go -indeed, I have never known an instance of their doing so; and though in the racing stables they are liable to sore shins, that does not matter to the hunter. They are not saleable, however. Our two-horse man must not be too fine to ride his horse on to covert, and he must never have both out at once. By careful and proper management he will find that he gets an interesting and healthful pursuit for half the weeks of half the year, with the possession of his nags for the other half. Whatever man has done man may do, and I speak from experience. Our friend will find he gets more return of enjoyment for his money than any other investment of the same sum would give him. And there is another thing; it is poor fun to fish all day without a rise, worse 
still to shoot without touching a feather, and the muff will, sooner or later, get choked off both pursuits; but any muff may enjoy himself out hunting, for, out of many hundreds that I have seen at the covert side, I never yet saw one who had discovered himself to be a tailor! 


\section{RESTIVENESS AND VICE.}

"ReSTIVEness" in horses is a thing which I take to be quite distinct from "vice" originally, although the former will often enough merge into the latter, forming a combination profitable to no one, now that poor Mr. Rarey is no more. In fact, according to my notion, a restive horse, like a poet, nascitur ; a vicious one, fit ! A restive horse wishes to have his own way; like many humans, he is generally amiable when he gets it. He wishes no harm to anyone. "Live and let live" is his motto. When he has had enough exercise he likes to turn home; and, when allowed to do so, home he will go tout bonnement. Thwart him in his desire, and he is not so particular as he might be as to what form of resistance he adopts. Still, he resists what he takes to be an imposition. He does not, like certain English politicians, pitch into the powers that be merely for the sake of having an argument and trial of strength. But the vicious horse does so. He has no more love for man than "Iconoclast" has for an archbishop ; and if the behaviour of the biped does not afford him a casus belli, he is not above making one for himself. What I understand by a restive horse is one who jibs in harness, who stops and turns round on the road, or who sulks and "sets up" when there is a question of his leaving the pleasant company of other horses. (The last habit, in a park hack especially, will occasionally be the means of placing many people at once in the falsest of positions!) 
The tricks of a restive horse always are put in practice with the greatest spirit and perseverance when he is fresh, and it is generally a question of spirit and perseverance between the horse and his rider who shall be master. Now a restive horse is more or less an intellectual one. You are riding him, we will suppose, and come to four cross roads : one road leads towards home, or the horse thinks that it does-for they are not always quite accurate in their geography-and he stops short. If a beginner, he may avail himself of the excuse of a bird moving in the hedge, or some such trifle; if an old offender, be will stop without any apology. In either case he "reverses his front," as soldiers say (almost always "left about"), and would be for going home, or down the desired path; but by this time you, the rider, have recovered your surprise, and, taking up the reins, pull him up. This is signal enough for a real old offender to begin, whatever may be his peculiar vanity in the way of resistance, but a tyro will stop, and then you try to turn him round again. He declines, and shakes his head. The rider spurs him; he kicks. Ditto repeated two or three times. Next, the biped probably gives the quadruped one down the shoulder with his whip. That the latter will convert himself into a biped for the time by rearing straight up is one of the "few certainties out." So far, so good. If the rider be timid he probably gives in, and the horse scores a victory; if otherwise, supposing that the ground is favourable-for the neighbourhood of a deep blind ditch or some such thing often makes a fight impossible-the rearing and kicking continue for sometime. The horse may rear and come back ; but he may rear very often and very high without doing so, and if he does it will not be on purpose. The bold 
and persevering rider eventually gets his horse to proceed, in most cases at the expense of severe punishment and some unwished-for excitement; and it is quite possible that ever afterwards he will be carried by the animal wherever he wishes to go without remonstrance. The horse is no fool; on the contrary, he is most intelligent, and he sees that his game won't do with that particular man. He has tried it on, and found it fail, so he does not waste more time and trouble. But, on the other hand, with the timid rider he found his plan of action answer; and, rely upon it, he will never carry him in a docile manner again, unless he happens to be ground down with work, or unless from some other cause a contest is considered undesirable by himself. Rearing and kicking are usually considered vice; but this horse I should not call vicious, though he has done both. Ho reared because he had probably found from experience that the proceeding usually got him his own way. He had no wish to fall back and crush his rider, or to hurt him in any. way. Very likely he did not kick with the hope even of kicking him off; he merely wanted to frighten him, and so gain his end. Allowed to go home in the first case supposed, he went quite quietly, and had no objection to carry his rider. The objection was not to the rider personally, but to his course of action. In a stand-up fight let those laugh who win, those who lose not bear malice. Neither in losing nor winning would this sort of horse bear malice. He would not object in the stable to the presence of rider No. 2 more than that of No. 1, the vanquished; and so I should not call him a vicious horse. These sort of rebels are invariably curs at heart, which may be a consolation to their owners. If the rider goes on long enough, he will eventually gain 
his point. A horse who is given to rear dangerously, on what he considers provocation, will be taught better manners by the use of a rearing bit; which, while it keeps his head down, renders any attempt to get it up futile, from the acute pain caused to the mouth, and has, indeed, the same moral effect as a twitch. And the kicking does not matter. A man who can be kicked off when he expects, and is prepared for, the manœurre, had better confine himself to pedestrian or carriage exercise. (I have heard of horses kicking themselves head over heels, but have never seen one do it, though I have had them scramble, as it were, on their fore feet, while they were performing a more than usually brilliant caper.) Vice under the saddle takes different forms, the principle being always the same-to get rid of the man, if not to damage him when disposed of. A restive horse almost always shows his disposition by a certain sulk of the eye, unmistakable to a horseman; a vicious one, not invariably. "Maneaters" especially I have seen with the mildest of countenances. A vicious horse will bite or kick a man in the stable, and possibly be quiet out of it; or he may be quiet to groom, and almost impossible to ride. But in either case he dislikes man, and in most cases, not to say all, has only too good reason for so doing. A vicious horse under the saddle will plunge or buck-jump until he or his rider is tired, and, if he succeeds in dislodging the man, will probably kick at him; but the stable savage and the unrideable one were not born so. In a few cases savage temper is hereditary, but almost always it is the result of ill-treatment. The stock of a horse called Manchester not unfrequently inherited his savage disposition; but how had the sire become what hewas? A horse has the best of memories, 
and such a thing as a punishing finish of a closely-contested race is never forgotten. Cruiser himself did not begin life as anything out of the way, as far as temper went. No ; a vicious horse has had occasion to fear man originally; he ends by making most men fear him. For this reason $I$ have an idea, grounded on experience, that a vicious horse is often to be radically cured of vice, but a restive horse seldom or never of his tricks. A resolute man will cure a restive horse, as far as he is concerned; but the animal will try his tactics afresh with every stranger who mounts him. Now, a vicious horse is to be cured, not by punishment, but by kindness; and, if uniformly well treated, he will sometimes become reconciled to the human race generally, even if he be suspicious of perfect strangers.

In harness the two chief misdeeds of which a horse is capable are jibbing and kicking; the former I should hardly call vice. The animal means harm to no one, but does not wish to drag a load after himself. In pursuance of this determination, he will, if remonstrated with, throw himself down now and again; but still he does not mean to do mischief. Bully him and set him kicking, and he does mean mischief, and no mistake. He means to smash all behind him, and sometimes succeeds in doing so; but he never would have kicked if he had not been flogged. The whip had made him vicious for the time. Nothing but patience pays with a jibber. Never let the collar be cold to the neck at starting; and if your animal won't start in single harness, put something behind the wheels - or better still, if possible, let the carriage front down hill. Strap up a fore-foot, and let the gentleman stand, for a week at a time if he likes. Try this a few times, and, if he is not something extraordinary, he will 
at length be too glad to go on when and where he is wanted to. Other cases of kicking in harness arise chiefly from the harness hurting the horse, or the carriage running upon him, neither of which accidents are the horse's fault. Sometimes a horse who is very fresh may give a jump and kick from exuberance of spirit, meaning no more mischief than the same action would do if he were being led. But it is dangerous, as he may be frightened or even hurt by his hocks coming against carriage or splinter bar; and if once frightened, a horse is a less pleasant conveyance than anything short perhaps of a "must" elephant. No! restive horses are a bore, vicious horses a dangerous nuisance; but your real promoter of coroners' inquests is a nervous horse, one who becomes frightened easily-he loses his head entirely, and is a dangerous maniac immediately. For them there is no cure. When least suspected, their peculiar idiosyncracy will make its unwelcome appearance ; and their rider or driver is instantaneously transformed, from a comfortable citizen taking an airing for pleasure, to the helpless victim of an aimless and objectless lunatic, whose bodily strength and insensibility to danger are in exactly inverse ratio to his reflecting powers. 


\section{THE "SCREW."}

WHAT is a "screw?" is a question easier to ask than to answer; at all events, few people agree in the definition of one. Properly the term would seem to apply to an unsound horse-one which cannot pass the examination of a qualified veterinary surgeon, though these gentlemen are not by any means infallible, as most owners of horses know to their cost. Some would term any blemished or aged horse a "screw ;" others again, mostly gentlemen in the first bloom of youth, consider and call every horse which is not a long-priced one, whatever his qualities may be, by this unflattering appellation. On the other hand, all men of any stable experience must be able to call to mind horses of the most expensive price which have been nothing more nor less than screws, and yet have been favourites and highly valued even by masters who are good judges.

There are, however, many forms of unsoundness which do not make a horse a whit the less valuable for certain purposes, while they would incapacitate him entirely from the performance of other duties. For example, a roarer or whistler would be of no use to a hard-riding man as a hunter; but for moderate harness work, unless the noise is so great as to be audible above that of the wheels, a roarer is frequently as useful as a sound horse, does his work as well as one, and will probably give his master as much satisfaction as a sound one, until he wants to sell him. Then he will find a difference between the two. 
I have instanced roaring as being a very common and a universally-known species of unsoundness. It is ruin to a hunter (owners of roarers are fond of telling one that "he makes a noise, but it doesn't stop him ;" in one case out of ten thousand perhaps it may not do so to any great extent) and next thing to ruin in a hack, for there is no comfort in riding a "bull," though he may carry one w ell on the road. But for harness, as aforesaid, a roarer may be as good as his neighbours. A harness horse, too, may have a leg that would never stand hunting, or even hacking, and yet, with no weight on his back, he may step away merrily for an indefinite time. In fact, as long as a machine has sound feet, he can get along with almost any fault. Even a ricked back will not incapacitate a horse for harness - of course, if the injury be moderate only. Sound feet are required, because a harness horse is always on hard ground; and sound hocks, for appearance sake, are desirable. A hunter may go for years with a spavin that lames him on coming out of the stable and after work, and often he gets no worse; but a harness horse who stands about would have to make so many fresh starts, "working sound" each time, but always starting lame, that the appearance of the thing would be objected to. The horse might do his work, however, without much inconvenience to himself.

A hack must be sound to be agreeable; he is knocked about on hard ground, he is wanted six days, perhaps, in a week, and, being required to minister both to business and pleasure, must be the nearest approach to equine perfection procurable. He must be perfectly sound; but really with other horses I must be allowed to say, "Je ne vois pas la necessité."

In a hunter soundness is an advantage no doubt, but 
how seldom met with. Many first-flight men would be much disgusted if their favourite flyers were called "screws;" but I think I am on the safe side when I say that, out of twenty-five hunters selected at random from (say) Melton stables, past their eighth year, and which have been ridden regularly, and fairly hard, half a dozen would be the outside number which could be passed by a veterinary surgeon as sound in every respect; and these half-dozen might quite possibly be the worst hunters of the lot. A horse who has done hard work must show it somewhere. Anyone who doubts the truth of these remarks may satisfy himself by having his aged hunters led at the end of the bridle on stones, without any whip or excitement; if they all go just as they do on the soft, he is a lucky man, and the exception that proves the rule into the bargain. There are so many shortcomings in the way of soundness that have no perceptible eeffct on the horse's power of crossing a country. Eyes and wind, of course, are indispensable; but how about legs and feet? He hits his legs; are not boots accessible and cheap, bandages still more so? He has bad feet, even chronic fever in them, or navicular disease; his work is all on the soft, and with careful shoeing he may go on with even these diseases for a considerable time, and his owner may not know of their presence. The groom takes the horse on to the covert side; he is sound when his master mounts him, and is possibly not seen again-out of the stable at any rate-if he belongs to one of the modern order of fox-hunters, until it is his turn to hunt again, by which time he is fit to go, though starting lame or groggy as before. Side bones and ossified cartilages do not stop a horse across country, but they make him most unpleasant to ride on the road, even when he is not 
exactly lame with them. Curbs are a bore; they often are not allowed to stop a horse's work, though they certainly ought to do so. Spavins are wonderfully common among hunters-in fact, almost the certain accompaniments of a particularly shaped hock; but horses will hunt for a lifetime with them, especially when they have been fired, coming out always stiff, and invariably working sound, as I have already remarked. String-halt is ugly, but there the evil ends, except in those exceptionally bad cases where the horse cannot start at once. I had last season two hunters affected with it; it was particularly apparent when they "turned over" in a stall; and for the first forty or fifty yards on leaving the stable in the morning it was noticeable, but on no other occasion. A vet. could not have passed these animals, but they hunted and hacked none the worse for their affection. It has been stated that horses with string-halt are the safest on the road. I am not sure that a friend of mine was far wrong who used to remark, "Sound horses be hanged! You never know where they may 'go;' they are a constant anxiety. Now I know the worst of my corns, curbs, and spavins, and it's hard lines if each nag is not contented with one example of screwiness!"

I don't, however, go so far as to recommend the purchase of notoriously unsound horses, though asserting that, ten thousand to one, the soundest of animals will, if you only work him enough and keep him long enough, become eventually a screw in your hands, and probably on your hands too, if you want to get back anything like his cost price.

Young sportsmen like to buy a young, fresh horse, and to exhibit him as a frosh importation at the covert side; they dislike the secoud-haud sort of notion conveyed by 
buying a horse of a neighbour. They know that a farmer, we will say, or anyone else of their acquaintance, has a bona fide reason for wishing to part with a horse; they know, too, that he is a good one ; in fact, they know, or can find out, all about him-and apparently for this very reason they won't buy him. They go to a dealer and pay more money for a horse of which they know nothing except what the dealer tells them. The fresh look of a made-up horse soon goes off, and then they are disappointed in the animal's appearance; and lucky they are if the disappointment ends there.

Now the consideration arises, how to get the greatest amount of work out of a screw. Buy where you may, and give what you like, you will always have a certain percentage of screws amongst your stud. With a good stud groom a master need not even think of a horse on non-hunting days; but, as everyone does not possess this advantage, the following hints may not be written altogether in vain. Many hunters are inclined to fever in the feet, the result of high keep and hard work. Anything that diverts the inflammation from the laminæ of the foot, after work, is here beneficial. As a blister rapid in its effects I know nothing to beat Farrell's Vesicant, and a little of this, painted on round the coronets after a hard day with hounds, has the best possible effects, the annoyance caused by it to the horse being over in a fow minutes. Then, last thing at night, put the fore-feet in bran poultices till the following morning, and if you have any luck your screw should come out next morning stepping like a lion rampant; at least, I adopted this treatment with a groggy horse, and with the best results. A mild blister round the coronets, if hunting be stopped by frost, is also useful. A horse, especially an old one, whoso 
joints fill and are stiff after hunting, will be much benefited by being bandaged, last thing at night, with flannel bandages wrung loosely out of the hottest water that can be borne; over these dry flannel bandages are placed, and left for the night. In the morning the inner bandage is dry and the outer one wet. The legs should be fine, and will generally be found so. Horses who hit themselves on the road may be dealt with by judicious shoeing in many cases, but hunters will require protection in the way of boots or bandages. If boots are used, they should be of cloth and leather, not indiarubber, and the horse should be measured for them. A horse who cuts behind is most objectionable, as a boot behind frequently lames the horse; in that case a three-quarter shoe will often effect a cure, the inside quarter being cut off. When this fails, try cutting off the outer quarter-a proceeding which is nearly infallible, but possessed of this disadvantage, that the horse slips about on greasy ground to an unpleasant extent. For the road the inside heel may be thickened with the same good result, and a similar proceeding with the fore feet will often be successful; but here care must be taken, as the fore feet do not allow of such liberties as the hind. Corns are best dealt with by the use of a three-quarter shoe, when the work is on soft ground. All this if the Charlier system be not approved of.

Lately a variety of inventions have been advertised, which, if their performance were equal to their promise, would render soundness a matter of no importance to the owner of horses. I have tried several of them, and as the inventors don't know "Impecuniosus" from Adam, can give my opinion freely. The two which took my notice mostwere "Edwards's Horseshoe Cushion," and Clark's "Neuras- 
theni-." I really can't trust myself to finish spelling the word from recollection. The former made soundness in feet a matter of no moment; the latter had the same effect upon legs, according to the advertisement. As I say, I tried them, and this is the result of my experience. The cushion would probably have performed its promise, could it have been kept on ; but at all sorts of odd times, and without any warning, cushion, shoe, and all would fly off. Sometimes they kept on through a long day's hunting; at others ten minutes' walking exercise disposed of them. While on, the tender-footed horse which wore them went on the hard with great confidence; his feet, too, grew very fast. Now for the long word. The application fines down some legs wonderfully, but on others has less effect, and on fired legs, as far as I know, none at all. I should much like to compare notes as regards the latter phenomenon with anyone who has tried the stuff.

These patent medicines lead one's thoughts back to veterinary practice; and concerning the professors thereof I must repeat (though with the utmost respect) that they are not infallible, and that the young purchaser of horses may often be mislead by them, to the extent of losing a good and cheap horse. Without knowing anything of his former history, the cleverest veterinary surgeon can only guess at his capability of standing sound. He can of course point out any present unsoundness, but he does not always stop there: e.g., I knew a mare which, being for sale, was examined, at the desire of a would-be purchaser, by a vet. of extensive repute. The vet. pronounced her sound at the time: "But," said he, "don't buy her; she has one foot rather smaller than the other, and will eventually be lame." The theory was 
undeniable; so the mare was returned. I afterwards accidentally learned that some time previously this mare had had a fearful overreach (the mark was visible enough), and that she had not used this foot, to speak of, for I think three weeks. Naturally the foot had decreased in size, but this did not affect her going, and I saw her a year after the transaction going sound, and heard that she had never done otherwise. Sometimes, too, they will make rather ludicrous mistakes, and I could give many instances of such, but that it is no wish of mine to cry down the attainments of a body of men allowed to be well-read and intelligent. I only mean to point out the possibility of their being mistaken occasionally in a casual examination of a horse who has done work. Further, many have not studied sufficiently the accidents and unsoundnesses peculiar to hunters. However, a professional opinion on a young horse is mostly correct, as they have no past history.

I have mentioned some few instances of unsoundness that do not of necessity stop work, and I could mention others of course, but that I should be trespassing on the ground of the qualified practitioner. But, although it be almost impossible to get anything but a young horse as a hunter which is perfectly sound, the nearest possible approach to that desirable state should always be sought; and, on the other hand, if ingenuous youth obtains a hunter who carries him well, and is fast, bold, and clever, he must not be too much disgusted on discoveringprobably through the agency of some "- goodnatured friend"-that the animal has some, perhaps latent, peculiarity which entitles him to the undignified appellation of "Screw." 


\section{THE HUNTER AT HOME.}

THE management and conditioning of hunters has, as we all know, made great progress in the last fifty years. It is seldom indeed that we hear of horses dying after a hard day, unless there is some good reason for such misfortune beyond the severity of the day; yet, in the recollection of most of us, it was a comparatively common thing to hear of horses dying in the field, and soon after their arrival at home. Horses "stop" occasionally now, but they do not die, unless there be, as I have just remarked, some cause independent of the gallop for their demise. If a horse has anything wrong with him at starting, a very moderate day's sport may finish him; but when such is the case he has no business at the covert side.

All stud grooms who are good for anything understand the management of "their" horses, as they call their masters' studs, well enough for any average emergency; indeed, the chances are that they have more knowledge of the treatment of hunters' accidents than the generality of veterinary surgeons, for the clear and obvious reason that their lives have been passed in contemplation of the mishaps peculiar to one description of horse, whereas the veterinary surgeon, though his general knowledge of horses is undeniable, may have a large practice, with hardly any hunter cases in it. Hence, I suppose it happens that many mishaps peculiar to hunters are all but ignored in veterinary works, which treat of diseases 
rather than accidents, and of accidents generally in a very general way, hardly mentioning those peculiar to the racing and hunting stable: e. g., I never saw in any veterinary work the mention of "sore shins," one of the most common of training troubles, though I may say unknown among hunters. Therefore, my excuse for writing on this subject is just this. Although first-rate stud grooms know a great deal more of it than I could tell them, everybody does not possess such an official. Sportsmen of experience, again, do not want teaching; but there are many tyros, who are beginning hunting on rather a small scale, to whom I hope these remarks may be of use. Young sportsmen, with a stud of two hunters, naturally like to get as much work as possible out of them; at the same time, they are hardly likely to have a highly educated individual to look after them, and to such are these remarks addressed. A man with a small stud should always be shy of young horses, but even seasoned hunters will sometimes go wrong. They will not remain sound for ever, though they are not so likely to be lamed in the field as young ones. Amongst the most common of accidents are bangs and blows on the legs. These may be either on the sinew or on the bone, and may have been given by some part of a fence, or by the opposite leg in a scramble. If the horse be not lame, nothing much beyond rest is required; rest, that is to say until the leg is cool and fine again. A slight blow on the sinew may not lame the animal, but by taking him out hunting again too soon he will very likely be lamed. - If the blow is on the bone, and the horse is lame, hot fomentations and rest will set matters straight again, in more or less time. It is a matter of no very great moment; but the event will often be impressed on 
the masters' memory by the appearance of a bony enlargement on the place that was injured, like a splint, but situated on the place where the injury occurred. This is better let alone, as it will not lame the horse, and often wastes away of its own accord. By interfering with it inflammation may be produced, and the horse laid up' for longer than his master likes. If the bump be very unsightly, I should wait till the end of the season before meddling with it, and then apply the mildest of remedies. As good a thing as any in such a case is a green cabbage leaf, put on under a bandage. It makes a sort of mild blister at last, and does not make the leg so sore as iodine or any blister of that kind. Still I should prefer leaving such things alone, for nature sometimes removes them, and if she does not, a blemish on a hunter's leg is of no great consequence, so long as the action of the limb is not damaged. A blow on the sinew is a much more serious thing. In a case of this kind the leg is hot and filled; and it requires some experience to determine whether a blow or a sprain has caused the mischief. But if ingenuous youth is not certain on this point, he may console himself by the reflection that the treatment of both is about the same, so he cannot go very far wrong. Fomentations with hot water, are the first requisite, and a hot bandage at night. By this I mean a flannel bandage wrung out of hot water and put on the leg, with a dry flannel bandage above it. If the horse is very lame, a mild dose of physic is to be recommended, and the hot bandage and fomentation should go on until the inflammation has subsided. At this stage blistering used to be recommended; but I would rather use cold applications, the heat having gone from the limb, and Mr. Clark's lotion with the unpronounceable name is the best thing I 
know of for such a case. When the horse is quite sound bring him to work by degrees, as his work may lame him again. Time is the great thing here. I have known a blow above the knee to lay a horse up for a whole season. If the blow be on the inside of the leg, the horse should wear a bandage for a good time after he works again, for fear of a fresh rap on the old place. Vinegar and hot water fomentations are even better than the water alone, both for blows and sprains. Inferior grooms always recommend a blister after a severe bang on the leg, though they would be puzzled if they were bid to explain the benefit which they expect from the process. Individually, I am opposed to blisters in a general way; rest is the thing for injuries to sinews, nor is nature the muff that some would-be clever ones consider her to be.

Taking misfortunes rather alphabetically, the next that occurs to me is a broken knee, or knees. This is of course not an accident peculiar to hunters; rather, indeed, are they exempt from it, which is odd, considering what atrocious hacks many good hunters are. But, as such an accident may happen, I may as well mention what I consider to be the treatment which brings the animal out again in the shortest possible time, for this is a point of importance with hunters, whose season of work is limited, and to be made the most use of. Of course a very bad broken knee, which involves serious damage to the joint, is a case for the consideration of the nearest good veterinary surgeon. But a moderate case, in which the cut is not very deep, may be managed at home, thus: first, the wound must be bathed with warm water, until no dirt or gravel can by possibility be left in it; next the horse should, after due preparation, have a mild dose of physic, and it will be well to rack him up for the first 
two nights, so that (poor victim!) he should not lie down, and by bending his knees interfere with the healing process. Also, for the first three or four days keep the knee continually wet with a lotion composed of tincture of arnica, two ounces; water, one quart. Arnica is a grand thing for a bruise, and the bruise is often the worse part of a slightly broken knee. If all goes on well, the horse should be out again in three weeks or so, where this treatment is followed; but, to save appearances, he will require a judicious application of some cosmetique for some time to come. When the chance of a blemish is important, and time is not so, a very mild blister has been recommended, which, by taking all the hair off from the knee, allows it to grow again altogether and even, and no doubt this would have the desired effect, but I have never tried it personally, though I have had some experience of broken knees. I have always treated them as above, and have generally got off with no blemish to speak of, and several times with none at all; but this (the blemish) depends a good deal on the nature of the original wound. A very deep cut must leave a mark, treat it how you will; but still the arnica wash reduces the amount of the blemish to the smallest possible extent. On no account should a bandage be put on or near the knee, as severe inflammation would be most likely produced thereby. Broken bones are only to be cured by a bullet, in the majority of cases. Broken legs may occasionally be so far mended that the animal may live and be used for breeding purposes, if it be qualified for such a career; but I do not think any adult horse with a broken leg has ever been repaired to the extent demanded for active work. Hunters are rather liable to fractures of the small bones of the foot or pastern; and for such accidents, if 
severe, there is no remedy. A stiff joint is the most favourable ending that can possibly be hoped for, and that is not a termination that would please a master who wished to use his horse for hunting. A broken neck speaks for itself, either in the case of the horse or his rider; so does a broken back, which is a case for merciful destruction. But while on this subject, let mo advise young sportsmen to be sure that their horse's back really is broken before they have him destroyed. A horse may fall, and lie for some time exactly as if his back were broken, when nothing of the sort is the case; and there are always lots of "good natured friends" about, who are only too ready to put a horse "out of his pain," when he belongs to "another fellow." A horse whose back is really broken I do not think suffers much, as he is paralysed everywhere behind the fracture; so it is no great cruelty to wait until a competent opinion can be had before proceeding to extreme measures. The test of trying whether the prick of a pin can be felt by the animal (of course behind the supposed place of injury) is not infallible. I remember a case in point; and, indeed, I pride myself upon my remarks being founded on actual experience. It happened very many years ago-when the young sportsmen, for whose benefit these lines are (with all humility) intended were in their "berceaunettes," if indeed they had made their appearance at all-at a country steeplechase meeting (it was one then, but now it would be a metropolitan one) a horse fell, and lay where he fell. A grand chorus arose from the excited spectators of "His back's broke! Cut his throat!" (I don't pretend to know whether the lenders of this demonstration had laid against the steed; possibly so; this occurred in the dark ages; we can now make "a dead 'un," with- 
out personal violence to him.) Well, this advice was acted upon; the poor horse's throat was cut, and in his last agony he rose to his feet, and staggered a little way. The frantic delight of the owner, as his horse thus demonstrated that his back was as right as that of the elephant at " the Zoo," who carries scores of children at once, may be "imagined, but not described." In another steeplechase I once saw a horse over-jump himself, and fall, and lie with all the wind knocked out of him, with the same recommendations from the bystanders. But the rider, who was also the owner, was a man of patience and wisdom, though only a baby cornet, and he quietly surveyed his prostrate steed for some minutes, at the close of which the animal rose, as well as he had ever been. The juvenile remounted, sent him along, and, by a lucky chapter of accidents, falls, and refusals, not only caught up the leaders, but actually won the race. A very little indecision on the part of this youth would have lost him his horse, as the crowd were absolutely thirsting for his blood. Sprains or "ricks" of the back are not uncommon. Sometimes the horse recovers from them perfectly; more often he does not. In any case advice of the best attainable veterinary surgeon should be taken. Injuries to the back cannot be dealt with by amateurs. I can call to mind two instances of ricked backs at this moment. Both accidents happened with hounds-one at a brook, the other at a fence. The one horse was laid up for a long time, but quite recovered, and was as good a hunter as ever afterwards, which I take to be an unusual instance. The other recovered so far as to go well in light harness, but her hind action was never, to my eye at least, quite the thing. I do not know how she ended, but she went in harness for two 
years after the accident. An odd case of injury to the back occurred to the horse of a friend of mine; a lot of hay trusses was dropped on to his back from a loft window. He was obviously damaged, but recovered so as to hunt again ; but paralysis came on a year after, and he had to be destroyed. Affections of the kidneys often cause a horse to move as if his back was damaged, but professional advice should be sought in all such cases. The common run of grooms are very fond of ascribing every abnormal movement to an injured back. I heard a sapient specimen suggesting, some little time ago, that the back was injured, of a horse who was rolling about rather oddly in single harness. The fact was, the creature was very groggy in both fore feet, which anyone of common knowledge could see; and this caused him to go, as it were, one pace in front, and another behind-the result being that he rolled about, and persuaded this ignoramus that his spine was damaged. Other fractures are luckily rare. Broken ribs have, I believe, reunited, but I have never seen a case. A fractured skull is not an accident that anyone would expect to happen, yet I have known two cases, and both victims were hunters. One got loose after a fall, or at exercise-I am not quite sure which, as I did not see it, and it is long ago; she ran her head against a bough of a tree, and was killed. The other was a hunter, who was being led through a low archway; being excited, he threw up his head, struck the brickwork, and perished. Curbs are unmistakably the property of hunters and racehorses, but more instances happen in the hunting than in the training stable. Many men who know a thing or two think but little of them, and I must confess I have never known a horse permanently lamed by one, though they often are lame for a 
long time. I have had, oddly enough, but one horse with a curb, during a somewhat extended hunting career in all sorts of countries; but then I never buy one with "curby" hocks. Every rule has its exception, and I did buy one once, but he had been fired, and was considered to be repaired. These hocks stood one season's work, but sprung a fresh curb the following winter-a sufficient proof of the uselessness of firing curbs. I worked the animal all through his recovery, after the first inflammation had subsided, stimulating the hock with a sort of absorbent blister on the curb place. The hock never went again in two years' time, when the animal diedI am glad to say not in my stable. Had I another case, I think I should apply Mr. Clark's lotion, the "Neurasthen," \&c., of which I have a very high opinion, and indeed the only fault I find with it is its absurd name. It is capital for all injured sinews or tendons. A curb is a misfortune which may happen to any horse any day, especially when they are shod in the usual way, with the frog off the ground. The injury being to the perforans tendon, or its sheath, is I think least likely to happen in a severe degree to a horse who has Charlier shoes behind, and whose frog is consequently engaged in its proper duties of assisting the tendons. I have known a hack spring a curb, and, receiving no rest nor treatment, cure himself; but this was a very slight case. Again, I know a mare who after every hard day presents an appearance in both hocks, which just stops short of being a pair of curbs. She does not go lame; but with a heavier weight, or her days coming quicker together, there would be no mistake about it. A high-heeled shoe is often put on to the foot of the curby leg, but I do not think it makes very much difference to the animal. I 
should prefer no shoe at all; or if the patient was shod à la Charlier, I should leave him so. If I could spare him, I should rest him ; if not, unless he was very lame indeed, I should work him : with a curb horses are often lame one day and sound another. I should apply the cold lotion with the long name, keeping the bandage on the right place by a piece of cloth, flannel, \&c., cut into strips at the sides, which strips are meant to tie as strings, two above the hock, the others below, leaving the point of the hock free. Next come corns. Some horses are very subject to them when shod in the common way. Horses with tips or Charlier shoes never have them, as they are caused by the pressure of the shoe, and these shoes do not approach the corn place. If the horse be very lame, and the usual style of shoeing be adopted, the most simple plan is to cut off the inside quarter of the shoe, and leave the inside heel bare. The horse will then often gosound, and you will have a tip on one side of his foot; and observing this, and that no ill effects occur, you may possibly arrive at the conclusion that with a regular tip, and his foot level, instead of on one side, your horse might go better still. When tips are worn, of course the sole and frog must be left in a state of nature, and neither they nor the heels will wear away too fast. Horses will go short in tips at first, of course. A suppurating corn is a case for the vet., so I will offer no suggestions on the subject. Cracked heels lame a horse sometimes to a very great degree, and where the groom is a careless or ignorant one they are not uncommon. A mild dose of physic and dressing with the following ointment will set most cases to rights :- Superacetate of lead $1 \mathrm{drachm}$, lard 1 ounce. Horses which are kept on good hard meat all the year round, with occasional physic, have 
no business to have cracked heels, and if these are not left wet after work, they will not be troubled with them. By the way, I have known cracked heels produced by the constant use of wet bandages in one case. Chronic cough is quite a hunter's complaint, though not peculiar to them. It arises in most cases from neglect in the first instance, and there is always the chance of its ending in roaring. This danger is reduced as much as possible by keeping the horse cool in his system. A few carrots now and then are always good for a horse suffering from chronic cough ; but, on the other hand, it is not wise to give them too oftentoa horse doing hard work. A common cough should be nipped in the bud by a smart blistering of the throat, combined with diminished corn, and the best application for the purpose is "Farrell's vesicant," a patent blister which is to be got of most saddlers now, and which raises a blister in a few seconds, ceasing to give pain in a few minutes. The whole thing does not occupy much more than five minutes, and, though the pain is sharp while it lasts, it worries the horse less than the comparatively slow action of a mustard embrocation. If a little of it gets on the groom's hand, it will give him a lesson concerning the sensation of a blister, which may possibly have the effect of preventing him from recommending blisters to be applied on all occasions to horses. Capped hocks do not lame the horse, and therefore need no consideration here. Contracted feet are not a cause but an effect of lameness-any foot lameness may produce them; but we will consider those to which hunters are most liable presently. Cutting and brushing are very common faults among hunters; hitting the legs, too, is a thing by no means unknown. A horse inclined to brush or hit himself may not do it while he is compara- 
tively fresh ; so as a hack or in harness, the same animal might be free from the fault who as a hunter would be guilty of it to a disgusting extent. For it is a "disgusting" sensation to the rider when his horse hits his fetlock, and then goes almost on three legs for more or less distance, and just as the pain is subsiding repeats the performance. Nor can it be pleasant to the horse. Hunters do this more than other horses, because they are ridden long distances on the road when they are tired, and when their failing spirits are rendered still lower by leaving the hounds and other horses. Now, a hack is never ridden till he is as tired as a hunter after a long day, with twelve miles or more to go home, and also he has not to undergo the dispiriting operation of leaving the hounds and plodding his weary way home alone. To begin with cutting of the fetlock, and the remedies for it: A horse who absolutely cuts in front is more than objectionable, he is unsafe; but luckily there are not many such, and those which answer this description must be ridden in boots. When the fetlock only is struck, a common " dealer's boot," which goes all round the joint, is best, as it cannot slip round; or rather it can, but in doing so it leaves no part unprotected. It must be fastened with a broad tape, or strap and buckle; a narrow one will cut the skin. A horse who hits a splint or the sinew must be ridden in boots or bandages. I much prefer the latter, as when properly put on they will not chafe the leg, and their protective power may be much increased by placing a strip of stout felt between the inner and outer folds of the bandage, cut to the shape of the leg. This will not stir, and will give all the benefit of a stout boot without any of its drawbacks; and to the use of boots there are several. India-rubber 
ones alternately contraet and expand, sometimes pinching the horse's leg, and then again becoming so loose as to admit no end of mud and chafe the skin; whilst leather ones become as hard as boards; and the best, the cloth faced with leather, do this a little, and also allow much more mud to get to the skin under the boot than bandages do. The latter properly put on and tied will never shift or come off, but if the groom mistrusts his ability in adjusting them, he had better put a few stitches and sew them on. Speedy cutting is a vile trick. Some horses do it when they are over-fresh, from wildly flourishing their legs about, others when they are tired, while some treasures are to be found who always do it. Proper shoeing may modify this fault, but a horse who speedycuts in his gallop is never safe without a boot. A stiff leather boot will protect the injured part, but the better plan is to put a common india-rubber ring boot on to the offending foot, between the fetlock and the coronet; this will fend off the blow, and is in every way preferable to a high boot, which must needs possess the disadvantages enumerated above.

As to cutting behind, I must have another turn at what my readers probably consider a "cuckoo cry," viz., the Charlier shoe. But facts are stubborn things, and since I have used this shoe behind, three different horses of mine have at different times ceased to brush, who did it before they were so shod.* Other ways of preventing this disagreeable action there are. To put a three-quarter shoe on behind is generally efficacious; if cutting off the inside quarter does not cure the evil, try cutting off the outside, and that will in almost all cases effect a cure, but of course the foot is on one side, which

* And since I wrote this sentence I have cured four more. 
cannot be desirable. Boots almost always cut the hind fetlock, and lame the horse until they are taken off. If they extend a little above the fetlock joint, and fasten. with two or more buckles, they will be less likely to do this sort of damage, as the lower fastening may be looser than it otherwise could. While on this subject, overreaches may as well be considered. With the inside edge of the hind shoe bevelled well off, or with a Charlier shoe let well in, they ought not to occur, in the form of a cut at least, though the blow will be the same, and a bruised heel the result. Still, a blow is better than a cut. I have, oddly enough, had only tro overreach cuts in the last six seasons; but this is good luck, and I may have two more the next two days that I hunt. One of these was done with the common shoe; the other with a Charlier shoe badly put on, not let in, and left sharp at the inside edge. I need hardly say that I saw this last article for the first time after the accident, owing to uncontrollable circumstances. An overreach high up, above the heel in fact, is a case for professional advice; but the common can be well treated at home by frequent bathing with arnica and water; a very loose flap of skin may be cut off. These mishaps seldom lame the horse, so he can do his exercise while the case progresses-a great point, as idleness in the season is most prejudicial to a hunter's future well doing. Do not hunt him again before the cut is healed, as another blow on the bad place would make a serious affair of what should be comparatively a trifling one-at all events, a business of ten days, say. An overreach on the sinew is beyond home treatment, as the cut if deep will require to be sewn up, and I never yet saw a groom who could be trusted to do that sort of thing. 
For cuts and wounds to which horses specially in wall countries are exposed, nothing is better than a little Friars' balsam and a good deal of patience. Bad feeders have no business in a small stud; if one finds his way there, the best plan is to leave him quiet in his box, and never disturb or approach him more than can be helped. Many horses who feed badly during the day will eat up at night any amount, in reason, that is given to them. Bad feeders are generally excitable, nervous animalsnot at all the style of steed suitable for a man who wants to see a maximum of sport at a minimum of expenditure. I have had very few bad feeders myself; indeed, that is a quality $I$ always avoid in buying as much as possible, as I never have found a way of mitigating the evil. Leaving them quiet is about the only thing that can be done for them if they are nervous ones, also feeding them always at regular intervals. "Nimrod," in his "Condition of Hunters," speaks of giving a bad feeder a teaspoonful of cayenne pepper; but this could hardly be administered every day, and some horses will be off their feed for a week after a hard day. Of course, it is a mere waste of breath for a buyer to ask whether the horse he is looking at feeds well, but a pretty good guess may be made by the look of the animal. Washy ones generally show their quality more or less in their appearance, unless they are tremendously "made up" for sale. Let us next consider the feet. About the worst thing that can befall a hunter is an attack of fever in the feet. A horse who is fit to go "ought" not to be subject to such a chance; but a great many hunters are ridden hard to hounds when they are anything but fit. My own experience of this very unpleasant malady is limited to two cases ; and here is their history. One resulted from 
riding a horse, who was not in condition, through " the run of the season." The proceeding would have been inexcusable had it been intentional ; but it was the fault of the second horseman, who lost himself before the second fox was found, the good run being with him (the second fox). The result of this day's work was an attack of general inflammation, which dropped into the feet on the second day. The mare was bled copiously, and her shoes were taken off; she also stood for a week on wet clay during the day. She never cared much about lying down during the attack; and in seven weeks she was sound and at work again. She never had a relapse, although her work was all on the road, and I rode her for more than three years, after the occurrence, as a hack, and also worked her in harness. I never hunted her again; indeed, she was not a hunter, though she might have been a first-class one had she been used as such. The other case was that of a four-year-old horse, who had a bad attack of fever in the feet after a long but not hard day, two days after the day's hunting. He lay down for two days or three, I am not quite sure which, as it was a long time ago. The veterinary surgeon who treated him would not bleed him, but gave him a strong dose of physic, and rest of course, his shoes being taken off. In a month's time he was so sound that I rode him with hounds again, the result of which indiscretion was a second attack, worse than the first. I then threw him up for three months, and blistered his coronets repeatedly. He then did a few days' hunting, with no ill effect, and carried a whipper-in for two seasons after that-being none the worse for his illness, any more than was the mare; but he required a little extra care in his feeding and condition generally. The cause of his attack was 
that the groom had, contrary to all orders and precedent, been giving him beans. Now, I think no hunter under six years of age ought ever to touch a bean, and if they wait till they are seven before making acquaintance with that vegetable, so much the better. For old horses they are excellent in most cases, but there are exceptions even here. I was decidedly fortunate in the termination of both these cases, and I do not mean to say that such luck is common, as shedding of the hoof is not an unusual ending to the illness, and perhaps dropping of the coffinbone to follow that. I knew a case in which a mare lost both her hoofs in front, and in time they were replaced by an equally good pair, and she fetched a long price with the new feet; but this is a very unusual case, the new feet being seldom good for much. I should always advise bleeding in the first stage of laminitis; had my young horse been bled, I do not think he would have had the relapse which he did have. When the inflammation has subsided, blister the coronets sharply all round, and shoe the horse, when he is shod, either with a bar shoe, a Charlier, or a tip-anything, in fact, which will divide the weight between the sole, heels, frog, and laminæ, instead of making the latter carry the whole weight of the horse, which the common mode of shoeing almost invariably does. Many old hunters suffer from chronic fever in the feet. The action of such horses plainly shows the nature of the complaint, as they go as much as possible on their heels, to relieve, if they can, the laminæ. Blistering the coronet diverts the inflammation, and these horses, above all others, should be shod as I have just directed. Tips are easier managed in remote country districts than Charlier shoes, and I really think they are as effective. 
I speak hitherto only of the fore feet, but no horse ever yet had laminitis behind only, although cases have now and then occurred, but very seldom, where all four feet were affected. In the acute laminitis putting the feet in hot water affords relief, by softening the horn; but it is very difficult to do this when both feet are affected, unless you have a bath for the purpose. When it can be managed, bleeding at the toe gives local as well as general relief; bleeding in the neck naturally affords the latter only. Many horses are never again sound in their feet after an attack of laminitis, but this is an evil to be dreaded rather than expected as a natural consequence. Laminitis was called "founder" by our forefathers; they also had an imaginary disease in their list called "chest founder," which was really foot lameness, and the muscles of the chest decreased from want of use of the arms and fore legs generally. The symptoms of acute fever in the feet are quite unmistakable; the most prominent is the position in which the horse stands. He leans back, with his fore feet out as far as possible in front of him, and bears all his weight on the hind legs. This attitude cannot be mistaken, and professional assistance should be sought at once. In its absence bleeding can do no harm, unless it be overdone; about a gallon of blood is an average quantity to take from a horse suffering from fever in the feet. If the horse be bled at the toe-which the blacksmith can generally manage to do well enough-the shoe will have to be tacked on again, in order to keep in its place whatever has been used (tow generally) to stop the bleeding. The worst case of chronic fever in the feet that I ever saw was that of a light harness mare; she was bought at Tattersall's, being to all appearance sound, 
and possessed of the most extravagant trotting action. This action soon decreased when she came to work; then she used to come out going short, and work sound; and finally she could not work at all. Then she was turned out to grass for five years, and, being the screw I describe, her sapient owner bred four foals from her, selecting a roarer as the sire. One foal, by the way, died at two years old; another had his dam's complaint from the end of the first month he was worked, besides being the worst roarer I ever heard; the third is still going, and is sound in his feet, though a fearful roarer; and the fourth was disposed of at the dam's foot, with her. This gentleman never ceases to declare that breeding horses does not pay! One would think that a winter's run, let alone five of them, would have done something for the mare's feet, but she got very little better, if any. I may as well mention that she was barefooted all this time. Pumiced foot is often the result of fever in the feet. I should fancy that the old-fashioned plan of standing the horse barefoot upon "pitching" might do good here, and a system of shoeing that allows of frog pressure might prevent a relapse, but I cannot speak from actual experience. General inflammation often ends in fever of the feet; it is a case for the ret. and above my powers of advice. Bleeding, however, is a safe mode of treatment in all cases of inflammation. Inflammation of the lungs may be brought on by standing about after a quick gallop-while a fox is being bolted, for example. Bleeding and blistering are the chief remedies to be applied, but the veterinary surgeon must direct this, and by no means the groom, the farrier, or the village cow doctor. Big legs are very common amongst hunters; sometimes they are to be reduced, 
sometimes the contrary. If they do not lame the horse, they are best let alone. They are often the result of indiscriminate blistering. A leg blistered while inflammation still exists in it is very likely to be a permanent blemish in this way. At the same time they (big legs) sometimes become fine of their own accord, after being out of shape for perhaps two seasons; but in such cases there has been no bony deposit. Bony enlargements of anything like long standing are best let alone, the remedy being often worse than the disease. If the horse is absolutely lame by them, that is another thing altogether; but then professional advice will be advisable.

Navicular disease is an affliction common to all horses, and it will be so as long as the frog, which is meant to protect the navicular bone, is pared away, or allowed to diminish of its own accord, which it will do when the foot is improperly treated and shod. Horses with weak feet, and who have always large frogs, are least liable to the disease. I am told that one of the most eminent of our veterinary surgeons (Mr. Stanley, of Leamington) has stated it to be his conviction that hoj ses shod à la Charlier will never have navicular disease, and certainly they ought to have the best possible chance of avoiding it. When the disease exists it is perhaps less prejudicial to a hunter than to any other horse, as his work is on soft ground, and I have known several horses hunt for season after season without it. It is not to be cured, I firmly believe, after it is once well established. The horse who suffers from it almost always points his toe in the stable, in a manner that must be familiar to every one. He also goes on his toe as much as possible, thereby wearing away the front of his shoe. The oldfashioned notion was that neglecting to pare the sole of 
the horse's foot was one cause of this disease, and a very far-fetched theory it was. Although all horses had their soles pared, the disease flourished. Time will show whether treatment the reverse of this will ward off the evil. No shoeing will make a horse go sound who is lame with navicular. "Nerving" will do so of course, but at a great risk. A nerved horse will bang his foot about until he literally knocks it to pieces, breaks some internal bone, or ruptures some important organ. Also, if he picks up a nail, or experiences any similar accident, he cannot inform you of the fact by going lame, and any amount of mischief may ensue. Also nerved horses are neither safe nor pleasant to ride, and there is an everpresent chance of their losing the nerved foot altogether, I knew a hunter, and a capital one was he, who hunted for five seasons with one foot nerved; but latterly the nerve must have reunited, as he used to be lame. His end was rupture of the perforans tendon, and death, of course.

Horses with navicular disease are always getting worse, slowly perhaps, but surely. If I had such a one, and he were a good horse, I should work him as long as I could, and then shoot him. The very small sum for which a lame horse can be sold ought not to weigh, even with the poorest owner, against the misery to which the poor animal is condemned by being sold to the only sort of person who buys lame horses. Another very common ailment among hunters is ossification of the lateral cartilages. This is said to be caused sometimes by a sprain, but I think it is more commonly the result of bad shoeing. The effect is simply to turn the cartilage of the heel into bone. While the change is progressing the horse is generally lame. When it is perfected, the horse may be sound, but he will always go in a stilty 
manner, with no spring, so to speak, in his action. When the disease commences it is generally curable. The horse goes short, or lame, more or less, and the groom will very likely ascribe the misfortune to a corn, a splint, or anything in the world but the true cause. Feel the heels of your horse above the coronet. If they are perfectly springy and elastic, they are all right, but if they feel hard anywhere, like bone or stone, they are wrong-ossification has commenced. Blister the heels, for two inches above the coronet, with biniodide of mercury 1 drachm, lard 16 drachms (mix). When the scurf caused by this application comes off, repeat it; meanwhile have your horse shod with tips and exercised moderately. Taken in time, the disease is to be checked -at least, I have succeeded in doing so in three different cases in the last two years; but I ascribe my success chiefly to the use of the tips and Charlier shoe, both of which I have tried. Ring bone is a more visible affection of the same nature. The treatment is the same; sometimes, however, firing is requisite, and that even is not a certain cure. Luckily, it is not a very common complaint with hunters, and does not always lame the horse, in which latter case of course it should be let alone.

Next we come to one of the most common maladies of the hunting stable, and one that I have never seen mentioned in print-I allude to "mud fever." It is not dangerous, as it never kills a horse, but it sometimes lames them, and, if the master goes in at all for appearances, it keeps the steed at home. It is very curious that no veterinary writer has, to my knowledge at least, ever alluded to this affection, with the exception of an article on it which appeared in the Field. This would lead one to suppose that it is an affection of modern 
date, as even "Nimrod," that most practical of writers upon stable subjects, never mentions it. So one would think that it was a new thing, and theory would suggest that it has arisen since clipping the hunter became general. I can remember the existence of such an affection for the best part of twenty years, and I am in a position to say that it has nothing to do with clipping or singeing, as I have had a mare attacked who was hunting with her winter coat on. I ascribe it to general foulness of the system, arising from hard work, stimulating food, and heats and chills. New oats are said to be a predisposing cause, but, although I have occasionally been obliged to give hunters (after Christmas) oats of the last harvest, I have never found them cause mud fever, although they are otherwise objectionable. Horses who have been summered at grass are especially liable to it. Washing hunters on their return home with hot water is said to cause it as well; but foulness of habit, or, in other words, want of physic, is, I am persuaded, the true cause. Since I have left off giving my horses green meat in the summer I have never had a spot of mud fever on any of them. But each horse has two doses of physic between his beginning exercise and Christmas each year, one about the middle or end of February, and one on leaving off hunting. My doses are, however, very mild, as I depend chiefly on the preparation, and never give more than 4 drachms of aloes, often only 3 ; this, of course, depending on the constitution of the individual horse. Little time is lost by these mild doses, as the horse can hunt on the fourth day after the physic has "set"-sometimes even sooner. This is my mode of prevention of mud fever. The cure is the physic, better late than never, and a little rest. When there is 
much soreness of the parts where the hair has come off, an application of fuller's earth is cooling and efficacious. When the skin peels off between the fore legs, the horse is quite lamed by the soreness thereby produced, and goes as if he were stumped up for life. A horse with mud fever all over him is a disgusting object, and continues to be one until his summer coat begins to come, and then for a time he looks still worse, being all over patches. The disease, if it may be called so, generally appears at the time when the winter coat has ceased to grow, and before the new coat has begun. But I have seen it appear before Christmas, and this was the case in which it appeared on an unclipped mare, and after her third day's hunting. Horses that are not working hard do not have it-at least, very seldom. It is those who are coming out in their turn all the season through, who are most liable to it. All that can be done is to give a dose of physic immediately on the appearance of the first spot. Roaring, whistling, \&c., I say nothing of, as, though they are the hunter's greatest bettes noirs, they are incurable. A man who buys a roarer without knowing it is a "muff;" one who sells one without mentioning the failing, a rogue. Sprains are a great bore in the hunting stable. I don't know anything much better than rest and cooling applications for them, though a vet. often manages to run up a fair-sized bill for embrocations and liniments, which he considers beneficial. Sprains of the shoulder are generally imaginary; when the groom cannot otherwise account for lameness, he declares it to be there. I have, however, known several cases of lameness from falling on the point of the shoulder, or from a blow received there, and these are very troublesome affairs, and often 
incurable. Veterinary assistance is here demanded, but rest is the great thing. For sprains of the back sinew, which are of all degrees, I know of no better application than the absurdly named lotion which I have alluded to above. Many people advise the wearing of a high-heeled shoe in these cases; I should prefer no shoe at all. Firing injured sinews is only too common a remedy. I had rather try the rest necessitated by the firing alone, without the pain to the horse of the operation. A horse fired on the fore legs loses more or less the action of them, even if the blemish is not considered. Frog pressure is the secret of clean fore legs. My idea that firing fore legs is not a certain improvement, is rather confirmed by the practice of the racing stable. As a general rule it may be said that no race-horse is of any use after he has been fired. However, many hunters will be fired on the back sinews, whatever a minority of horse owners may think on the subject. Now, though I do not approve of firing sinews, I do approve of the use of the iron for bony excrescences when they are first appearing. For spavins I believe firing is the most effectual remedy. If a horse is lame by a spavin in the middle of the season, if he be sound enough to work at all I should not rest him; that is, supposing that he goes sound when he has travelled a moderate distance. I should after each day's hunting blister the hock with some absorbent-perhaps the ointment recommended in the case of ring-bone is as good as any, though it is very mild, according to some people's notions-and at the end of the season I should have the hocks fired. But there is no occasion to score the hocks all over, as a few lines drawn on the spavin place answers every purpose, and of course heal quicker, with hardly any 
blemish to follow; also the horse need not be cast, which is a great point gained. Many horses have injured themselves for life in struggling when thrown down; the back has often been damaged in this way. Splints generally go away of themselves sooner or later; if they interfere with the sinew, the same ointment would suit them as has been mentioned above. I think I have already said that a cabbage leaf is a mild but effective sweating blister for a splint. Sore backs are a tremendous nuisance when they occur in a hunting stable, and some horses are much more liable to them than others. For their prevention, the stuffing of the saddle should be carefully looked to; the back of the horse, under the saddle, should never be clipped; and the saddle should not be taken off too soon after the horse comes in. When the skin is broken the clothing must be kept off the place, and salt and water applied. This, with time, generally effects a cure. A "sit-fast" is better attended to by the veterinary surgeon. Lately a contrivance which promises to do away with sore backs has been invented; it is a leather saddle cloth, polished and smooth on the side which touches the horse, and I was lately assured by a gentleman that a horse of his had recovered from a sore back-that is, that the back had healed-without rest, and merely by the use of this article under the saddle; but I presume that the sore had begun to heal over before the horse was ridden. As a prevention I think it will be found capital. Stubs and thorns are peculiarly the property of hunters, and a great bore they are. A stub in the foot or fetlock demands more scientific treatment than the groom can give, and so may a thorn if it be allowed to remain in. After a day's hunting the legs and joints 
should be thoroughly well searched for thorns, and when the skin is wet they are much more easily discovered than when the hair is dry. When found they must be taken out whole if possible, and a pair of tweezers will usually effect this. Sometimes the skin will have to be slit up a little to get at the thorn; this can be done easily enough as a rule, but there are localities, such as the knee, where a groom must not run risks of this kind. When the point of a thorn is deeply seated and inaccessible, it will be got rid of by suppuration; but sometimes it will be a long time first, and I should not rest the horse if he can work-by which I mean if, as in the case of spavin, he "works sound." Work will hasten suppuration. Bran poultices, too, should be applied to the place where a thorn is supposed to be, if it can be done; but of course there are places where they cannot be kept steady. If the thorn be in the knee, and the pain and swelling great, hot fomentations are advisable, and rest until suppuration begins. After a hard day, when gruel cannot be had, water with just the chill taken off is most refreshing to the tired hunter, but if it be too warm it will produce scouring. When the day has been so hard as really to distress the horse, he should be "done up" as quickly as possible, have his gruel and plenty of mash, but little corn; and it will be wise, if his feet have been knocked about by jumping into roads or otherwise, to place them in poultices for the night. His legs will be benefited by being enveloped in hot bandages, and some more gruel last thing will not hurt him if he will drink it. Next day fifteen or twenty minutes' leading in hand, with plenty of water, not too cold, and perfect quiet in his box, ought to set him to rights, unless he has sustained any accident. 
Being staked is the hunter's accident par excellence. In such a case return the intestine if it protrudes, and make a bandage of girths and your own waistcoat. If the horse be very restless. or if he kicks, tie up a fore leg until the bandage is complete; then lead him slowly to a stable. If the intestine cannot be returned, or if it be injured itself, your horse will probably die, and that pretty quickly. A stake elsewhere than in the belly kills from loss of blood; and if the bleeding be excessive, no amateur can do much. Of course professional assistance must be sought in all these cases; without it, in any but the slightest cases, death is all but a certainty; and with it a large percentage will end fatally. This ends my list of hunters' ailments, and my readers may remark with truth that they have heard no news-also that my chief remedy seems letting injuries alone to cure themselves. Well, there is nothing new under the sun, and, knowing as I do the number of men as well as horses who have found remedies worse than diseases, $I$ always like to give Nature a chance where I can, in preference to her younger sister, Art. And I would advise my young friends to do the same, Dame Nature being a person whose experience exceeds any of ours, though she has never attended a college, and indeed I may say is all but unknown in such places! 


\section{USE AND SHOW.}

No horse owner would confess to keeping even one animal solely to look at, but many men do so by more than one horse. Every horse is kept, or supposed to be kept, for some purpose more or less useful, and, as there are many about who perform no useful duties whatever, it may be fairly assumed that they are kept to look at, though their owners would never acknowledge the fact. A hunter which cannot cross a country is not a very uncommon article, nor is a harness horse whose pace in harness is about equal to that of an energetic pedestrian an unheard-of thing; while, again, there are scores of so-called hacks to be met with who shy, stumble, are restive, or in other ways shirk their duty, which is to carry a man safely along the road. All such animals are kept to look at, unless they have some other talent of a different nature from those which their professions would argue the possession of. Thus the useless hunter may be a rare harness horse; but if he be only a useless hunter, and nothing more, he will be "kept to look at," for a time depending upon the judgment and luck of his owner.

Some men never know when they have a good horse; many more don't know when they are in possession of a real brute. The latter will keep the useless brute and believe him to be valuable, and if the owner be satisfied no one else has a right to complain. A good judge, on the other hand, may occasionally be saddled with a brute; 
but, though while he has him he keeps him "to look at," as the phrase goes, he keeps him no longer than he can help, and, if he be a judge of men as well as of horses, may sell him to some one whom he will suit perfectly. But this requires tact and judgment. If a seller said to his customer, "This horse is not worth his corn to me, as he will stop in ten minutes if ridden straight to hounds, but is worth money to you, as being sound and quiet, with a failing that you will never discover, as you seldom gallop, and never jump," would the buyer take the horse in a gift? I rather imagine not. If the fault was not mentioned, the timid rider would find himself perfectly suited, and could have no reason for complaining-would, in fact, probably be delighted with his purchase. If such a horse, on the other hand, was sold to a hard-riding man, he would consider himself "stuck," and justly so. For, in stable matters above all others, we find the truth of the proverb, that "what is one man's meat is another's poison." The Clipper was considered to be about the best horse in Leicestershire, and, with Mr. Lindo on him, I believe he was so; but what would a nervous elderly gentleman have thought of him? Such a one would most likely never have got him to the covert side at all, and, if he had managed that much, why, so much the worse for him afterwards.

Some men keep horses for show, others for use. To do the first is the part of a rich man-at least, any other who attempts it will find out his mistake. Of course no one would for choice possess a really frightful horse; but poor men must sacrifice appearance, more or less, to utility. A pair of $40 l$. phaeton horses may be found, which will do as much work as the most expensive pair that ever came out of-shall we say Mr. Sheward's stable? 
And to a man who wants to be conveyed about quickly and safely, and nothing more, they are as good as the expensive ones ; but they are sure to be wanting in showy qualifications. They are most likely ugly, or not perfectly matched in some respect; their action is only just good enough to enable them to scratch along at a fairish pace without danger of falling; or there may be fifty other shortcomings which will not prevent them from doing their work, and doing it well, but which would prevent a person who goes in for appearance having anything to say to them; and the expensive pair might be possessed of elegances that would be thrown away upon, or not appreciated by, the man who merely wants his carriage dragged about. The same remarks apply to hacks. A country gentleman of agricultural tastes requires a sort of beast very different from that which carries a young guardsman up and down Rotten.row. Good temper, good paces, and soundness are the chief requisites of the first; the other need not be a model of soundness to begin with, but he must be especially neat in appearance, and possessed of action, which would be quite thrown away in a ride round the farm or to a magistrates' meeting. But though the stepper would be the inferior animal for country work, his action being fatigue to himself and loss of time to his rider, the country gentleman could enjoy a ride in the park on his country hack, show not being an object.

Buying horses for show is a very different thing from buying for use, and the former requires less judgment. No good judge, if buying for immediate use, appearance not being of much importance, would buy a young horse. A bad judge would; perhaps on the principle that a full bottle will afford more drink than one out of which a 
glass or two has been taken. But horses are not like bottles of wine; no man, however clever he may be, can be certain about how a young horse will turn out, let the juvenile be ever so promising. All that anyone can say of an untried horse is that he ought to make a good one, while the virtues and shortcomings of a horse of mature age are pretty well known, and generally more or less visible. In buying a fresh young horse of a dealer, you get a sound horse; the dealer warrants him to be sound at the time of sale, but of course he cannot answer for his remaining so when put to hard work. There are many blemishes which in no way detract from a horse's working powers, but which unfit him for purposes of show, such as London work, where appearances must be studied. Such animals, and sound aged horses, are the ones to buy where work, and work only, is the object. Persons who wish for "performers" who are also handSome must go to a first-class dealer, and be prepared to pay. Then they must use their judgment, or, with all their expenditure they may find that they have missed getting hold of perfection. Looks they are pretty sure of obtaining; but it is possible that they get "only that, and nothing more." Poor men will do well to avoid young horses, and even the six-year-old sound horse of the dealer. They are sure to lose by the latter, as they buy him at the time when he is most valuable- "quoted at par," as it were-and the dealer must make his profit on him. The rich man will keep his horse, if he likes him, until the animal be worn out. If he sells his stud, for any such reason as going abroad, he expects to lose, and does not mind doing so. This does not suit a poor man. Hunters differ from other horses, as being fancy articles in most cases. It may pay a poor man who is a 
good horseman to buy a four-year-old and make him a hunter; if he is lucky as well as skilful, the animal at six or seven years old will be worth a good deal more than he was at four. But this only applies to hunters. A hack must not be knocked about much before he is five years old, and he is then worth as much as he ever will be. A harness horse the same. A dealer can make a profit on them by buying them from the breeder; but no gentleman can do so in buying them from the dealer. Nor could he do so if he went to the breeders direct, except in very isolated instances. A man who wants work done at a moderate price need not risk a fortune; but he must be content to put up with some shortcomings in his stud, and must cast all idea of show and appearance to the winds. His harness horses may be of the "useful" description of the sort described above. His hack may be hardly fitted for Rotten-row. It may be plain, possessed of a bad mouth, even perhaps of "a temper," and yet be able to get over fourteen miles in an hour, and to do this, or something like it, three days in the week or more. His hunters will not be beauties; they will be blemished, or possessed of qualifications which would cause them to be rejected by many men. They need by no means be sound from a dealer's or vet.'s point of view, and may yet do an infinity of work across country. Indeed, many of the most expensive hunters belonging to the greatest "swells" in the kingdom would cut but an indifferent figure if run out upon stones the morning after a hard day's hunting under a professional eye. What, then, can be expected of forty and fifty pounders?

The great discovery of modern times, as far as hunters are concerned, is that of clipping. Although many horses are clipped and singed now, who would not have 
required it fifty years ago, it gives a wonderful chance to horses who have been badly summered. Of course no sensible man would turn a hunter to grass in the summer if he meant to hunt him the following season; but if by misfortune, one gets hold of a horse that has been so treated, clipping or singeing affords the only chance that there is of getting him anything like fit to hunt before Christmas-in a fast country at any rate.

In speaking of aged horses as being more calculated to do work than others, I of course allude to sound ones, or to those who may be unsound in some way that will not interfere with the particular work for which they are intended. It should be remembered by young buyers that a horse who is sound at eight years old will, with luck, be sound for another six or eight years, he having been a really sound horse to begin with. But a four or five year old is like the proverbial young bear, with all his troubles before him ; and where his soft place may be can only be discovered by experience. A model of soundness at four may be a heap of infirmity at seven years old. 


\section{LIGHT HORSE. *}

"THERe is life in the old dog yet," now may admirers of cavalry say. Recent events have proved its utility, and disproved the arguments of those who considered it an exploded and useless force. These latter, by the way, were a very considerable portion of one's acquaintances. Every civilian now considers that he knows more about soldiering than soldiers themselves at all events used to do, whilst that admirable force the volunteer army is better informed on the subject than soldiers and civilians put together. To quote the sentiments expressed so lately as the end of last July by my esteemed friend "Smallbore," of the 50th Administrative Battalion Pimlico Peashooters, "Cavalry, sir, has seen its day. Whether it was ever worth the attention bestowed on it is not for me to say; but, mark my words, in future wars we shall never hear of such arm. What chance could it ever have against the worst disciplined infantry armed with 'arms of precision?" (Was he thinking of his own company?) "Before they could advance a hundred yards a brigade of cavalry must be cut to pieces," \&c., \&c., and next day he returns to town, and shows his military ardour by appearing on parade in Hyde Park and his fitness for command by manfully "clubbing" his company! I cannot pretend to answer that question, which, to all appearances, puzzles wiser heads than mine - viz., how it is that officers of volunteers who have never 
learned their drill, should be ignorant of field movements (for after all this is in a few words the sum and substance of the text on which so much has lately been said and written), nor is army reserve a subject for my pen, but as it is surely allowable for a sportsman to look at the mounted arm of the service with a sportsman's eye, and from a sporting point of view, I propose so to do, and to consider, now that cavalry is proved to be not useless, how it can be made most useful. In time of peace, and in these civilised times, horses are animals of very secondary importance to the world at large. A man may go from Edinburgh to London without troubling any such animal, and, arrived in town, may travel all over it in underground railways. If he wants to send a message, there is the post, which conveys his letter by steam; if time presses, is there not the telegraph, which, worked by an economical Government, carries a message correctly, at least once out of fifty times; and so on. But civilisation, from the very completeness of its machinery, can be easily upset. The more completely comfortable a neighbourhood is in peaceful times, when all goes well, the more any irregularity is felt. A watch is ruined by a fall which would not be noticed by a walking stick, so an invading force in the backwoods of America would do no very lasting damage when their stay was at an end; but look at the effect of the same thing on France. There is only one thing easier than to tear up the rails of a railroad, and that is to cut telegraph wires; and then what becomes of art and civilisation? Then, a man who wishes to travel fast must have a horse, and the power of riding him-an accomplishment not possessed by everyone; then, mounted messengers are required, and then people are likely to discover the "deterioration of their 
saddle horses," if such exists. Cavalry, then, is an essential part of any army, as much so as ever it was; but cavalry must not stand still while the other arms of the service are progressing in efficiency. Some little alterations must be made if dragoons are to work, either in concert with, or opposed to, rifled ordnance and infantry, armed as they now are. Our infantry are very different people now to what they were at the battle of Waterloo, or even at the Alma; but the difference in our cavalry is not so great. They have a different saddle and bridle; but the horse is still over weighted, and so incapable of rapid or long-continued movement.

Now rapidity of movement is of every importance. Cavalry, incapable of getting about speedily, is an incumbrance, and a useless trouble and expense to the army and country that own them; while, if ever they are engaged, they are bound to be the victims of a mistaken system. Slow-moving dragoons are only useful as targets for the enemy's marksmen. In outpost duty not only must individuals be able to get about quickly, but, to be useful, so must bodies of mounted men collectively. If news is to be carried, the quicker it travels the better; if any enemy is to be avoided the advantage of speed is obvious; so it is where detached parties have to be cut off; and above all, if cavalry are to charge, the quicker they do it the better for them. No general in his senses would ever willingly put his cavalry in the position in which the Light Brigade found itself at Balaclava; but, if unavoidable circumstances compel a mounted corps to charge for a long distance under a hot fire, the difference of a minute or two in the time which they took to get over the ground would make a very perceptible difference in the subsequent return of killed and wounded. For 
cavalry to charge under adverse circumstances, such as over rough ground, and from a distance is madness; but the lighter and more active the force is the more will its commanding officer be able to pick his ground and his opportunities. Now the first thing to be considered in the equipment of a dragoon is his horse. This must be well bred, or he cannot go fast; he must be good tempered, or he will often endanger the life of his rider; he must be strong, as an overweighted horse can "go on" at no work; and he must be sound for obvious reasons. Also he must have a good and hardy constitution, or a very short spell of campaigning will see him out. Nor must he be very expensive to buy or difficult to replace. Such, unluckily, is what the troop horse ought to be, not what he is. The English trooper is often too tall. Height has nothing to do with size. I should never wish to see an hunter much over 15.3, if I could have them made to order; and I do not think the troop horse has any business with height exceeding 15.2.

A trooper should be a hunter in everything but pace, which is not so great a requisite as handiness and endurance. My reason for putting the height of my model trooper at 15.2 only, is that I think horses of that moderate size usually "rough it" better than the 16 handers, and that they retain their condition better on a short allowance of forage. Large horses decidedly require more food than small ones, as the experience of any good hunting groom will show, and on service forage is now and then apt to run short. The English trooper is not only frequently too tall, but an undue proportion of value is given by many colonels to high knee action to the exclusion of other more sterling qualities. Do not let it be for a moment understood that I undervalue good 
action; a horse who has it not is, in my opinion, useless for any honourable employment, but the kind of action which I have deprecated is the clambering, round action -only fit, to my mind, for harness work in town, but which is eagerly sought after by many purchasers of remounts for cavalry.

English remounts are chiefly Irish-bred horses, and are very often mares, they being to be obtained at a less price than horses, and so much the better for the cavalry, at least I think so. Taking them with all their faults, I prefer mares, in England, as troopers. The Arabs consider that they bear privations better than horses; I am not so sure of this as regards entire horses, but they are not used in the ranks in England. The trooper as seen (say at Hounslow) is usually pretty well bred, and for the most part looks worth a good deal more than the regulation price, which used to be $25 l$., then was raised to $30 l$., and has lately gone up again to $40 l$. For the last price very useful horses ought to be procured, if there were time to look for them. Cheap bargains cannot be found by a purchaser who is in a hurry, and the secret of $30 l$. horses turning out as well as the majority of troopers do is to be found in the circumstance that the colonel can take his time in his deals to this extent-that he is never, in time of peace, buying as it were against time; so, when an animal does not please him, he can send him to the right-about, and depend with certainty on there being more where he came from. Thus, if a good judge, a colonel never need buy "a brute;" but, unluckily, all colonels are not good judges, horses being amongst the few things that a man may pass his life in the midst of without ever learning much about them, unless he have a natural inclination that way. Still, troop horses are, as a 
rule, much better, as well as better-looking, animals than the price paid for them would warrant one in expecting; but they are bought as babies-four years old, or occasionally a few months short of that age. Then they are kept on good, hard meat, and in the stable, and the regimental V.S. takes care that they have no very important unsoundness or weak point to start with. Thus they are found to improve. But whether they have constitutions for campaigning is another thing altogether. The parents of the trooper are, we will say, a thoroughbred horse and hunting mare, which is well enough, but which is still a pedigree that, for soldiering purposes, might be improved upon. Newspaper correspondents from the seat of the late war have stated that such horses as have Arab blood in their veins stand the campaign better than others. I should be much surprised, knowing what I do of Arabs, were this not the case. But, àpropos of this statement, a letter has appeared in an influential journal, written by Mr. Edmund Tattersall, who, while he calls attention to the necessity of high breeding in the troop horse, recommends the employment of English thoroughbreds in the ranks. Granting that the Arab is the best of chargers, he quotes Admiral Rous, to the effect that the English thoroughbred is an "Arab improved"-improved for the purposes of racing on the flat doubtless, but how otherwise. Not in power, not in endurance, not in soundness, not in wear-andtear qualities as a war horse. I have not the presumption to set up my opinion as regards racehorses or thoroughbred stock generally, against such authorities as the Admiral and Mr. Tattersall; but, as my experience of troop horses in the field is at least equal to theirs, on that subject I will state my convictions, which are simply that 
at even weights (say 14st.) an average little 14.1 Arab would wear out any English thoroughbred horse in campaigning, on short allowance of bad forage and in the winter months. And we want a horse that can feed on something different almost every day, and lie out during cold nights without being the worse. I should stipulate that the Arab be entire, so may the other for all I care. But the Arab must be an Arab, and not a Turk or a Barb. Now well-bred Arabs cannot be procured in sufficient numbers to mount our cavalry, but I humbly conceive that the best breed of horses attainable for European warfare would be the produce of the Arab horse and English mare, the latter to be as well bred as possible, but if thoroughbred to possess substance. People will say horses so bred will be too small. But this is a mistake ; they will usually be 15.1 or 15.2 , which I think is quite tall enough, the rather as they are likely to have power and constitution. I have seen several half-bred Arabs in England. They have mostly been 15.2, and one I saw of 16 hands. They are always possessed of wiry legs and sound feet, which is more than can be said of the average English thoroughbred. I have seen them with sometimes more, sometimes less, of the Arab character in appearance, but their understandings have always been sound. I remember one mare of 15.1, or a trifle less, who was the Arab all over, and an admirable hunter. "Going on," was more her forte than galloping, though she was not slow, but she could go on for a week at a time, and at eighteen years old had not a windgall on her legs. Of course sire and dam must have good shoulders, as like begets like. Such horses as the mare I have mentioned are the animals wanted for troop horses, not weeds who can gallop, it is true, with almost incre- 
dible speed for half a mile, but whose accomplishments end there.

A winter at the picket post is about as great a trial of constitution in a horse as well as can be, and to say that our thoroughbreds are the animals best calculated to pass through that ordeal with credit is absurd. Now the beauty of the Arab is that he stands cold almost as well as heat, besides retaining his condition on forage of limited amount, and possibly indifferent quality. The Hungarian horses are, many of them, model troopers; they have a strong infusion of Arab, added to the best English blood. My high opinion of the Arab does not, I trust, lead me into a state of unreasonable admiration. Although I consider him the best of war horses, he is not the animal I should for choice bestride at Nobottle Wood or Ranksboro' Gorse. At the same time, I have expressed my conviction that our breed of hunters would be all the better of an occasional return to the primitive stock; and the troop horses still more so, for a hunter lives like a prince when he is not absolutely at work. We are not surprised when we hear all manner of evils from a cough, upwards and downwards (for I for one do not think lightly of a cough), attributed to change of stable. Why the troop horse on service, if he be in a stable at all, is probably in a different one every day. For my own part, I think that it would be all the better if troop horses in summer lived in the open-at least in open sheds. Canvas stables were, if I am not mistaken, found to be unsatisfactory when tried at Aldershot-probably on account of indifferent ventilation. As long as fine weather lasts, the dragoon himself is mostly in better health in camp than in quarters; and there is no reason to suppose that the same rule does not apply to his horse. 
However, an economical Government is not likely to stand a double set of stabling to each regiment, one for summer and another for winter; so it is no good thinking or talking of such a thing. Yet it is to be hoped that if Government ever does attempt a breeding stud for troop horses, its members will remember that, though the Arab is not the best hunter, hack, or racer in the world, he is beyond doubt, "taken all round," the best horse, and, above all, the best war horse.

Passing from Hounslow to (say) Poonah, it will be found that all Indian cavalry officers prefer the little Arab to the stud-bred or the much larger Cape horse, or Australian, while the country-bred animals are, or until lately were, considered the worst of the four sorts. Col. Shakspear, in a recent instructive letter in the Field, on breeding Indian remounts, objects to the Arab-and he is the only Indian officer I have ever heard of as doing so-considering him to be too fiery and hot-tempered for the ranks. This is not the general character of the animal; and, if it were, it is a good fault on service, where work is usually in excess of food. But Col. Shakespear, very naturally, may be prejudiced in favour of his own service. Everyone is so more or less. The Irregular Cavalry of India are nearly always mounted on country-bred horses, and they get about so well on them that for their use such horses may be preferable to Arabs or Gulf horses, which latter were always more numerous in the ranks than the high-caste desert-born charger, whose price is usually considerably above regulation troop-horse price, this being 750 rupees. The Irregulars had, and have, to my thinking, an advantage, inasmuch as they ride mares in the ranks, which the Europeans never used to do, and probably do not do now. One 
would think that Englishmen could do what native horsemen can, but apparently their rulers thought differently, and where almost all horses are imported there is no temptation to employ mares, simply because they are not shown as remounts. Stallions being out of fashion for the ranks of India, mares may be used, but the advantage, if it be one, is gained at too high a price. A stallion has his drawbacks-he may be noisy or quarrelsome-but I think there is no doubt about his superior powers of endurance, and of roughing it generally. Mares are all very well, but at certain seasons not to be depended upon. Our Indian cavalry can, or at all events a few years ago could, march and campaign in a way that would puzzle the same regiments in England, and how is this? They were mounted on entire horses-as much as possible on Arabs or Persians-and they did not carry an excess of dead weight.

Colonel Haly, in a recent letter in the Field, states as his opinion that the little Arabs of the 17th Lancers, which he saw at Bangalore (I think) were over-weighted. Then arises the question, "What is being overweighted?" As long as a horse looks well, works cheerfully, and is fresh on his legs, I should not consider that he was carrying too great a weight; and the 17th troopers answered this description. And they had been knocked about a good deal in the year' 58 ; had, in fact, enjoyed rather "monkey's allowance" than otherwise. And what was the experience of this campaign? Simply that the Arabs could, and did, wear out the Capes and Walers, who, though so much larger, could not hold a candle to their little comrades, when long marches and short commons. were the order of the day. These horses carried neither sheepskins, shabraches, nor valises, but a 
Lancer is bound to be no feather, from the nature of his arm, which cannot be handled to effect by a "dumpy." Cape horses as troopers I do not like; they are usually plain, and often unamiable. The Walers are larger, generally plainer, and still more unamiable.

All the cobbler's wax in the world will not retain you, $O$ gentle reader ! in the pigskin, if a Waler considers that you are better out of it, and it is quite on the cards that as you go to grass, in the shape of a cocked hat, you may find yourself attended by your saddle, with the girths burst sometimes-sometimes without that formality.* Australian horses, though, are improving, and becoming better bred every year, and they are not all buck jumpers. As artillery horses I admire them much, but they are not my fancy for a Light Dragoon at present. The fourth description of Indian remount is the "stud bred." These were (I speak of twelve and more years ago) bred in or near the Government establishments for that purpose. If the stud bred were a good horse, he was a very good one, but he was just as often the reverse, and his temper was in many cases, to say the least of it, variable. "He was not unfrequently a " man eater," and so a very unpleasant addition to any society. Some years ago the Bengal Horse Artillery had some sweet specimens of this class in their ranks, and this justly-famed corps showed the courage and resolution for which they were so universally admired and respected, in nothing much more than in the cool way in which they tackled these confidential creatures! Arabs

* The author refers to the extraordinary faculty some Australian horses have of "bucking" the saddle right off over their heads, without bursting a girth or drawing a single $\mathrm{D}-\mathrm{a}$ feat we have seen performed on more than one occasion, and one which is often referred to by correspondents of the Field.-ED. 
(which included Gulf horses, Persians, \&c.), Cape Horses, Australians, and stud breds are the four descriptions of horse upon which our Indian Regular Cavalry is mounted. Of course they are armed just as at home, though in dress some little concessions are made to the climate. As I have said, they can beat the home regiments at marching; but the irregulars, on inferior horses, or in deference to Col. Shakespear's opinion I will say only equally well mounted, beat them again. How is this? The irregular man is lighter for one thing; his saddle looks objectionable, but is I think comfortable to the horse, and above all, he rides in his own natural way, and not in an acquired seat. Also he carries no luggage. But chiefly he is a born horseman; for dragoons, as a rule, are not. Still they might learn more useful horsemanship than they generally do. To be able to go through a double ride in the school, and to sit like a poker, with sword or lance at the carry, in trotting past, is all very well; but a man should be able to do a good deal more than this before he can defend himself in a single combat-a thing that every dragoon ought to be able to do, although he may not twice in his life have occasion to exercise his talent. Although dragoons might be in some respect better horsemen than they are, they are not the muffs that some ignorant people profess to consider them. In riding restive horses they usually excel civilians, at least the average of them can do this better than the average of even sporting civilians. This is simply because they are more or less used to them. A troop horse in his course of training has to be taught many performances that are not at all natural to him. If he has a temper, he probably shows it; but our system is so far good that sooner or later all horses become 
pretty handy troopers, though of course they are not all equally pleasant or easy to ride. For a horse to be cast because the men cannot ride him, is almost an unheard of thing, and the men of the troop to which such an animal belonged would consider the circumstance far from being a feather in their cap. The training of a troop horse is a stereotyped kind of thing. He is bought somewhere, at about four years old. An English fouryear old is, of course, by way of being quiet to ride. An Irish ditto is not improbably an accomplished hunter, besides being quiet in harness. He is delivered at the barracks, a man is told off to him after it is determined to what troop he shall belong, and this is usually settled by drawing lots. He most likely has strangles to begin with, and when he is through that, and has recovered some condition, his training commences. And here I think a mistake is commonly made. The young horse is allowed not only to get up a due amount of strength, but very often to become "fresh;" and in this state he is naturally likely to give more trouble than if he were otherwise. Overworking young horses is a grievous blunder, too; but there is a middle course, which might with advantage be more frequently adopted. The young one is saddled very carefully, the man to whom he belongs being always under the eye of a superior, lunged more or less, and finally mounted, with a "stripped saddle" - that is, the regimental "saddle lightened of everything that will come off, such as wallets, and with only the bridoon on his mouth. He very likely takes all this easily enough; and the first bone of contention is often the crupper, an article to which I have a lively hatred. Then come his paces. Commencing with the walk-which, by the way, he is generally made to execute 
rather more on his haunches than the hack of a civilian does-he progresses to the trot and the "bending lesson." This latter is a performance unknown to civilian horsebreakers and riders generally, but indispensable in the education of a steed who is to be ridden with one hand on the reins, and only one. In plain English, it consists of walking more or less sideways, in obedience to the pressure of the rider's leg or heel. It is practised until the least pressure of one leg causes the horse to sidle away from it, and its use is chiefly noticable in closing up in the ranks when the squadron is halted. Then the young horse, being perfect in these lessons, and also in "reining back," proceeds to learn the canter. The canter of the manége is as slow and collected as it is possible to be, all on the haunches, which result is attained by the practice of the pace in a gradually decreasing circle, until he is as nearly as possible competent to perform that often described, but never witnessed, accomplishment-cantering round a cabbage leaf. All these lessons have been practised with the bridoon only, and its use is sometimes continued so long as to give the horse a habit of boring on it, which he never loses. Bitting is a separate difficulty, or otherwise, as the case may be. The greatest attention is paid throughout to the carriage of the horse's head, and with success; at least I never saw a troop horse who declined altogether to bend to the rider's hand, as many hunters do, though some, of course, are not so perfect as others. Here we have got our horse quiet to mount and ride in the school, handy at turning and backing, and pretty well confirmed in his paces; and up to this point the training is satisfactory enough, excepting, perhaps, that the bit might often have been used sooner than it is. About this stage 
of the proceedings, however, routine and red tape usually step in, and, combining their forces, drive common sense and practical horsemanship out of the field. A sportsman possessing a young horse trained to the extent mentioned above, would take him out on the roads a little, if he were destined to be a hack; if a hunter, his jumping education would commence as soon as he thoroughly understands the indications of rein and heel. But this course of proceeding is not laid down in the cavalry regulations, consequently cannot be followed. It is true that the trooper is supposed to be both a hack and a hunter, as far as the capabilities of doing the duties of each go, and he is thus prepared for them. To make him a clever fencer, or rather to teach him to jump (for in the eyes of a riding master of dragoons all fences are alike, and to be negociated alike), he is made to jump over a bar in the school. As much care is taken with this part of his education as with any other; he is first led over the bar as it lies on the ground, and it is gradually raised until he leaps it at a fair height, neatly and coolly. And so far this is a wise and horsemanlike course of instruction; but unluckily it stops there. The horse is never asked to jump anything but the bar, nor is he ridden about the roads by himself. And what is the result? Why, that nineteen out of twenty troopers make a fuss about leaving the ranks, if they do not decline to do so altogether; and that when confronted with a small ditch or grip, they either refuse or fall at it, to the damage of their rider's bones, and to the increase of work for the regimental surgeon. When the remount knows all his paces in the school, he is ridden by degrees with arms. Some object to the sword, others to the carbine; but, as a rule, the better bred the young one is, the 
less he cares for these details. When he allows of the sword and lance exercise being gone through by his rider, and when he bears the firing of a pistol or carbine off his back with tolerable equanimity, he is dismissed the school, and ridden in the ranks; not at regular drills, but at little parties made for him and his compeers, at first under the riding master, then under the adjutant. Finally, he makes his appearance at a field day (and sometimes, by the way, makes an informal disappearance thence in the direction of his stable, to the delight of everyone but his rider, to whom, being run away with round paved corners, and perhaps into a half-open stable door, presents no attraction whatever), and thence forward he is a "trained horse," and never forgets his lesson all his life, wherever the vagaries of Fortune may lead him -into a hansom, a hunting stable, or what not. The officer's charger is trained in just the same way, excepting that he is not ridden absolutely in the ranks; but in the place which he is likely to occupy, in rear of the line, or when practicable, in front of it. Now this is a good enough system of training, in the main, and would be sufficient if cavalry always acted en masse on a plain like Newmarket Heath.

But as a man often has to be detached, and sent over ground which has not been levelled for his accommodation, it is clear that a horse who won't go anywhere by himself, and who declines altogether to cross any obstacle but the bar in the school, is not the most useful animal to carry a dragoon, and three-fourths of our troop horses possess these amiable weaknesses. They are not unknown in the hunting stable-some good hunters are restive on the road, others are refusers; but they are the exception, whereas the exception in the troop stable is 
the other way about, and is the natural, nay, the inevitable, result of his training. This might very easily be altered. A careful man might surely be trusted to ride his horse a little about the roads or the camp, and then a horse who declines to go alone out of the barrack-gate would be a comparative rarity. At present he is not so. Then as to leaping. A bar is the least useful, or rather the most objectionable, thing that a young horse can be confronted with. I do not mean to condemn its use for a few times with a young horse; but a very short acquaintance with it is sufficient, and he should not be allowed to knock it down. A troop horse is not wanted to jump ox-fences or sensation water jumps, but he should be able to be trusted at a flight of hurdles or a moderate timber fence of any kind. Nor should he be stopped by a five-foot drain or an average bank and ditch. This last is the kind of fence to make horses clever. I would have young remounts first led, then ridden, with a steady horse to lead them over all these sort of fences, never of course asking them to jump a big place or a dangerous one, until it comes as natural to them to surmount any moderate bar to their progress as it does to an old hunter. To jump large fences without some excitement, indeed, as a rule, without hounds, is to teach the art of refusing; but in cold blood a horse can almost always be got over quite small places with little or no trouble, and if he does the little place neatly and cheerfully in cold blood, he will, when excited, think comparatively little of a "rasper." Another fault in the usual training of remounts is that they never gallop. In all their training they never exceed the collected canter of the school, and most likely have not galloped from the time they join their corps until "gallop" is sounded by the 
trumpeter in a field day. Hinc illce lacrymce! Wiggings from inspector-generals, and so forth! This accounts for much unsteadiness in the ranks, as also for the not uncommon disappearance of a young horse right off the field of action, likewise for a troop leader's sensation of mingled rage and terror as some heavy body cannons against the quarters of his charger, and flies off at a tangent over the field, said body being the last remount and his rider, the latter ere he disappears looking back at his deserted place with an air of natural apprehension, tempered with the resignation which attends the British soldier in all difficulties and dangers.

Man and horse probably return at last, and the circumstance attracts no great attention. An audible passing allusion to "Johnny Gilpin," from the wag of the troop, probably causes the squadron leader to request, with more or less polite energy, that silence be observed in the ranks; but the same thing will happen again, often, or otherwise, before our young one is really steady. The reason is twofold. First, the horse has never galloped, and so becomes delirious with excitement when he finds himself let go, even to the extent allowed in " an advance in line." Secondly, the man has, except on the occasions on which he has been bolted with, never ridden a horse at full speed! So he thinks he is run away with before he really is so; besides, being wholly innocent of the art of handling a horse at a gallop, he very likely makes him worse instead of better. Never having galloped the horse, all its games at that pace are new to him, and will not all candid horsemen confess to having sometimes experienced that most unpleasant of sensations-ignorance of what one's horse is liliely to do next? It is fair on neither man nor horse to exercise them for 
months at a slow pace, and expect them to be equally au fait as fast ones. Horses will always pull more or less when galloping in line, but if the men have often galloped them independently they will be accustomed to their peculiar styles and tricks of pulling; and though many old cavalry officers would condemn the permission to gallop as likely to produce wildness and unsteadiness in the ranks, I am persuaded that it would have the contrary effect. The men and horses would know each other better, and that alone would be a grand point gained. Of course all galloping would have to be done under very careful supervision; but so has every other part of a soldier's duty. Also, as for jumping, horses who are clever at small cramped fences are not so likely to fall at grips as others who are not, and every dragoon knows what fearful falls are to be had at narrow ditches; indeed, the narrowest of them. This is partly attributable to the weight carried by the horse, but chiefly to his being unaccustomed to collect himself suddenly on coming to an unexpected thing of this kind. From the nature of their training, which sets troop horses so much on their haunches they make clever hunters with less time and trouble than any other horses, and yet, for want of the little extra teaching required, they are usually the clumsiest brutes out. It is only fair to the horse who has just tumbled into a two-foot drain to consider that the rider, being as unaccustomed as his horse to crossing anything but a level plain, most likely was guilty of every practical blunder that the situation admitted of. The man would benefit as much as the horse by a course of steady galloping and jumping. Can anyone be called a horseman who cannot ride at speed? And a dragoon ought to use his weapons at speed too. Post practice, as done 
in the school, is a pretty performance, and very well in its way, but it ought to be only the first chapter in the study of the use of arms mounted. More than education is wanted, though before the trooper can do fast work, and plenty of it, his load must be lightened. It is true that he seldom carries his full kit, indeed, only on the line of march, and on marching order parades, and field days, which don't come every day. The average trooper is equal to carrying thirteen or fourteen stone, not to hounds, of course, but in marching order. Even a hussar rides eighteen stone. It is the custom to thus overweight the horse, who on service would of course carry all this load; but why is it? Why should the cavalry horse be worse treated than other animals in this way? Attempts have been made, and talked about, at lightening the weight, but the reformers begin at the wrong end. They would lighten the man-not the dead weight. Now an undersized dragoon is not desirable; a little dumpy fellow will seldom be able to use his weapons, unless they are also reduced in size. Our light dragoons are not a bit too big or heavy, but their saddlery is. Why should the horse carry a valise at all? It is very heavy, cumbersome, and in every way inconvenient. It causes many sore backs, and it helps to necessitate the use of the crupper. Why cannot every squadron have a light cart attached to it, which would with ease carry all the valises of two troops; or one cart per troop would not be an expensive addition, as it might be drawn by troop horses (two) and driven by two men, who might receive some small addition to their pay, as their work would be a little in excess of other men's. Of course, the cart horses must be eligible for service in the ranks on occasion. Then, the valise being disposed of, the soldier's 
saddle might be lightened. No average light dragoon ought to ride over fourteen stone, and a reform in weight might be effected without altering the standard of size for the men. The saddle, for example, without a valise, would not require to be nearly so big. Something like the saddle of the mounted police would surely be lighter than, and might be as durable as, the present hussar saddle. The soldier's saddle must carry a cloak; that is easily managed, also wallets or holsters, and a pair of spare shoes; but surely a saddle somewhat stronger than a hunting saddle could do all this, and be very little heavier. A felt "numnah" is most useful, and should always be worn under the saddle. A breastplate, I conceive, to be useful to every horse who does any very hard work under the saddle; and thus the list of things to be carried, besides the man and his arms, might end. A sheepskin is not heavy, and might be retained if it were considered needful. It certainly keeps the contents of the wallets dry in rainy weather. But with a baggagecart marching in rear of the regiment the soldier would not require to carry many valuables in his wallets, and when detached (on service) or on outpost duty he would not require much more of a trousseau than they would contain. A forage cap, a pair of highlows and dry socks, with a clean shirt (flannel shirts are best) take but little room; and almost all the present appliances for cleaning belts and uniform I would summarily dispose of. The present pattern of bridle is well enough. A collar-chain is indispensable of course. The only alteration that I can think of in the dragoon's bit is that I would not have the cheeks of the bit connected by a bar, as they are at present. A fractious horse can, by throwing 
up his head, catch the bar across the nose, and the bit is useless when he does so. The remedy is to loosen the rein, when the bit is obliged to reassume its proper place; but, while the rider is doing this the horse has time to do a good many things too. Further, I would never have the lower branch of the bit more than double the length of the upper, and in training the remount I would use a standing martingale, when temper or carriage of head demands any extra assistance. Our horse has now, we will suppose, an easy bit, a comfortable saddle, not too heavy, yet roomy and strong; but before he is mounted we must have a glance at the man. The present height of the recruit is all right, but what about his drill and dress? The drill is well enough, with this exception, that he ought to be trained, in addition to what he learns at present, to ride over real fences, and to use his arms at speed. His riding drill admits of one more improvement. On the march, and on all occasions off parade, he should rise in his stirrups at the trot. The seat without rising is preferable in the school-it is easier, for example, to ride a young horse up to his bit so, than when one is "jockeying," as rising is termed in the army : in riding in line also it is difficult to rise, and almost impossible for men to dress well when so doing; but it is neither in the school nor the drill field that sore backs are given, and they would be less common on the march were rising in the stirrups permitted. On the march cavalry should travel at a seven-miles-an-hour trot (walking of course at intervals), the men keeping the sides of the roads, and rising in their stirrups. As a general rule, the length of a man's arm shows the length of his stirrups. No horseman, least of all a dragoon, should ride too short; to do so is a worse fault than the reverse. 
How should the light horseman be armed? The first and most important arms for a dragoon are his sword and spurs, the latter to make the former available. In addition to these, a double-barrelled brecch-loading pistol, carried at the waist, would be a useful article. When the pistol is carried in a holster, in the event of the horse being killed, the man most likely loses it. Swords ought to be sharp, but metal scabbards soon take the keen edge off them. A few months ago lancers were sneered at as being bearers of an obsolete weapon. Since then the Uhlans have told us a different tale. The English lancer carries a pistol in addition to his sword and lance. A breech-loading carbine is very well in its way; but a dragoon should not be a sharpshooter, though attempts are being made to make him so. His business is to ride over his enemy, not to pop at him. The notion that he should fire while charging is not a wise one. At the same time he must be able to skirmish a little dismounted, but on such occasions only every other man should dismount, and then the squadron could move about after a fashion if required, each man having one horse to lead. As to the men's dress. Firstly, white belts and their attendant pipeclay ought once and for ever to vanish. The brown leather belts are serviceable, if not handsome. White belts look well on parade and in line; but the pipeclay comes off on the tunic or jacket, and they are not only a great trouble, but tho materials for cleaning them take up room. A rather loose jacket, something like that worn by the officers of the Staff College, is in every way preferable to a tunic; it rides clear of the saddle behind, and it admits of the existence of pockets. These a soldier is not supposed ever to possess (is it because he cannot be supposed to 
have much to put in them?); but on service they are mighty handy things. Also a waistcoat should be worn under a loose jacket in winter. For the legs, boots and breeches are the most comfortable; but none of our dragoons have them, presumably for the reason that, if the boots were being repaired, the man could not turn out, and that two pairs per man would take too much room.* Well, there is no great fault to find with the present overalls in fine weather; but boots and breeches are infinitely preferable in wet. In camp, anyone may observe that when the weather is wet the soldier tucks his trousers inside his boots on all possible occasions; whilst officers, if they are allowed to, come out in butcher boots at once. But this is a question which no civilian. can decide upon. On the headdress anyone may give an opinion. For cold climates a light helmet, and for hot a turban, is my notion; and if all troops had white cap covers to their forage caps for summer wear, as they have in India, we should hear less of "fatal marches." This would be hard on the penny-a-liners; but still it is an ill wind that blows nobody any good. A light curb chain run over the shoulder and down the arms is a wonderful protection against sword cuts, and would not be expensive. The sabretache has been much abused, and is now only worn by certain regiments; its chief merit is to keep the sword or scabbard steady, and no trifling: merit either. Of course the sword belt would be worn under a loose jacket. Apropos of boots and breeches, if the Household Brigade and Irregular Indian Cavalry car wear them, why cannot other regiments? But white

* Since the abore was written boots and pantaloons hare been tried, but for the reason given here are to be discontinued, two pair of boots and spurs per man being incompatible with the principles of economy norr rampant at the War Office. 
buckskins would be too troublesome for common wear; pantaloons, or even knickerbocker breeches, not too loose, of stout cloth, would have plenty of wear, and want but little cleaning, nothing, indeed, but brushing, as the stripe common to all overalls, and which takes a good deal of pipeclay or chrome yellow, might be dispensed with. A pair of gaiters and highlows for fatigue dress would be comfortable and convenient. The stable management of the horse I have bardly glanced at. It is generally pretty well managed, though sufficient attention is not paid to coughs and colds, which neglect shows itself in the number of troopers who are roarers. Also an occasional dose of physic would benefit the Queen's horses as much as it does the human subjects; but unless on special occasions they nerer get it. Shoeing is always important, and might be improved upon. My fondness for the Charlier shoe is no secret; but on service, or when dragoons are likely to be detached and away from their own farriers, the fitting of such shoes might be difficult. Therefore I should prefer in such cases tips on the forefeet; they wear longer than common shoes, and do not easily come off, neither do they pick up stones or ball with snow. The hind feet might wear common shoes, the sole being left in a state of nature. This shoeing I should recommend only where the Charlier shoe is inaccessible. There can be no doubt that a regiment armed, trained, and mounted something after this fashion could move about more rapidly than the dragoons we possess at present. Where baggage carts cannot travel (though they could go wherever artillery could-there are countries devoid of high roads), baggage animals could transport the valises (as they did, and very likely do) in India. 
When quick work in the field is required, it is a mistake to have too strong squadrons. The crowding in an advance of very strong squadrons is much more than when they are weak, and the steadiness of the advance suffers accordingly. There has lately been a rage for doing everything "inverted," and doing: away with pirots; and of this it may be said that such drill demands an amount of intelligence in officers and men that is desirable if attainable. The old-fashioned inverted line is all very well, and by its use a regiment can be made to front in any direction quickly; but to invert squadrons must be more or less confusing to the men, especially in the smoke and confusion of an action. The shortest way of reversing the front of a regiment is by wheeling the squadrons about, which gives an inverted line to the rear, and the regiment may work and march home, too, inverted, if the commanding officer likes. To do the same thing by wheeling the troops about is by no means so convenient. In like manner, to form line to the right from open column of squadrons right in front by the old custom would be, "To the reverse flank right form line," the execution of which manœuvre would give time for a good deal of shooting to the foe on the right. But nothing could be desired much quicker or more simple than "Inverted line to the right. Squadrons right wheel into line." There you are at once. If from columns of troops squadrons would have to be formed in the first instance, the trumpet-calls for "right" and "left" should be unmistakeably distinct. A timely wave of the colonel's sword in the direction required is an immense help to every one. Space prevents a further discussion of field movements; and into the question of Double versus Single Kank I cannot pretend to go, 
though my own fancy is for the former, for many reasons. All that I have endeavoured to show is, the ease with which the troop horse may be assimilated to the hunter, and the small amount of difference in his training and treatment required for this result-a result that, if attained, will enable cavalry to act at speed over all sorts of ground in reason in a way that shall prevent the "arms of precision" having it all their own way. Anything that adds to the dash of the dragoon without decreasing his steadiness is an advantage, and this fact must be my excuse for an action not contemplated by the Mutiny Act, the Queen's regulations, or "the book"* itself, viz., considering light horse from a sporting point of view!

* The "cavalry regulations" are usually thus deseribed by adjutants, and regimental staff generally. 


\section{STABLE REFORMS.}

LATELY a writer on the subject of hippophagy stated, as a reason why that practice was not likely to become popular in England, that "the horse is the friend of man." Every thing in this world goes by comparison, and compared to the ox, or the more humble pig, the horse may call himself his master's friend; but he is, after all, in the position of a very humble friend-the not over and above wellused class, out of which we charitable worldlings get all the benefit that we can; use them, in fact, when wanted, and as long as they can be useful, and then cast them aside. The dog has an advantage over the steed here. No man sells a dog because he is old and used up; but then it must be remembered that there is no demand for superannuated dogs, so it is not of necessity the goodness of heart of the master that insures the faithful old dog either a prolonged and useless existence on the hearthrug or elsewhere, or a speedy, painless passage to the happy hunting grounds. But the common fate of the old horse is "too well known to need description." Facilis descensus, and no mistake, is the career of the three hundred-guinea hunter when he becomes not quite equal to the work required of him by the opulent owner. The first downward step is probably Tattersall's, when he fetches $£ 50$, and is hunted another season is some less fashionable country than his last one. Then Aldridge's or some provincial repository - "Going at 20 guineas, gentlemen; can't dwell; gone!" Say he hunts another season as a 
hack hunter-an animal whose employers are not over and above exigécunts as to soundness-then $£ 5$ and a cab is his fate; and my knowledge of the subject does not permit me to follow him further. Poor brute! had he been lamer to begin with, his first owner might have shot him; but he was just worth selling. To be waked suddenly in the midst of a nightmare is a shock, but to sleep on is more unpleasant; and I cannot but think that the poor horse, lately so valuable, now so much the contrary, would, even with his limited intellect and natural instinct of self-preservation, welcome the bullet which, crashing through his brain, consigns him to oblivion, could he but foresee even one day of the toil, stripes, and starvation to which he is consigned by his amiable master, who certainly "takes no thought of the morrow" as far as it concerns his property, when he carelessly remarks to a friend looking over his stud, "That's a nailer, but his day is about done" (the failing is here specified, bien entendu that the friend is certain not to become a buyer); "I shan't ride him another season." And remember, ye who own a "fine ruin," that the sterling qualities which enabled him, with you on his back, to "see out" all the second horses that day that you "did the trick" so completely to your satisfaction, and to the discomfiture of all your dearest friends (and it is to be hoped that most of us have once in our lives "had the best of it") will prolong his misery in the cab or 'bus. As he was the only horse who could jump into the field where they killed at the ond of that blazing fifty-five minutes, and the only horse who trotted into the town on his way home, so will he on three legs whirl the Hansom containing a tipsy snob and his companion faster up from Cremorne than his fellows; so 
will he, worn out and diseased in body, but possessing the same brave heart as of old, trundle a four-wheeler, against time, to catch a train, containing, say a rural family of four adults, three children, and their combined luggage, and "go on" at the wretched trade, whose wages are blows and hunger, when a worse one would sink under his load of misery. 'Think of this, individuals before mentioned, and sell your old slave, whose glory has been reflected on to you so often, to save yourselves $5 l ., 20 l$, or 50l. if you choose-if you can ; but call yourselves no longer by the honourable term of sportsmen. and if you are at a loss for a designation come to me for one! Yet it is, after all, no affair of mine what becomes of my neighbours' horses, but in no way is the ingratitude and hard-heartedness of our fellow-creatures so apparent as in their treatment of dumb animals, and horses specially. A dog cries out if you hit him, and probably sulks; a horse suffers in silence, and exerts himself the more.

Having glanced at the miseries entailed on that noble animal Equus Ca'oallus by unsoundness, let us see whether it be possible to at all events ward them off for a timein fact, to preserve our horses sound, and consequently useful, and entitled to kind treatment for a little longer space in his natural life. Most people who know anything about the horse know that his natural life extends to from twenty-five to thirty years. I have known a few horses who have lived over the latter age, and worked to within a short time before their demise; but they are rare instances; and the oldest of them was only thirtythree "off," nor was his work latterly very severe. He was an old carriage horse. I also know a hunter of twenty-one-at least I saw him in the field last season, 
and very well he looked and went, but he was not sound in his wind, whatever his legs might be. But the majority of horses lave finished their career at fifteen years old. And after some experience of "screws" I have come to the conclusion-and, indeed, expressed this opinion before-not only that more horses are lame in their feet than are lame elsewhere, but that many lamenesses of the leg originate in bad management of the foot. Consequently, we ought to be ready to hail any inventions or ideas which promise to amend the treatment of that essential part of the horse's frame. "No foot, no horse," has been long a stable proverb; but how little the comfort of the foot has hitherto been consulted! The ideas on the subject have sprung from wrong roots, so to say, altogether; or rather let us say they have been built on fanciful and insecure foundations. "No foot, no horse," is a sound notion enough; yet in practice how few men pay much attention to the foot, if it be not obviously diseased, so long as the legs are clean and the action unimpaired. Of course a dealer, so long: as he sells a sound horse, cares not how long the animal continues sound. Indeed, the sooner in reason that the creature is worn out the better, as the customer will require a fresh one. Owners of horses too often act as if their intention was to wear out their property as soon as. possible. We should think but little of the common sense of a man who, having bought an expensive watch, knocked it about in every conceivably unfair way; but we think nothing of such a course of action pursued toward a horse-and why? Because everyone does it, I suppose; at least I can think of no better reason. Our system of feeding and conditioning horses is good enough, but we have hitherto mismanaged their feet grievously; and, 
indeed, the prevalent idea of the groom and the blacksmith seems to be that they know better what a horse's foot should be than the Creator of the animal does. For they are never satisfied until they have altered the natural foot into a form of their own, which they think the right one; and, though lameness usually attends their efforts, they ascribe it to every cause but the right one, and,indeed, resign themselves complacently to the presence of many diseases confessedly caused by their treatment, perhaps because these diseases do not hurt their own sacred persons! It is really curious to observe in all that has been written about the horse's foot the sort of follow-myleader principle, which is more evident here than in writing on any other subject with which I am acquainted. Very, very seldom is an original idea to be found, and still more seldom an original idea that is not marred by some adherence to the old grooves to which preceding authors have confined themselves. The oddest notion, and the one which has held its ground in undisputed security until lately, is the idea that the sole of a horse's foot requires paring. And almost all writers have insisted on the necessity of this operation. The late Mr. Apperly ("Nimrod") was by far the most practical writer on horses of the last hundred years or more. He wrote from personal experience, not from theory, and he taught us most of what we know at the present day as to the condition of hunters. He it was who first proved the absurdity of turning the hunter out to grass in the summer. He also demonstrated the necessity of giving periodical doses of medicine to the horse during the process of conditioning. In short, although his use of drugs and medicines appears to have been somewhat excessive, his book is a very useful study for the young 
horse master to this day. It treats of almost all the ills to which the hunter is subject, with one exception-he never mentions "mud fever." So I suppose that this is an evil of modern date, although I cau remember its existence ever since I have hunted, and that is some time; and it has nothing to do with clipping, for I have had a horse affected with it which had its natural winter coat on. But "Nimrod," excellent and practical as is lis work (with this exception), falls into the mistake of paring the sole. He says, "From La Fosse downwards to the writers of the present day, fears have been expressed of the ill consequences of paring the sole, which my experience cannot confirm." His idea was to prevent the sole growing too thick, and consequently losing its elasticity; but as the sole never attains more than a certain thickness, and then scales off of itself, showing a new sole ready for work underneath, I cannot see the force of his reasoning. So much for the practical man-now for the theorists. La Fosse, by the way, first demonstrated the possibility of a horse going with his foot on the ground instead of on the shoe only, and invented a system of shoeing very similar to that of M. Charlier, but not so good. Nevertheless the idea of the Charlier shoe was no doubt taken from the shoe which La Fosse invented. The idea that the horse ought to walk as Nature makes him do, with his foot on the ground, never gained mucl of a position in England until lately. "Nimrod," indeed, thought little or nothing of frog and sole pressure while his horses were at work, and professed to despise the frog and its offices thoroughly. But his precept and practice differed here, as his horses went barefoot in the summer, and he speaks of the bencfits experienced by the horse walking a certain 
distance every day "with the frog well let down on to. the ground ;" but this good notion is spoiled by the addition of "the sole being thinly pared." Many writers. of that day waged war against an imaginary disease called "contraction." "Nimrod" pointed out what ought to have required no indication, viz., that contraction may be a consequence of sereral diseases, but is in itself not a cause but an effect.

This notion is at the present day not worth wasting ink over, so we will go on to the next notion, which had a little consideration for Nature. This was Professor Coleman's bold assertion that "the frog must have pressure or be diseased." The idea is undoubtedly correct; but his practice was like the move of a knight at chesss. one step forward, and the other to the side. He was steering for the open sea of Nature, as I should be inclined to call pressure on the frog; but by a tack, like that of the chess knight, ran upon the rock of art, as exemplified by paring the sole. He recommended the use of a shoe thick at the toe and thin at the heel. This let the frog on to the ground; but, as he pared both sole and frog, and put the toe above the heel, the shoe was a failure. Then Mr. Bracy Clarke came to the front with a jointed shoe-another failure. Mr. Miles, if he did not invent, at all events brought prominently forward the advantages of nailing the shoe far back on one side only. But he pared the sole, the horse stood and worked entirely on the wall of the hoof, and foot lameness was not much decreased. Matters remained stationary for some twenty years until lately, when an extensive crop of new systems. of shoes and shocing has appeared. Always on the lookout for stable reforms, I have given most of them a trial, and my experience is at the service of anyone who cares. 
to read it. M. Charlier's appears first, but I will discuss it last, merely remarking en passant that he proposes to shoe the horse so as to approach as nearly as possible an unshod condition. And before looking into these inventions let us make up our minds what we want, as ladies invariably do before they enter, say Messrs. Marshall and Snelgrove's shop. We want shoes and a system of shoeing that will cause our horses to remain sound as long as possible. Our horses are, some hunters, others hacks, others again machiners of different kinds. These all do different work on different surfaces of ground, aud the work itself is likely enough to lame them, therefore it behoves us not to equip them in a manner also calculated - to incapacitate them; for a lame horse is no good to anyone, being merely an object of dislike to his master, and derision to his groom.

Hunters shall come first. They are more rarely lame in their feet than other horses. Their work is on soft ground ; concussion is thereby diminished, and they have while in the field the support of the ground over the whole surface of their foot. Also, they generally pass the summer without their shoes, their feet thereby having a chance of resting as it were from the contest which they must have waged during the winter with their shoes. On the other hand, their shoes are nailed very often too tightly, with the view of preventing their being pulled off ; and they have the cliance of getting ferer in the feet from causes unconnected with shoeing, also of injuring the navicular bone in jumping on to hard roads and stones with a pared sole. So their shoe must be light, for its weight is carried for many hours; it must be easy to the foot, and calculated to prevent slipping as far as possible; also it must stay on. The liack wants 
much the same article, though he works on the road exclusively; his shoe must, abore all, not be uncomfortable to him. The harness horse also works entirely on the hard, and not only that, but often on a very slippery surface. His shoes must enable him to take a good hold of the ground above all things, or he will be liable to slip up; and how to make such a shoe as will effect this, and at the same time keep the foot in anything approaching a natural condition, is a problem not easy of solution. At present we have several styles of shoeing to choose from, all of which are supposed, or said by their. inventors, to be infallible. The principal ones are, first, the steel-faced and grooved shoes of (I think) Mr. Gray, of Sheffield. These are very well on sound feet, and they give a secure foothold on slippery stones; also they wear a long time, and look neat, if that be a consideration; but, as far as being the cause of disease, they are open to the same objections as the common shoe, though it is not a certainty that either or any other shoe should cause disease. It has been truly remarked that horses lightly worked and not highly fed may be shod almost anyhow, and their feet will remain sound; but this fact does not help us much, as the great majority of us want to work our horses hard, and consequently must keep them highhigh keep being, as most people do not require to be told, the greatest of all provocatives to inflammatory attacks of every kind, and notably of the feet. So Mr. Gray's shoes have no great advantage over the common ones, excepting for use on slippery stones, and that they are thinner, and so may allow of some frog pressure. Next come Messrs. Downie and Harris's rubber pads. These have been fully described in the Field newspaper; but, as everyone may not have read the article referring to 
them, I may shortly describe them as being a piece of india-rubber the shape of the foot surface, but with a " rabbet," so called, or grooves, the width of the shoe. The pad is wider than the shoe, and protects most part of the sole. It diminishes concussion, and prevents stones being picked up by the shoe, and is so far a good thing. But eomplaints are made of its eausing the shoe to come off, from the play of the nails caused by the elasticity of the rubber. They are almost, if not quite, the same as Edwards's horseshoe cushion, though there may be a sufficient difference between the two to warrant their being called by different names. I have personally made a fair trial of the horseshoe cushion, and this is the history thereof. Some years ago I had a remarkably brilliant hunter, who was also remarkably unsound. He had an inclination to pumice feet, and could hardly get along at all on the road. I shod him with these rubber cushions or pads, and the horse went very much betterin fact, went on the road as if he were on the soft. So far so good. But I had to leave them off because the shoes were always coming off; and always when least expected did this accident occur. Sometimes the whole thing would stay in its place for a long day's hunting; sometimes it would become loose in the middle of a run; and sometimes it would take wings and fly away like a quoit when the horse was doing walking exercise. To be sure of its merits, I tried it on another horse; the result was just the same, and I naturally gave the shoes up, after using them for more than two months and losing no end of them. And I am persuaded that the same objection will apply to all elastic pads for the same reason, viz., the play of the nails caused by the pad being compressed under the shoe and swelling out again. I should say 
that the hoof grows very fast when shod with these cuslions, which goes to prove another theory of inine, of which more hereafter. Next comes the Goodenough shoe, concerning which more absurd statements have been made (chiefly in advertisements) than I have ever read on any one subject before, even including $\mathrm{Mr}$. Goodenough's other most highly successful venture, tho Rarey system of horse-taming, which has already sunk into oblivion. This shoe was "the only humane (?) shoe; it was to supersede all others, and its virtues took up in their enumeration an immensity of space in various advertising columns. For the benefit of anyone who has not seen the shoe, I will describe it. It is pretty much like any other shoe, bevelled on both the inside of the foot and of the ground surface, and armed with a calkin at the toe, one on each side, and one at each heel. It has eight mail holes. Now, there is no great novelty here, as the calkins are merely the common way of roughing shoes in North America, and, bar the calkins, there is no great difference between this and a common hunter's shoe. The advertisement states that the intention is that the shoe should, though calked, preserve the level position of the foot. This is a manifest absurdity, as the calkius will not wear away evenly, and then the foot is not level. The toe calkin goes first, and then the shoe is no better than a common turned-up shoe, which is objectionable (though sometimes necessary on slippery stones) as throwing all the weight upon the toe. It was to prevent cutting-another absurdity. It might or it might not do this, as horses differ so in their way of executing this objectionable performance. Finally-and this assertion is still made in the very much curtailed advertisement"horses shod with them will retain sound feet to the end 
of their natural lives." This is tall talking; but it is easy to talk. In theory this shoo is defective, as being nailed too near the heels, in making the crust sustain the whole weight of the horse (for, though a model is sold of a foot and Goodenough's shoe on it à la Charlier, it is an absurdity, the frog of the model foot being such as no horse ever possessed), and because the toe calkins would naturally make the horse stumble. In practice I found the following faults: A hack shod with them on the fore feet, previously a good goer, stumbled shockingly until the calkin was worn away. Theory and practice agreed here for once. Two harness horses got along pretty well so shod all round; but "forged," as the phrase goesthat is to say, hit the toe of the fore shoe with the toe calkin behind, until the latter was worn down, thereby making a constant noise most unpleasant to the driver, and not unattended with danger of falling. They stumbled, but, having no weight on their backs, did this less than the hack. A hunter went much as usual on the soft-neither better nor worse, for calkins are of no good in soft ground, the whole foot being then choked up with mud; but in his first gallop a shoe broke in two. So did a shoe apiece of both of the harness horses. The hack's did not, but were an exception in not doing so. Of course no sane man would put shoes with a toe calkin on a hunter's hind feet; we have overreaches enough without that. But the mishaps enumerated above are only what might be expected from the make of the shoe. The calkins speak for themselves, and the great size of the nail holes must make the shoe very liable to break close to them when at all worn, and even, as in the case of the hunter, when not worn, that being a very weak point. The advertisements stated that the shoos 
would not pick up stones or ball with snow. As regards the stones, this is pretty correct; but the snow statement is quite wrong. So large a snowball does not form in the foot of a horse shod with this shoe; but it stays there longer than in a common one, so perhaps that makes them even in that respect. Finally, the General Omnibus Company (which had adopted the Goodenough shoe, has discontinued it. No doubt the promoters of the shoe could give some good reasons for this; but facts are stubborn things, and a firm of business men, using many horseshoes, are not likely to give up those which they found were "the best and cheapest in the world," and which these shoes are said to be-by their own advertisement. The next and last shoe that deserves notice is the Charlier; and, lest I should be accused of undue partiality to it, I will give my experience of it at length, as I have done with the others. A short description may be needed. As it is some time since the shoe was discussed, the Charlier shoe is, in a few words, a shoe which is the width of the crust to which it is to be applied, and rather thicker than, or of the same thickness as the sole. The foot is prepared for the shoe by shortening the wall all round the foot, but leaving the sole, thus making a groove. The shoe is accurately fitted to the foot, placed in the groove, and nailed in the ordinary manner. Any smith can make the shoe, all can make it alone, whilst it takes two men to make the common one. When the shoe is on, the horse stands on his foot as if he were unshod, the outer border of the sole, the frog, and the bars combining with the crust to sustain the weight of the horse, which with the common shoe is carried entirely by the crust. Consequently, the foot being in a natural position, the horse is comfortable, 
and those diseases which are caused by the shoe are not likely to attack him. The sole must never be pared, nor the frog; they will wear down of themselves. The number and situation of the nail holes depend on individual tastes. I shall not describe the adaptation of the shoe further, as a little illustrated pamphlet is published which gives every detail-some of which require illustrating-but will merely give my experience of the article. Towards the end of the seaon '68-69, I found myself with a stud of five hunters much the worse for wear. No. 1 was ten years old, very good legs, and strong (too strong) feet; she went rather short on the road, and had a most hateful trick, which had come on in the last two seasons, of knuckling over on her front fetlocks, and in fact she had fallen on the road twice, but without hurting herself. Being a strong-footed one, I shod her $\grave{a}$ la Charlier one day, and hunted her the next. Having her feet on the ground made little or no difference in her going; but the first difference I perceived in her was that she galloped much lighter through plough, "dirt" having been previously her weak point. This is easily accounted for, as the common shoe comes out of the deep ground with a "suck," which is absent when the shoe lies close into the foot. The common shoe makes the ground surface of a foot so shod something like a cup. The hacking improved slightly, but not much. In August, '69, I shod this mare with Charlier shoes behind also, and after the first few days she never made a "peck" on the road, and felt quite different under meso much more springy. The fact is, I don't think we attend enough to the hind feet. They don't show the effects of bad shoeing like the fore feet, and so they don't get attention; but what is bad in front can't be 
good behind. The mare's heels became much more open; no man need desire a better hack on the road; and, oddly enough, she pulled through last season without falling. This, of course, was not the shoeing; but it shows that horses do not slip worse in Charlier than in other shoes. No. 2 was a five-year-old, which looked very much like going to the kennels at six. This animal enjoyed incipient side bones and ossification of the cartilages, having a narrow brittle hoof. She might also have reasonably backed herself to be the worst hack in England. Being a good hunter, I gave her a chance, and after a month's rest, with blistering of the coronets, I shod her all round, and she did exercise until it was time to hunt again. I did not know my own animal when I rode her in the autumn. Her heels were springy; she had recovered her action, and left off a habit of boring on the bit, which arose from her grogginess. This mare continued sound. No. 3 was a flat-footed horse, with calf knees, and legs that were always swelled. He never was lame; but when shod with these shoes his feet became much stronger, and his legs never filled all last season (69-70.) As we all know the connection between the frog and flexor tendon, this is an interesting fact. I had ridden the horse two seasons with round legs, and never succeeded in getting them down. Both this horse and No. 2 used to cut behind badly, but they have not done it with the Charlier shoe; which, indeed, has much less to cut with-less, in fact, to the extent of the thickness of the ordinary shoe, as this one is sunk in the foot instead of projecting beyond it. No. 4 had chronic laminitis. He improved very much during the summer, when I sold him into a comfortable home; but his owner, a friend of mine, put common shoes on him, and I should fancy he 
might get bad again; however, I shall see him ere long, and judge for myself.* No. 5 had corns. The cause being removed, the effect followed; he was otherwise a sound horse, but not a safe hunter, and, not being an old friend, I sold him also. Last season I had two new ones. I shod them with the Charlier shoe all round; they were sound, and continued so. Therefore I do not recommend the system without fair ground for doing so. Besides hunters, I have tried it with equal success on harness horses and road hacks.

A friend at Melton tells me that the Charlier shoe is in use there, and gaining ground; but that the sportsmen there use a very short one-hardly more than a tip, and extending only to the bars-and that it answers well. I have used still shorter tips, let into the foot, à la Charlier, and with great success, but chiefly on the road. The theory of tips is that they are apt to strain the sinew from lowering the heel, but I cannot say that I have ever experienced this evil, nor seen it happen to others. To end a very long yarn, we ought to come to a conclusion as to what is the best shoe for all purposes. I should say for hunters and hacks the Charlier shoe all round, turned up behind if you like, and in strong feet only coming as far back as the bars of the foot, in weak feet to the heel-at all events until they grow strong. But, by the way, nothing makes the heels grow so fast as the wearing of tips. For light harness horses I should say the same; but for heavy work on the stones I should recommend something different, for the hind feet at all events. Calkins are absolutely needful for the hind feet of omnibus horses, and in addition I would have the too or some of it, square, so as to give a good point d'appui * With common shoes he became as groggy as ever. 
for the hind leg in starting up slippery hills; and this, with an unpared sole and a tolerably wide shoe, taking a bearing on the crust and the exterior border of the sole (which will stand some pressure if it be left in a state of nature), is about all that can be done for the hind feet. For the fore feet of omnibus horses I cannot but think, if Charlier shoes or tips be not approved of, that the steel grooved shoes shortened into tips would be useful. They would prevent slipping, and the heels and frogs would be on the ground; of course the sole would have to be left unpared. Horses accustomed to full shoes will naturally go very short at first in tips; but they soon get used to them. and recover their action. A sportsman, well known some little time ago in the Shires, shod all his horses with tips -hunters, hacks, and carriage horses; but, although it was seen that his stud went very well shod in this manner, no one followed his example, the world in general being staunch Conservatives, and diametrically opposed to any innovation in stable matters, whatever their opinions may be on other subjects. Apropos of tips, I came upon the following sentence in a chapter devoted to the consideration of "corns," in that remarkably well-meaning though not wholly satisfactory work, "The Illustrated Horse Doctor" : "Some horses will go sound in tips, which cannot endure any further protection." The moral, so to speak, of this is, that it is the shoe, not the road, that hurts the horse; for if so weak and tender a foot as is described can go sound when all but unshod, why should not the strong sound one do the same? The obvious conclusion is, that we require a strong sound foot to stand, not our work, but our shoe! My idea of the way to keop horses" feet sound is this: "let the frog come to the ground, and leave it and the sole alone. 
Any system of shoeing which is compatible with these two rules will do for me; but I know of none excepting the Charlier shoe and the tip. The Groodenough shoe is supposed to be let into the foot like the Charlier-sometimes, at any rate-but it is much too thick, and to bring the frog flush with the calkins would necessitate a serions mutilation of the foot; in fact I think it would be impossible, as the Goodenough is nearly as broad as a common shoe, and, as far as the foot surface goes, it is identical with the common concave-seated shoe, both being eased off so as not to press upon the sole. The common shoe is generally, not always, a little the wider of the two. If that part of the foot which breaks away on hard ground faster than it can be reproduced be protected from wear, I cannot see what the rest of the foot, which does not wear away, wants with any so-called protection. Corns are always caused by the shoe ; side bones, I think, generally so; and though it may be said that tips expose the animal to the danger of a bruised heel, bruised heels were by no means unknown under the old system. With tips, too, snow does not ball in the foot; with every other shoe it does so more or less. I may as well say, while giving my own experiences, that $I$ have lately been working a hack in common short tips, not let into the foot, and the horse goes very well on the road. As the animal was made to travel barefoot, I do not see the advantage of making him incapable of doing so by a long course of artificial treatment. But one thing must be remembered: although many lamenesses are attributable to bad shoeing, there are other causes of disease in the feet wholly unconnected with the blacksmith's shop. A horse may have acute laminitis, for instance, who has never been shod, if he has been otherwise mismanaged. 
Bar shoeing, the management of horses is pretty well understood in the present day. In bitting, however, there is room for improvement; and a very fair reform bill has been brought forward by Major Dwyer concerning this matter. With much of Major Dwyer's book I do not agree. Although he talks a little of hunters, it is clear that he knows but a very little of them, or he would hardly recommend a snaffle for general use in the field. His double bridle, however, is very good, and, light though it looks, it is a very powerful instrument. People, however, must read the book and judge for themselves. The bit is to be got at Messrs. Gibson's, Coventrystreet, Leicester-square; and I think it excellent for most pullers, and also for star-gazers and ewe-necked horses. Being rather severe, it requires "hands" to make the most of it. A mutton-fisted yokel attempting to control a violent horse with it will find himself in a false position. It is far more reliable with a puller than the advertised nosebands, most of which deaden the mouth, while they enliven the temper. Griffith's snaffle is on the principle of the Bucephalus noseband. I once saw it fail altogether in the hands of a first-rate horseman; but I have heard of its success elsewhere. If the horse pulls with his head on one side it becomes useless, and the horse will in most cases discover this little fact. Out of pages on pages of advertisements, I have selected the above as being the only new invention that even gives fair promise of being worth trying.

Every innovation is not a reform, and this remark applies specially to stable practice; but any real reform in shoeing is reform indeed, and the greatest respect and attention are due to it. But how few of these old discoveries, which are from time to time re-invented, are 
worth even the limited amount of attention which they command.

P.S.-Since writing the above I have seen a letter in the Field from a gentleman who, after stating that he has found the use of the Goodenough shoe very satisfactory, rather spoils this praise by saying that at the commencement of a frost he had the calkins steeled. Now, as in the country the only times that these calkins can be of any use is during a frost, if they are useless, and if they require alteration, then what is the good of them? and, without them, what becomes of the muchvaunted shoe?

London: Printed by Horace Cox, 346, Strand. 



\section{LIST OF B OOK S}

PUBLISHED BY

\section{HORACE COX, AT 346, STRAND, LONDON, W.C.}

FACTS and USEFUL HINTS relating to FISHING and SHOOTING; being a Collection of Information and Recipes of all descriptions of the greatest utility to the general Sportsman, to which is added a series of Recipes on the Management of Dogs in Health and Disease. Vol. I of "THE FieLD" Library. Second Edition. Large post 8vo., price 5s. cloth; post free, $5 s .4 d$.

THE COUNTRY HOUSE; a Collection of Useful Information and Recipes, adapted to the country gentleman and his household, and of the greatest ntility to the housekeeper generally. Illustrated. Vol. II of "THE Field" Lrbrary. Second Edition, enlarged and revised. Large post 8vo., price 5s. cloth; post free, 5s. $4 d$.

THE FARM: being Part I. of the Second Edition of "The Farm, Garden, Stable, and Aviary." Valuable to country gentlemen, farmers, \&c. Vol. III of "The Field" Library. Large post 8vo., price 5s. cloth; post Pree, 5s. $4 d$

THE GARDEN : being Part II. of the Second Edition of "The Farm, Garden, Stable, and Aviary." Vol. IIL of "The Freld" Lubrary. Large post 8vo., price $5 s$. cloth; post iree, $5 s .4 \mathrm{~d}$

THE STABLE : being Part III. of the Second Edition of the FARM, GARDEN, STABLE, and AVIARY. Large post 8vo., price 5s.; post free, $5 s .3 d$.

A YEAR OF LIBERTY; or, Salmon Angling in Ireland. Vol. IV. of "The Field" Library. Price 5s. cloth; post freo, 5s. 5d.

POPULAR ILLUSTRATIONS of the LOWER FORMS OF LIFE. Illustrated. Vol. V. of "The Field" Library. By C. R. BREE, M.D., F.L.S., F.Z.S. Large post 8 vo, price 5 s. cloth; post free, $5 s .3 d$.

EXPERIENCES of a GAME PRESERVER. Vol. VI. of "Tue FleLd" LIbrary. By "DEADFALL." Large post 8v0, price 5s. cloth; post free, 5 s. $3 \mathrm{~d}$

PRACTICAL FALCONRY; to which is added, HOW I BEOAME A FALCONER. Vol. VII. of "THE FIELD" LIBRART. By GAGE EARLE FliEEMAN, M.A. "Peregrine," of "The Field"). Price 5s, cloth; post free, 5s. $3 d$. 
SKETCHES of LIFE, SCENERY, and SPORT in NORWAY. Vol. VIII. of "The FieLD" Library. By the Rev. M. R. BARNARD, B.A. The work is admirably adapted for use as a Sporting Tourist's Handbook, while it is of absorbing interest to the general reader. Price $6 s .6 d$; post freo, $6 s .10 \mathrm{~m}$.

DOGS OF THE BRITISH ISLANDS. Edited by "STONEHENGE." Second Edition, greatly enlarged (including new Parts on "Kennel Management of Dogs" and "Judging at Dog Shows and Field Trials." 4to., gilt edges, printed on toned pæper, price 10s. $6 d$; by post, 11s. $4 \frac{1}{2} d$.

PART I-DOGS USED WITH THE GUN, containing Setters (with four Illustrations), Pointers (with Illustration), -Retrievers (with two Illnstrations), Field Spaniels (with two Illustrations), Deerhounds (with Illustration).

PART IL-COMPANIONABLE DOGS, containing Terriers (with four Illustrations), Bull Terrier and Bull Dog (with two Illnstrations), Mastiffs (with three Illustrations), Sheep and Drovers' Dogs (with Illustration).

PARTS III. and IV.-HOUNDS and TOY DOGS, containing Greghound (with Illustration), Bloodhound (with Illustration), Foxhound (with two Illustrations), Harriers (with Illustration), Beagles (with Illustration), Fox Terrier (with Illustration), Truffle Dog (with Illustration), King Oharles and Blenheim Spaniels (with Illustration), Maltese Dog (with Illustration), Pug Dog and Italian Greyhound (with Illustration), Chinese-crested Dog (with Illustration).

PART V. - On the MANAGEMENT of LARGE and PET DOGS, and TREATMENT of DISTEMPER, MANGE, and WORMS.

PART VI.-JUDGING at DOG SHOWS and FIELD TRIALS.

N.B.-The new parts on "Kennel Management of Dogs" and "Judging at Dog Shows and Field Trials," may be had together, price 1s. $6 d$.; post free, 1s. $8 d$.

\section{SHIFTS and EXPEDIENTS of CAMP LIFE, TRAVEL,} and EXPLORATION. By W. B. LORD, Royal Artillery, and T. BAINES, F.R.G.S. The work is written expressly for the use of Military and Naval Offcers, Missionaries, Travellers, and any who may be obliged to "rough it" in Foreign and Savage Countries; and it is believed that the "Shifts and Expedients" here gathered together will be found of the greatest service to all such. The work contains about 900 pages, and nearly 400 lilustrations. Price 45 s, cloth gilt; or in 17 Parts, 2s. 6d. each.

THE ARTS of ROWING and TRAINING. Demy 8 ro., cloth gilt, price 4s.; post free, 4s. 2 d.

THE SILKWORM BOOK; or, SILKWORMS ANCIENT and MODERN, their FOOD and MODE of MANAGEMENT. By W. B. LORD, R.A. Illustrated. In demy 8 vo., price 2s. 6d., cloth gilt; post free, 2s. $8 \mathrm{~d}$.

\section{THE COURSING CALENDAR AND REVIEW, Edited} by "STONEHENGE." Published hall-yearly. Fcap. 8ro., price 10s. 6d. cloth; post free, 10s. $9 d$.

ROUND THE TABLE; or, Notes on Cookery and Plain Recipes, with a Selection of Bills of Fare. By "The G. C." Post 8vo., pp. 300, price $6 s$. ; free by post, $6 s .5 d$.

THE IDSTONE PAPERS. A Series of Articles and Desultory Observations on Sport and Things in general, written originally for "The Field "Newspaper. By "IDSTONE." Large post 8vo., price 7s. 6d. ; post free, 7s. 11d. 


\section{THE DIAMOND DIGGINGS OF SOUTH AFRICA:}

Personal and Practical Account. By CHARLES A. PAYTON "SARCELLE" of "THE FreLd." With a Brief Notice of THE NEW GOLD FIELDS. With Irap, large post 8vo., price 6s.; post free, $6 s_{.} 5 d$.

THE FIELD DUPLICATE JUDGING BOOK facilitates the work of the Judges at Poultry and other Shows, by a very simple method of entering and preserving a duplicate judging list Price $6 d$; or $23.6 d$. the halfdozen.

THE WISE, THE WITTY, AND THE BEAUTIFUL : A collection of good things in prose and verse, adapted for penny readings, railway travellers, and all who wish to pass an hour pleasantly. In small 870 ., cloth gilt, price 1s. ; post freo, 1s. $3 d$.

ALL ENGLAND CROQUET CLUB.-Regulations for the MANAGEMENT of PRIZE MIEETINGS. Price $6 d$; post free, $7 d$.

THE BOOK of DINNER SERVIETTES (Second Edition), which contains a new Introduction on the Decoration of Dinner Tables, and General Directions for folding the Serviettes, of which there are Twenty-one different kinds given, with Ninety-two Woodcuts illustrative of the various Folds required, and the serviettes complete. In demy 4 to., on toned paper, and in fancy cover, price $2 s$.; by post, $2 s .2 d$.

THE ART of SKATING; containing many Figures never previously described, with Illustrations, Diagrams, and Plain Directions for the Acquirement of the most Difflcult and Elegant Movements. By GEORGE ANDERSON (" OYCLOS"), for many years President of the Glasgow Skating Club. Second Edition. In post 8 vo., limp cloth gilt, price $2 s .6 d$; post free, $2 s .8 d$.

THE RAIL and the ROD; or, The Tourist-Angler's Guide to Waters and Quarters. In Parts, paper wrapper, price 1s. each : in cloth, 1s. $6 \mathrm{c}$; post Pree, $2 d$. extra.

No. 1. Great Eastern Ramway. | No. 3. South-Western Railway.

No. 2. Great Western Rallway.
[No. 4. South-Eastern Ruluwat.

$\left.\begin{array}{c}\text { No. } 5 \\ \text { and }\end{array}\right\}$ Great Eastern, Londow and North-Westers, MrdLand, and

No. 6. $\}$ Great Northers RaILWAYs.

May be had in two vols, cloth, 4s. each.

TWENTY YEARS' REMINISCENCES of the IEWS. By "SIXTY-ONE." Crown 8vo., cloth, price 10s.; by post, 10s. $5 d$

A TREATISE on HARNESS, SADDLES, and BRIDLES : their History and Manufacture, from the earliest times down to the present period. By A. DAVIS. In large post 8vo., price 2s, cloth; by post, 2s. $2 d$.

THE RIVER'S SIDE ; or, TROUT \& GRAYLING, and How to catch Them. By SIR RANDAL ROBERTS, Bart. Illustrated. In feap. 8ro., price $3 s .6 d$. cloth gitt; post free, $3 s .8 d$. 
REPORTS on SALMON LADDERS, with Original Drawings, Plans, and Sections. By FRANCIS FRANCIS. In post 4 to., price $2 s .6 d$; by post, 2s. $7 d$.

THE ANGLER'S DIARY, wherein the Angler can register his take of Fish throughout the year. An extensive List of Fishing Stations throughout the World is added. Post 8 vo., price 1s. $6 d$; ; by post, 1s. $8 d$.

THE SHOOTER'S DIARY for $1872-73$ contains Forms for Registering Game killed during the Year, either by a Single Gun or by a Party, or off the whole Estate. A List of Shooting Stations throughout the World is also given. Post 4to., price 1s. $6 \alpha$; post free, $2 d$, extran

THE RURAI ALMANAC and SPORTSMAN'S ILLUSTRATED CALENDAR. Its contents comprise Information of the greatest utility and interest to the Sportsman and Country Gentleman. Mllustrated. Published annually. Price 1s.; by post, 1s. $2 d$.

THE ILLUSTRATED QUEEN ALMANAC and LADY'S CALENDAR; comprising Work-table and other Patterns, and much Information interesting and useful to Ladies. Published annually. Price $1 s$; ; by post, 1s, $2 d$.

THE FIELD QUARTERLY MAGAZINE and REVIEW. In Quarterly Parts, price 2s. 6d.; post free, 2s. 9d. Yearly Subscription, 11s.

"WHETSTONES FOR WITS:" or Double Acrostics. By VARIOUS HANDS. Edited by "CRACK." Price 5s; ; by post, 5s. $4 d$.

"You have not the book of riddles about you, have you? "-Merry Wives.

OUR COMMON INSECTS: First Steps to Entomology. By Mrs, E. W. COX. Price 2s, $6 d$; by post, 2s. $8 d$. 

University of California

SOUTHERN REGIONAL LIBRARY FACILITY 405 Hilgard Avenue, Los Angeles, CA 90024-1388

Return this material to the library from which it was borrowed. 
